Federal Reserve Bank of Minneapolis

Research Department Staff Report 473

Revised February 2016

\title{
Technical Appendix: On Financing Retirement with an Aging Population*
}

Ellen R. McGrattan

Federal Reserve Bank of Minneapolis

and University of Minnesota

Edward C. Prescott

Federal Reserve Bank of Minneapolis

and Arizona State University

* The views expressed herein are those of the authors and not necessarily those of the Federal Reserve Bank of Minneapolis or the Federal Reserve System. 


\section{Introduction}

This appendix provides additional details for our paper "On Financing Retirement with an Aging Population." Specifically, we provide more details on our data sources and construction of the model's national accounts and fixed asset tables, some balance sheet items, distributions of incomes and transfers, and sources underlying the demographic variables. We discuss in more detail the baseline parameterization and the methods used in computing the model equilibria. And, finally, we provide predictions for the transition paths and further details underlying the sensitivity analysis of Section 5 in the main text. For those interested in trying their own experiments, we have also made the codes available at McGrattan's websites, www.minneapolisfed.org and www.econ.umn.edu/ ${ }^{\sim}$ erm.

\section{U.S. Macro Data}

Here, we describe the main sources of our data: the U.S. national income and product accounts, the fixed asset tables, several balance sheet items from the flow of funds, population statistics and projections, and employment and hours.

\subsection{National Accounts and Fixed Assets}

The primary source of data used in our model accounts is the U.S. National Income and Product Accounts (NIPA) and Fixed Asset Tables compiled by the Bureau of Economic Analysis. These data are published in their Survey of Economic Business (and online at www.bea.gov). We use estimates prior to the 2013 comprehensive revision (which is still ongoing). For certain imputations that we make, we also rely on data from the Flow of Funds Accounts of the United States compiled by the Federal Reserve Board of Governors and the Statistics of Income compiled by the Internal Revenue Service (IRS). The source is noted in the tables.

In Table A1 - which is an expanded version of Table 1 in the main text - we provide all of the details of how we revise the NIPA to conform with theory. The main source of the domestic income data is the NIPA, Table 1.10. With labor income we include compensation of employees and 70 percent of proprietors' income. All other income is categorized as capital income, which is adjusted in two ways. First, we subtract taxes other than property tax from the NIPA measure of taxes on production and imports. Second, we impute capital services for consumer durables - which we treat as investment - and government capital. The imputed services are estimated to be 4 percent times the current-cost net stock of consumer durable goods and government fixed assets. These 
stocks are reported in the BEA's fixed asset tables. In addition, we need to include depreciation of consumer durables, which is reported in the flow of funds accounts. With these adjustments, capital income is the sum of corporate profits, part of proprietors' income, surplus on government enterprises, rents, net income, property taxes, depreciation of capital, and imputed capital services.

On the product side, revisions must also be made with regard to sales taxes and capital services. The sales taxes are assumed to be primarily taxes on personal consumption expenditures. ${ }^{1}$ We assume pro rata shares when assessing how much of the taxes are on durables, nondurables, and services. We include nondurables and services with consumption and durable goods with tangible investment. Therefore, we subtract sales taxes from both product categories. The imputed capital services only affect our measure of consumption, which combines personal and government consumption from the NIPA.

In the model, we distinguish between businesses that pay corporate income taxes (sector 1) and those that do not (sector 2). Businesses that pay corporate income taxes are Schedule C corporations. The others are Schedule S corporations, regulated investment companies, real estate investment trusts, proprietors, partnerships, household businesses, and government businesses. The BEA does not break out income and product data for Schedule C corporations, but the IRS does report data from tax returns separately for Schedule C corporations in the Statistics of Income. We use these return data to estimate the investment and capital of our sector 1. In particular, we use the ratio of depreciable assets for Schedule $\mathrm{C}$ and all other corporations to estimate the ratios of stocks and investments in the model. According to the IRS, 83.5 percent of corporate depreciable assets are owned by Schedule C corporations. If we decompose gross private domestic investment into corporate and noncorporate components and assign 83.5 percent of corporate investment to Schedule C corporations, then we estimate that 0.069 GNPs of investment is done by Schedule C corporations. The remaining investment, 0.142 times GNP, is the sum of gross private domestic investment for other private business plus consumer durable goods net of tax, nondefense government gross investment, and net foreign investment.

Fixed assets and other capital stocks used in our analysis are shown in Table A2. In addition to fixed assets and consumer durables reported by the BEA, we include inventories, land, and intangible assets. The source of data for inventories is the NIPA; the source of data for land values is the flow of funds. As with investment, we decompose corporate capital stocks into those of all other corporations by assuming that the ratio of corporate stocks is equal to the ratio of depreciable

1 Some taxes are assessed on purchases of goods and services that should in theory be subtracted from investment or government spending. Unfortunately, we do not have a breakdown by product category. 
assets reported in corporate tax returns. We then add together capital stocks of non-Schedule C corporations and noncorporate businesses. This results in an estimate of 0.885 GNPs for tangible capital in Schedule C corporations and 3.232 GNPs for tangible capital in all other businesses. Our estimate of 1.7 GNPs for the stock of intangible capital is based on studies that find that the stock of business intangible capital is as large as business tangible capital. We experimented with the share of this stock in our two sectors.

\subsection{Balance Sheets}

Table A3 lists balance sheet items that we reference in the paper, namely, household net worth and government debt. The source of these data is the flow of funds accounts.

The first item is net worth of households, which also includes assets of nonprofit institutions. Households have tangible assets that averaged 1.79 times adjusted GNP over the period 2000-2010 and financial assets that averaged 3.16 times adjusted GNP. Subtracting liabilities of 0.86 GNPs implies a net worth of 4.1 GNPs over the same period.

The second item is end-of-period government debt, which averaged 0.549 GNPs over 20002010. Close to 70 percent of this debt is in the form of U.S. Treasury securities.

\subsection{Population, Employment, and Hours}

Using data from the U.S. Census, the Social Security Administration, the NIPA, and the Bureau of Labor Statistics, we have estimates of population by age, survival probabilities, fulltime equivalent employees, and annual hours of work. We summarize the relevant statistics for population, employment, and hours in Table A4.

According to U.S. Census estimates of the population, the annual growth rate in the population ages 16 to 64 over the decade $2000-2010$ is a little over 1 percent per year, more specifically, 1.1 percent (see Table B-34 of the Economic Report of the President, 2012). The annual growth rate for the total population is slightly lower than 1 percent, more specifically 0.93 percent.

Survival probabilities are found in the period life tables used by the Social Security Administration (see Bell and Miller, 2005, Table 6). We take an average over males and females for the year 2010.

Data on full-time equivalent (FTE) employees are found in the NIPA, Table 6.5. The number of FTE employees equals the number of employees on full-time schedules plus the number of 
employees on part-time schedules converted to a full-time basis. Over the period 2000-2010, the number of FTEs averaged 124 million.

The primary source of our annual hours of work series is the U.S. Department of Labor, Bureau of Labor Statistics, Employment and Earnings. The raw data underlying the series are persons at work, aged 16 years and over, and average hours worked per week for persons at work. They are based on the Current Population Survey (CPS). Total hours for military are added using data on military personnel from the Department of Defense and an estimate of a 40-hour week. (See Prescott, Ueberfeldt, and Cociuba, 2005, for full details of the primary sources.)

\subsection{Consistent Parameters}

The parameters that govern preferences and technologies are set so that the model national accounts and fixed asset tables are consistent with the data in Tables A1-A4. To accomplish this, we added additional equilibrium conditions to the code for computing a balanced growth path. The additional conditions are as follows:

$$
\begin{aligned}
K_{1 T}^{\prime} & =0.885 \mathrm{GNP} \\
K_{2 T}^{\prime} & =3.232 \mathrm{GNP} \\
K_{1 I}^{\prime} & =\omega 1.7 \mathrm{GNP} \\
K_{2 I}^{\prime} & =(1-\omega) 1.7 \mathrm{GNP} \\
w L & =0.585 \mathrm{GNP} \\
L & =L_{1}+L_{2}=0.277,
\end{aligned}
$$

where $\omega$ is a weight that we experiment with. The additional unknowns to be computed for the balanced growth path - in addition to the interest rate and one policy choice of the government that ensures budget balance - are the sectoral capital shares $\left(\theta_{1 T}, \theta_{2 T}, \theta_{1 I}, \theta_{2 I}\right)$ and the preference parameters $(\alpha, \beta)$. The depreciation rates $\left(\delta_{1 T}, \delta_{2 T}, \delta_{1 I}, \delta_{2 I}\right)$ can be pre-set so that the investment rates of the model match those of the United States. When computing these rates, we detrend the investments and stocks by dividing by population and technological growth. The technological growth rate is chosen to be 2 percent. That leaves only one technology parameter, namely, $\theta_{1}$. We arbitrarily set this parameter to $1 / 2$ because we do not have Schedule $\mathrm{C}$ incomes and stocks broken out in the U.S. accounts. This is another parameter that we experiment with.

For baseline policy parameters, we need the defense and debt shares, tax rates, and transfers. The ratio of defense spending to GNP, is set equal to 0.044 , which is equivalent to the U.S. share 
from the NIPA shown in Table A1. The ratio of debt to GNP is 0.533 , which is equivalent to the U.S. share from the flow of funds shown in Table A3, after dividing by the growth terms $(1+\gamma)(1+\eta)$. Note that these shares depend on endogenously determined GNP, which must, in equilibrium, satisfy the resource constraint. The paths for tax rates and transfers differ depending on the policy experiment and are described in detail in the main text.

\section{U.S. Micro Data}

The main sources of our micro data is the March Supplement of the Current Population Survey (CPS) and the IRS Statistics of Income. In this section, we provide additional details about these data that are not in the main text.

\subsection{Population Counts}

In our analysis, we rely heavily on tax data from the CPS. Table A5 shows the counts of tax filers and nonfilers - both unweighted and weighted - in the 2005 CPS March Supplement. Tax filers are listed as either independent if they do not appear as a dependent on another tax return or dependent if they do. As the numbers indicate, most filers are independent. Listed separately are the spouses and non-filing dependents. About 42 percent of all tax returns include a joint-filing spouse. We separate dependents under and over age 15 because the latter are included in our working-age population count. We do the same for nonfilers. In this sample, 79 percent of the population is age 15 and older.

\subsection{Comparison of AGI in CPS and IRS}

To construct the distribution of incomes and transfers used in our analysis, we start by sorting families by per capita AGI. For some tax filers, data are missing because of topcoding. In these cases, we start with the taxable income. If that is topcoded, but we have data on federal or state tax payments, then we can use information about the filing status (that is, whether they are married filing jointly, head of household, etc.), along with the relevant 2004 tax schedules, to work backward to figure out the taxable income. Given taxable income, we can use IRS ratios of AGI to taxable income for the specific tax bracket to estimate the AGI. If all variables are topcoded, including the taxes paid, we use the CPS incomes to sort the filer into a tax bracket using IRS incomes.

To check the accuracy of these imputations, we compare the CPS estimates and IRS data 
with respect to numbers of returns, AGI, and AGI per return, sorting filers by AGI bracket. In Table A6, Panels A through D, we show these results for all returns, married filing jointly, head of households, and a residual category that includes singles and all others. There are 132 million IRS returns and 124 million estimated based on the CPS. Breaking this down by filing status, we see that the largest discrepancy in total returns arises when comparing estimates for heads of households; the CPS records 13 million filings and the IRS records 20 million. These discrepancies are not a result of our imputations because most of the differences across reports are found in the lower AGI brackets that have not been topcoded. For example, in the case of singles, we see that 6.3 million in the CPS reported no AGI and 2.3 million reported AGI in the first bracket, whereas the IRS reports 1.2 million and 10 million, respectively. Despite these discrepancies, the AGI per return estimates are very similar in all cases, except in the very highest group of filers reporting over $\$ 500,000$ in income. As a result, when we construct parameter estimates for our model, we take those making $\$ 200,000$ or more as the top bracket.

\subsection{CPS Money Incomes and BEA Personal Incomes}

In the main text, we report distributions of BEA incomes based on CPS data. Here, we show the money incomes underlying those estimates. In Table A7, we report the distribution of money incomes from the 2005 CPS March Supplement. The grouping of AGI is not the same as in Table A6, which used the AGI of the tax filer. Here, we use the per capita AGI using all filings from the same family. To do this, we first group individuals into families. Families are related persons in the same household or unmarried partners and their relatives grouped together. We sum together AGIs for all tax returns filed by members of the family and then divide by the number of people over the age of 15 in the family. Some households include multiple families, and these families are treated separately. Once an individual is put into an AGI bracket, we attribute CPS incomes for that individual to that particular bracket.

What we see from Table A7 is that wage and salary is the main category of money income, accounting for 77 percent of the total. Capital income, which is the sum of dividends, interest, and rents, is less than 5 percent, in large part because household assets are held indirectly by fiduciaries. Self-employed income that is part labor income and part capital income is 5 percent. All other money income, which is mostly government transfers, accounts for 13 percent of the total.

Table A8 shows the per capita estimates after dividing the total money incomes by the workingage population (that is, those age 15 and over). Note that the totals do not necessarily lie in the 
AGI brackets because IRS AGI and CPS money income are different income measures. This is especially true for those in the lowest and highest brackets; those in the lowest brackets rely heavily on government transfers and those in the highest brackets have proprietors' and capital income that is not included in the CPS measures.

The distribution of money incomes shown in Table A7 is used to fill in the distribution of incomes in Table A9 (which is the same as Table 4 in the main text but reproduced here for convenience). ${ }^{2}$ The totals in Table A9 are personal incomes in the BEA plus contributions for social insurance made by the employee and employer plus nondefense spending. Notice that now wage and salary income accounts for 44 percent of the total, proprietors' income accounts for 7 percent, and capital income accounts for 13 percent. If we compare totals, the measure of total CPS money income is about 59 percent of the total income used in our analysis.

For distributions of wages and salaries, we use the CPS wage and salary data. For proprietors' income, we use the CPS income of the self-employed. For capital income, which includes the same categories in both measures, we use the CPS capital income. For Social Security, we use the CPS social security. For Medicare, other transfers, and wage supplements listed in Table A9, we use CPS income data for transfers other than Social Security (with the exception of the category Family \& Friends in Table A8, which is not included with BEA personal income) and other information that is not included in the measure of CPS money income. Specifically, for Medicare, we use the CPS estimate of the person market value, which is the average cost of the program for all respondents who say they are in the program. For other transfers, we add together income from worker's compensation, supplemental security, public assistance, unemployment compensation, and veteran's payments, as well as the person market value of Medicaid, the earned income tax credit, the child tax credit, and the additional child tax credit.

To derive estimates for wage supplements, we use CPS data on employer contributions to health insurance, participation in employer pension plans, and FICA payments made by workers. The distribution of contributions for health insurance is used as a proxy for all insurance recorded by the BEA. For those who participate in a pension plan at work, we include a percentage of their wage as the supplement to wages, with that percentage chosen to have all payments sum to the BEA total (which turns out to be roughly 10 percent). Finally, FICA payments of employees can be used to infer the FICA payments of their employers.

2 As we note in the main text, the unassigned income is constructed by subtracting BEA-derived AGI plus nonfiler income from BEA personal income. See Survey of Current Business (SCB), 2007, for more information about BEA's measure of AGI and how it compares to the IRS AGI. 
The last column in Table A9 is the contribution of nondefense spending. Each person over age 15 is assumed to receive $\$ 7,269$.

As before, we can compute the per capita estimates by dividing the incomes by persons of working age. These estimates are shown in Table A10. Again, note that the totals do not necessarily lie in the AGI brackets because IRS AGI and BEA income are different income measures and because we have included contributions to social insurance and nondefense spending in the BEA's measure of personal income. These per capita incomes reveal, perhaps not surprisingly, that transfers are significant for nonfilers and those with no AGI and employer benefits are significant for those in the middle and higher brackets. These facts play an important role in our analysis.

\subsection{CPS Tax Data}

In addition to incomes and transfers, we need marginal and average tax rates by income bracket. In Table A11, we report the underlying data for our tax rate estimates taken from the CPS.

The total AGI is $\$ 6,854$ billion, which is what we reported in Table A6, Panel A. Here, we report the AGI data using per capita AGI for the family rather than AGI for an individual tax filer. For example, if the unit of analysis is an individual tax filer, then the AGI attributed to the $\$ 50,000$ to $\$ 75,000$ bracket is $\$ 1,157$ billion and the AGI per return is $\$ 61,008$. If, instead the unit of analysis is a representative family member, then the AGI attributed to this bracket is $\$ 1,065$ billion and the AGI per working-age person in the bracket is $\$ 62,281$.

Listed next, in the sixth column of Table A11, is taxable income, which is the measure of income used with the IRS 1040 tax schedules and can be used to calculate each tax filer's marginal tax rate. For jointly filing spouses, we assign the same marginal rate as the tax filer. Column 7 shows the distribution of FICA payments by workers. These data are used to construct FICA tax rates.

Federal and state income taxes are shown in columns 8 through 11, both before credits (BC) and after credits (AC). Columns 12 through 14 are the total amounts of credits by type: earned income tax credit (EITC), child tax credit (CTC), and additional child tax credit (ACTC). These data are used to adjust the marginal tax rates of recipients. We do this by using the IRS worksheets.

Table A12 shows our constructed marginal and average tax rates for all AGI brackets. We use the methodology of Barro and Redlick (2011) to construct income-weighted average marginal 
tax rates, and then we adjust the rates to account for refundable tax credits. For tax credits, we use the IRS worksheets to estimate the adjustments to the tax rates. As shown in Table A12, the income-weighted EITC adjustment is large and negative for the lowest income bracket, roughly -10 percent-but is positive for higher brackets. The child tax credit adjustment is negative for all income brackets.

In the case of means-tested transfer programs such as the Temporary Assistance for Needy Families (TANF) or the Supplemental Nutrition Assistance Program (SNAP), the CPS survey does not provide sufficient information to use tax worksheets but, even if it did, the task of constructing marginal tax rates is daunting. As the Congressional Budget Office (CBO) makes clear in their study of effective marginal tax rates on low- and moderate-income workers, "the income tax system does not make marginal tax rates readily apparent, and complex rules and interactions between the tax and transfer systems tend to further obscure those rates" (see U.S. Congress, Congressional Budget Office, 2012). We do know from hypothetical examples, however, that the marginal rates can be greatly affected by the phaseout of benefits, especially for low-income households. For example, the CBO shows that some households face marginal rates as high as 95 percent.

Adding columns 6 through 10, we have the total marginal rate used in the analysis. The total marginal rate is 5 percent for those with per capita family AGI in the $\$ 1$ to $\$ 5,000$ bracket and is as high as 44 percent for those with per capita family AGI over $\$ 200,000$. Average rates, including federal, state, and FICA, are around 14 percent for the lowest brackets and rise to around 37 percent for the top bracket.

\section{Computation}

In this section, we provide details on computing equilibria for the balanced growth paths and then for the transitions. To avoid messy notation, we assume one productivity level $(K=1)$ and, at the end, note where additional computations are needed for cases with multiple productivities.

\subsection{Balanced Growth Paths}

We have several codes at our website for computing balanced growth paths. They differ in the fixed-point method employed and in the choice of unknown variables. A fixed point is found for the equilibrium interest rate and for a residually determined variable, which is either common government transfers to households or the tax rate on consumption. 
Two fixed-point methods are available: functional iteration and Newton-Raphson. The former simply updates the unknown variables iteratively as follows:

$$
x^{k+1}=\omega x^{k}+(1-\omega)\left(x^{k}-r\left(x^{k}\right)\right),
$$

where $x^{k}$ is the $k$ th iteration of the unknowns, $\omega \in[0,1]$ is a weighting parameter that aids convergence in many cases, and $r\left(x^{k}\right)$ are the first-order conditions that need to be satisfied by an appropriate choice of $x^{k}$. The Newton-Raphson method uses the following updating scheme:

$$
x^{k+1}=x^{k}-\left[d r(x) /\left.d x\right|_{x=x^{k}}\right]^{-1} r\left(x^{k}\right)
$$

and, if necessary, a weighting parameter can be used to help with convergence:

$$
x^{k+1}=\omega x^{k}+(1-\omega)\left(x^{k}-\left[d r(x) /\left.d x\right|_{x=x^{k}}\right]^{-1} r\left(x^{k}\right)\right) \text {. }
$$

The two first-order conditions $r(x)$ that have to be satisfied by $x$ are (1) the condition that sets the return on tangible capital equal to its marginal product and (2) the condition that imposes the government budget balance. After manipulating all of the other necessary conditions, we can write the step-by-step algorithm needed to evaluate $r(x)$, starting with a guess for $x$, as follows: ${ }^{3}$

- Set the interest rate $i$ equal to the first element of $x$.

- Set the common transfer $\zeta$ equal to the second element of $x$.

- Use the fact that after-tax returns on capital net of depreciation are equated to the interest rate to get the four capital rental rates (that is, for the two types of capital in the two sectors),

$$
\begin{aligned}
& r_{1 T}=i /\left(1-\tau_{1}^{\pi}\right)-\delta_{1 T} \\
& r_{2 T}=i /\left(1-\tau_{2}^{\pi}\right)-\delta_{2 T} \\
& r_{1 I}=i-\delta_{1 I} \\
& r_{2 I}=i-\delta_{2 I} .
\end{aligned}
$$

- Use the capital share parameters to get estimates for the two ratios of sectoral labor inputs to total labor inputs,

$$
\begin{aligned}
& L_{1} / L=\theta_{1 L} \theta_{1} /\left(\theta_{1 L} \theta_{1}+\theta_{2 L} \theta_{2}\right) \\
& L_{2} / L=\theta_{2 L} \theta_{2} /\left(\theta_{1 L} \theta_{1}+\theta_{2 L} \theta_{2}\right),
\end{aligned}
$$

3 In order to be precise, assume that the second element of $x$ is the level of common transfers given to the households. 
where $\theta_{i L}=1-\theta_{i T}-\theta_{i I}$.

- Use the capital shares and capital rental rates to get estimates for ratios of capital stocks to compensation. Note that there are four ratios because there are two types of capital and two sectors, that is,

$$
\begin{aligned}
& K_{1 T} /\left(w L_{1}\right)=\theta_{1 T} /\left(\theta_{1 L} r_{1 T}\right) \\
& K_{2 T} /\left(w L_{2}\right)=\theta_{2 T} /\left(\theta_{2 L} r_{2 T}\right) \\
& K_{1 I} /\left(w L_{1}\right)=\theta_{1 I} /\left(\theta_{1 L} r_{1 I}\right) \\
& K_{2 I} /\left(w L_{2}\right)=\theta_{2 I} /\left(\theta_{2 L} r_{2 I}\right) .
\end{aligned}
$$

- Use the aggregate production function, sectoral labor ratios, and capital-compensation ratios to get an intermediate variable, call it $z$,

$$
z=2\left\{\left[K_{1 T} /\left(w L_{1}\right)\right]^{\theta_{1 T}}\left[K_{1 I} /\left(w L_{1}\right)\right]^{\theta_{1 I}} L_{1} / L\right\}^{\theta_{1}}\left\{\left[K_{2 T} /\left(w L_{2}\right)\right]^{\theta_{2 T}}\left[K_{2 I} /\left(w L_{2}\right)\right]^{\theta_{2 I}} L_{2} / L\right\}^{\theta_{2}} .
$$

Note that the coefficient of 2 is used to normalize the ratios of outputs (found below) but can be changed without loss of generality.

- Use capital shares and the intermediate variable $z$ to get an estimate of the wage rate:

$$
w=\left[z\left(\theta_{1 L} \theta_{1}+\theta_{2 L} \theta_{2}\right)\right]^{1 /\left(1-\left(1-\theta_{1 L}\right) \theta_{1}-\left(1-\theta_{2 L}\right) \theta_{2}\right)} .
$$

- Multiply the four ratios of capital stocks to compensation by the wage rate to get estimates of the capital-labor ratios, $K_{1 T} / L_{1}, K_{2 T} / L_{2}, K_{1 I} / L_{1}$, and $K_{2 I} / L_{2}$.

- Use the capital-labor ratios to construct ratios of intangible to tangible capital for the two sectors and the ratio of tangible capitals across the two sectors:

$$
\begin{aligned}
K_{1 I} / K_{1 T} & =\left(K_{1 I} / L_{1}\right) /\left(K_{1 T} / L_{1}\right) \\
K_{2 I} / K_{2 T} & =\left(K_{2 I} / L_{2}\right) /\left(K_{2 T} / L_{2}\right) \\
K_{2 T} / K_{1 T} & =\left[\left(K_{2 T} / L_{2}\right) /\left(K_{1 T} / L_{1}\right)\right]\left[\left(L / L_{2}\right) /\left(L / L_{1}\right)\right] .
\end{aligned}
$$

- Multiply the intermediate variable $z$ by the wage rate raised to a power to get the aggregate labor productivity, that is,

$$
Y / L=z w^{\left(1-\theta_{1 L}\right) \theta_{1}+\left(1-\theta_{2 L}\right) \theta_{2}}
$$

- Solve the household dynamic programming problem-assuming the set of asset choices are $\left\{a_{i}\right\}$, which are equally spaced points on $[0, \bar{a}]$. The steps are as follows: 
- For the terminal value function $v_{J}$, assume that the optimal next period assets and current labor supply are both 0 (that is, if $J_{r}<J$ ), and that determines the final level of consumption via the household budget constraint.

○ Working backward from $j=J$ to $j=1$, iteratively solve

$$
v_{j}(a, s)=\max _{a^{\prime}, c, \ell}\left\{u(c, \ell)+\beta \sigma^{j} v_{j+1}\left(a^{\prime}, s^{\prime}\right)\right\}
$$

subject to the budget constraints

$$
a^{\prime} \sigma^{j}=(1+i) a+\left(1-\tau^{\ell}\right) w \ell-\left(1+\tau^{c}\right) c+\psi^{j} .
$$

The programs find the maximum in a brute-force way, which is slow but ensures that inequality constraints on asset holdings are enforced.

○ At each step $j=J-1, \ldots, 1$, store the optimal decision functions.

- Use the probabilities of survival and the growth rate in the population to determine the fraction of people in each age group $j$, call this $\mu^{j}$, where $\sum_{j} \mu^{j}=1$.

- Add everything by summing optimal choices for consumption, labor, and asset holdings, weighted by the $\mu^{j}$ 's. This implies values for total consumption $C$, total labor $L$, and total beginning-of-period assets $A$.

- Multiply the aggregate labor productivity $Y / L$ by $L$ to get total output, $Y$.

- Multiply the ratios of sectoral labor to total labor by $L$ to get $L_{1}$ and $L_{2}$.

- Use the fact that assets are equal to business equity $V$ plus government debt $B$ in order to back out values for the capital stocks. In doing this, we need to remember that $B=\phi_{B}$ GNP and GNP is output less intangible investments. In other words, we have ${ }^{4}$

$$
\begin{aligned}
A & =V+B \\
& =V_{1}+V_{2}+\phi_{B} \mathrm{GNP} \\
& =V_{1}+V_{2}+\phi_{B}\left(Y-X_{1 I}-X_{2 I}\right) \\
& =\left(1-\tau_{1}^{d}\right)\left(K_{1 T}+\left(1-\tau_{1}^{\pi}\right) K_{2 T}\right)+K_{2 T}+\left(1-\tau_{2}^{d}\right) K_{2 I}+\phi_{B}\left(Y-X_{1 I}-X_{2 I}\right) .
\end{aligned}
$$

Also, note that on a balanced growth path, $X_{i I}=\left[(1+\gamma)(1+\eta)-1+\delta_{i I}\right] K_{i I}$. Using this fact plus the values for $A$ and $Y$ computed in the earlier steps, we have

$$
K_{1 T}=\left(A-\phi_{B} Y\right) /\left\{\left(1-\tau_{1}^{d}\right)\left(1+\left(1-\tau_{1}^{\pi}\right)\left(K_{1 I} / K_{1 T}\right)\right)\right.
$$

\footnotetext{
4 Note that here we are equating beginning-of-period stocks.
} 


$$
\begin{aligned}
&+\left(K_{2 T} / K_{1 T}\right)+\left(1-\tau_{2}^{d}\right)\left(K_{2 I} / K_{2 T}\right)\left(K_{2 T} / K_{1 T}\right) \\
&-\phi_{B}\left[(1+\gamma)(1+\eta)-1+\delta_{1 I}\right]\left(K_{1 I} / K_{1 T}\right) \\
&\left.-\phi_{B}\left[(1+\gamma)(1+\eta)-1+\delta_{2 I}\right]\left(K_{2 I} / K_{2 T}\right)\left(K_{2 T} / K_{1 T}\right)\right\} \\
& K_{1 I}=\left(K_{1 I} / K_{1 T}\right) K_{1 T} \\
& K_{2 T}=\left(K_{2 T} / K_{1 T}\right) K_{1 T} \\
& K_{2 I}=\left(K_{2 I} / K_{2 T}\right) K_{2 T} .
\end{aligned}
$$

- Use the capital stocks, growth rates, and depreciation rates to compute the four investments

$$
\begin{aligned}
& X_{1 T}=\left[(1+\gamma)(1+\eta)-1+\delta_{1 T}\right] K_{1 T} \\
& X_{1 I}=\left[(1+\gamma)(1+\eta)-1+\delta_{1 I}\right] K_{1 I} \\
& X_{2 T}=\left[(1+\gamma)(1+\eta)-1+\delta_{2 T}\right] K_{2 T} \\
& X_{2 I}=\left[(1+\gamma)(1+\eta)-1+\delta_{2 I}\right] K_{2 I} .
\end{aligned}
$$

- Use the capital stocks and labor inputs for the sectoral outputs and prices:

$$
\begin{aligned}
& Y_{i}=K_{i T}^{\theta_{i T}} K_{i I}^{\theta_{i I}} L_{i}^{\theta_{i L}} \\
& p_{i}=\theta_{i} Y / Y_{i} .
\end{aligned}
$$

- Use output and the intangible investments to compute the NIPA analogues of GNP, accounting profits, and corporate dividends:

$$
\begin{aligned}
\mathrm{GNP} & =Y-X_{1 I}-X_{2 I} \\
\Pi_{1} & =p_{1} Y_{1}-w L_{1}-\delta_{1 T} K_{1 T}-X_{1 I} \\
D_{1} & =p_{1} Y_{1}-w L_{1}-X_{1 T}-X_{1 I}-\tau_{1}^{\pi} \Pi_{1} \\
D_{2} & =p_{2} Y_{2}-w L_{2}-\delta_{2 T} K_{2 T}-X_{2 I} .
\end{aligned}
$$

- Use GNP and age-dependent transfers to construct the variables relevant to the government budget constraint:

$$
\begin{aligned}
& G=\phi_{G} \mathrm{GNP} \\
& B=\phi_{B} \mathrm{GNP} \\
& \Psi=\sum_{j} \mu^{j} \psi^{j}+\zeta .
\end{aligned}
$$


- Construct the first-order conditions $r(x)$ as follows:

$$
\begin{aligned}
& r_{1}(x)=r_{1 T}-\theta_{1 T} \theta_{1} Y / K_{1 T} \\
& r_{2}(x)=\Psi+G-\tau^{\ell} w L-\tau_{1}^{d} D_{1}-\tau_{2}^{d} D_{2}-\tau_{1}^{\pi} \Pi_{1}-B^{\prime}+(1+i) B-\tau^{c} C .
\end{aligned}
$$

- Update $x$ and check whether the iterations have converged.

We add elements to $r(x)$ when we compute our initial baseline economy (with current demographics and current policy). Specifically, we add the constraints in (2.1)-(2.6) as residual equations in $r(x)$, and we add $\theta_{1 T}, \theta_{1 I}, \theta_{2 T}, \theta_{2 I}, \alpha$, and $\beta$ as unknowns in the vector $x$.

The Fortran programs for computing balanced growth equilibria are available at our website in the directory ./codes/balgrowth. The naming convention for the codes is bgxxyy.f90 with choices for $\mathrm{xx}$ and $\mathrm{yy}$. The choices for $\mathrm{xx}$, namely, $\mathrm{xx}=$ 'tr' and $\mathrm{xx}=$ 'tc,' depend on whether the residual variable is the common transfer to households (tr) or the tax rate on consumption (tc). The choices for yy, namely, yy='fi' and yy='nr,' depend on whether we employ a functional iteration update as in (4.1) or a Newton-Raphson update as in (4.2) or (4.3).

When we include multiple productivity levels $(K>1)$, we have to compute $K$ different dynamic programs, which is straightforward. We also modified our codes to include the option of using a net tax schedule rather than a proportional tax and, therefore, included an additional subroutine that computes the marginal tax and the total tax paid.

\subsection{Transitions}

For the dynamic case, we need to compute time paths $(t=1, \ldots, T)$ across different birth-year cohorts and productivity levels. To speed up the computations, we wrote the transition code to take advantage of parallel processors, assuming they are available. To simplify the code (called trantf.f90), we assumed that $T / n$ birth-year cohorts would be assigned to each processor, where $n$ is the number of processors. For example, if $T=240$ and $n=48$ (as is true in our case), then there would be five birth-year cohorts with $K$ different productivity levels per processor. For cohorts alive at $t=1$, computation is done starting with the initial conditions of our baseline economy.

The core of the computation in transition is the same as for the balanced growth paths, namely, solving the household problem. But, in this case, we are solving the household problem for each cohort and, therefore, have to keep track of all variables by age and time.

The iterations for finding $x_{t}$ to solve $r\left(x_{t}\right)$ are also similar except that now we keep track of time series for the unknown variables, and we add two other unknowns, namely, the wage rate and 
GNP. We add these additional variables to the vector of unknowns because we cannot write all other variables explicitly in terms of the interest rate and the residual variable for the government budget balance. In addition, we add two residual equations. First, we add an equation relating the wage rate in vector $x$ to the marginal product of labor. Second, we add an equation relating GNP in vector $x$ to output less intangible investments.

Otherwise, the steps are the same as in the case of the balanced growth path computation.

\section{Transition Paths and Welfare Gains}

In this section, we report the full results for our numerical experiments in Section 5. Tables A13-A32 summarize the key variables on the transition paths as the U.S. economy transitions from the current demographics and current policy to the new demographics and new policy.

The first transition, which is a continuation of U.S. policy, is shown in Table A13. Components of the government budget constraint are shown first, as a share of GNP, national account and fixed assets are shown next, again as a share of GNP, and detrended levels of several key variables are shown in the last rows of the table. The main change in public financing that occurs during the transition is an increase in tax rates on consumption that finance the increased transfers to retirees. The consumption tax rate required to finance these transfers rises from a baseline rate of 6.5 percent to roughly 12 percent. The net tax schedules for workers and retirees are not changed, but revenues and transfers change in response to the demographic transition. In terms of outcomes, we find a steady decline in the labor input, with the eventual drop at roughly 10 percent below the current level. GNP is 1 percent below trend in the first decade and eventually falls to 4.5 percent below trend. Consumption changes little, in part because there are increased transfers that affect all productivity types.

Tables A14 and A15 show the transition paths when FICA taxes and transfers are phased out. The first shows the case that these taxes and transfers are phased out gradually (at the same rate that the retiree population rises) and the second shows the case that transfers are phased out gradually and taxes are phased out more quickly. The latter case was discussed in the main text. In Figures A1 and A2, we show the welfare gains for these policy reforms. Figure A1 shows that retirees alive at the time of the policy change are indifferent between continuing the current policy and switching because their benefits are not affected either way. Figure A2 (which is the same as Figure $3 \mathrm{~A}$ in the main text) shows that retirees suffer slight losses if the taxes are phased out more quickly because the consumption tax rates must rise to make up the difference in revenues. 
Table A16 shows the transition paths when we additionally phase out the deductibility of employer benefits. This case is discussed in the main text. The associated welfare gains are shown here in Figure A3 (and in Figure 3B in the main text). Most of the differences between the transition path in this case and those in Tables A14 and A15 show up in the timing of consumption and labor tax revenues and retiree transfers. We also find that the labor input on the new balanced growth path is higher than the current U.S. level, not lower.

Tables A17 and A18 show transition paths for our baseline reforms with marginal tax rates reduced temporarily and permanently, respectively. We noted in the main text that we can generate a Pareto improvement in these cases because the net tax revenues from workers is higher than if the current policy is continued or if there is policy reform without a flattening of the tax schedule. This can be seen by comparing rows 5 and 6 in Tables A17 and A18 with those rows in Table A13 through A16. The welfare gains for these cases are reproduced here for convenience in Figures A4 and A5. For the experiments in Tables A19-A32 (and the corresponding Figures A6-A19), we use the same tax schedule as we did in generating Table A18 and Figure A5 (with marginal tax rates permanently reduced). We refer to the latter case as the baseline reform.

The next two tables show the transition paths for two alternative reforms. Table A19 reports the case with only Social Security phased out and Medicare payments left in household transfers. Not surprisingly, the transition paths are similar to the baseline and the changes in aggregate data are smaller by roughly 30 to 40 percent. Figure A6 shows the welfare gains in this case. For all productivity types, there is a gain to swiching to the new policy.

Table A20 assumes that the debt to GNP ratio is equal to one in the current and future periods. Capital stocks rise by less than in the baseline case but the higher debt levels make it easier to find a Pareto improving transition. In fact, the welfare gains, which are displayed in Figure A7, do not fall below 0.6 percent for any birth-year cohort or type.

Results in Table A21 are based on the case with the more productive living longer than the less productive. The welfare gains in this case are displayed in Figure A8. If we assume that the more productive live longer than the less productive, our predictions for the welfare gains are slightly higher for all but a few cohorts, and our predictions for the rise in GNP and household net worth are slightly lower than in the baseline. Overall, there is little difference between this case and the baseline case.

We experimented with two alternative choices for productivities over the life cycle. In the first, we use CPS data to construct family wage profiles and derive estimates of productivities over the 
life-cycle. In the second, we use Hansen's (1993) productivity estimates, which are based on data for individual wages. Tables A22 and A23 report the transition paths for these experiments and Figures A9 and A10 report the welfare results. In both cases, we find the results are surprisingly close to those of the baseline model that has constant profiles by type over the life cycle.

We investigated the impact of assuming perfect annuity markets by first shutting them down and then allowing for intergenerational transfers. For the latter, we assume that each age cohort bequeaths 10 percent of their assets to family members five years younger. This choice is arbitrary because we do not have detailed data on intrafamily transfers, but the experiment allows us to test this channel of intertemporal smoothing. With the annuity markets shut down but no intrafamily transfers, there is a modest impact of policy on the welfare gains for future cohorts, which are between 1 and 3 percentage points higher than in the baseline. The full results of this experiment are displayed in Table A24 and Figure A11. The findings when we assume that families do not have access to annuity markets but do use intergenerational transfers and bequests are shown in Table A25 and Figure A12. In this case, the equilibrium outcomes are closer to the baseline estimates.

We varied the parameter $\zeta$ governing the labor elasticity with the results shown in Tables A26 and A27 and Figures A13 and A14. As we discuss in the paper, the choice of $\zeta$ has important consequences for the overall increases in aggregate data, much as it does for business cycle predictions. Interestingly, however, the welfare plots in Figures A13 and A14 are not that different from the baseline case shown in Figure A5. There are some welfare losses when $\zeta=5$ (and the elasticity is 0.5$)$, but they are small relative to the huge gains for future cohorts.

We investigated the impact of including only national defense spending in our measure of $G$. The transition paths for these experiments are shown in Tables A28 and A29 and the welfare gains for the policy reform are shown in Figures A15 and A16. In our baseline parameterization, nondefense spending is included with private consumption because many of the goods and services purchased by the government are fairly substitutable with goods and services purchased by households. To check this assumption, we recategorize some categories of spending that are less substitutable with private consumption - specifically, public order and safety and general public service - and include those categories along with defense spending in $G$. (See Table A28 and Figure A15.) We also ran an experiment recategorizing defense spending with other government spending. (See Table A29 and Figure A16.) The results in both cases are similar to the baseline case, with all types and cohorts benefiting from the policy reform and a significant increase in the wage rate, GNP, and household net worth. 
We considered an alternative one-capital, one-sector model with the results shown in Table A30 and Figure A17. In this case, we needed to modify the net tax function to include more AGI bins. Because the piecewise linear net tax function allows for discontinuities, we had trouble computing the optimal household decision functions as they did not converge in the case that the United States continues its current policy. We added more AGI bins to help with convergence. ${ }^{5}$ Specifically, we replaced one AGI bin with five by linearly interpolating the slopes and intercepts of $\alpha_{i}+\beta_{i} y$ between income intervals for $i=10$ and $i=12$.

A comparison of Table A30 with Table A18 shows sizeable differences in magnitudes along the transition paths. First, the government budget financing is much different. For example, all tax revenues must be generated from Schedule C profits, consumption, and labor when we shut down the second sector. Second, with a smaller capital stock, interest rates are much lower and increases in aggregate variables are much smaller. In terms of welfare, this translates into much smaller gains from the policy reform for all but the top 1 percent of households. However, we were surprised to find that while there were some losses on the transition path, they were not large. In other words, including all capital available to retirees is important for the quantitative results, but less important for devising a Pareto improving transition than we originally thought.

Because we introduced more AGI bins in the one-sector, one-capital model, we also reran our baseline parameterization with the modified net tax function in order to determine if we still generate a Pareto-improving transition. We find that we do. The results of this exercise are shown in Table A31 and Figure A18.

Finally, we added more productivity types in order to introduce a very low productivity type, one with a productivity level set so as to generate the same share of labor income as that of U.S. families in the lowest AGI bracket of our sample (with either no AGI or AGI less than $\$ 5,000$ in 2004 dollars). The average per capita compensation for this group is only $\$ 1,200$, much lower than what they receive in government transfers. If we use the same net tax schedule and retiree transfers as we did in the baseline case (corresponding to Figure A5), we again find a Paretoimproving transition for all existing and future cohorts. All families prefer to switch policies, even those with very low per capita earnings. The results of the experiment are shown in Table A32 and Figure A19.

5 In this project, we use published data from the IRS. If we had the data for all tax returns, we could more precisely estimate the U.S. net tax function. 


\section{References}

Barro, Robert J., and Charles J. Redlick. 2011. Macroeconomic Effects from Government Purchases and Taxes. Quarterly Journal of Economics 126(1): 51-102.

Bell, Felicitie C., and Michael L. Miller. 2005. Life Tables for the United States Social Security Area 1900-2100. Social Security Administration, Publication No. 11-11536.

Board of Governors. 1945-2013. Flow of Funds Accounts of the United States, Statistical Release Z.1 (Washington, DC: Board of Governors of the Federal Reserve System).

Economic Report of the President. 2012. (Washington, DC: U.S. Government Printing Office).

Hansen, Gary D. 1993. The Cyclical and Secular Behaviour of the Labour Input: Comparing Efficiency Units and Hours Worked. Journal of Applied Econometrics 8(1): 71-80.

Prescott, Edward C., Alexander Ueberfeldt, and Simona Cociuba. 2005. U.S. Hours and Productivity Behavior Using CPS Hours Worked Data: 1959-I to 2005-II. Manuscript. Research Department, Federal Reserve Bank of Minneapolis.

U.S. Congress, Congressional Budget Office. 2012. Effective Marginal Tax Rates for Low- and Moderate-Income Workers (Washington, DC: U.S. Government Printing Office).

U.S. Department of Commerce, Bureau of the Census. 2012. Statistical Abstract of the United States (Washington, DC: U.S. Government Printing Office).

U.S. Department of Commerce, Bureau of Economic Analysis. 2007. Comparison of BEA Estimates of Personal Income and IRS Estimates of Adjusted Gross Income: New Estimates for 2005 and Revised Estimates for 2004. Survey of Current Business (Washington, DC: U.S. Government Printing Office).

U.S. Department of Commerce, Bureau of Economic Analysis. 1929-2013. National Income and Product Accounts of the United States, Survey of Current Business (Washington, DC: U.S. Government Printing Office).

U.S. Department of the Treasury, Internal Revenue Service. 1918-2013. Statistics of Income (Washington, DC: U.S. Government Printing Office). 
Table A1. Revised National Income and Product Accounts, Averages Relative to Adjusted GNP, 2000-2010

Total Adjusted Income

1.000

Labor Income $\quad .585$

Compensation of employees (NIPA 1.10)

Wages and salary accruals (NIPA 1.10) 433

Supplements to wages and salaries (NIPA 1.10) 099

$70 \%$ of proprietors' income with IVA, CCadj (NIPA 1.10) 053

$\begin{array}{ll}\text { Capital Income } & .415\end{array}$

Corporate profits with IVA and CCadj (NIPA 1.10) 073

$30 \%$ of proprietors' income with IVA, CCadj (NIPA 1.10)

Rental income of persons with CCadj (NIPA 1.10)

Surplus on government enterprises (NIPA 1.10) $\quad 000$

Net income, rest of world (NIPA 1.13)

Indirect business taxes $\quad .072$

Taxes on production and imports (NIPA 1.10) $\quad .068$

Less: Subsidies (NIPA 1.10) $\quad 004$

Business current transfer payments (NIPA 1.10) 008

Less: Sales tax $\quad 042$

Federal excise taxes (NIPA 3.5) $\quad 005$

Federal customs duties (NIPA 3.5) 002

State and local sales taxes (NIPA 3.5) $\quad .029$

Motor vehicle licenses (NIPA 3.5)

Severance taxes (NIPA 3.5) $\quad .001$

Special assessments (NIPA 3.5) $\quad 001$

Other taxes on production and imports (NIPA 3.5) 004

Consumption of fixed capital (NIPA 1.10)

Consumer durable depreciation (FOF F.10) $\quad .060$

Statistical discrepancy (NIPA 1.10) -.004

Imputed capital services $^{a} \quad 037$

Consumer durable services $\quad .013$

Government capital services $\quad .025$

See table notes. 
Table A1. Revised National Income and Product Accounts, Averages Relative to Adjusted GNP, 2000-2010 (Cont.)

Total Adjusted Product

Consumption .745

Personal consumption expenditures (NIPA 1.1.5) .655

Less: Consumer durable goods (NIPA 1.1.5)

.081

Less: Imputed sales tax, nondurables and services

.037

Plus: Imputed capital services, durables ${ }^{a}$

.013

Government consumption expenditures, nondefense (NIPA 3.9.5) 111

Plus: Imputed capital services, government capital ${ }^{a} \quad .025$

Consumer durable depreciation (FOF F.10) $\quad .060$

Tangible investment $\quad .211$

Gross private domestic investment ${ }^{b}$ (NIPA 1.1.5) $\quad .145$

$\begin{array}{ll}\text { Schedule C corporations } & .069\end{array}$

Other private business $\quad .076$

Consumer durable goods (NIPA 1.1.5)

Less: Imputed sales tax, durables $\quad .005$

Government gross investment, nondefense (NIPA 3.9.5) $\quad 025$

Net exports of goods and services (NIPA 1.1.5) $\quad-.042$

Net income rest of world (NIPA 1.13) $\quad 007$

Defense spending $\quad .044$

Government expenditures, national defense (NIPA 3.9.5) 044

Note: IVA, inventory valuation adjustment; CCadj, capital consumption adjustment; NIPA, national income and product accounts; FA, fixed assets; FOF, flow of funds. Expressions in parentheses are the data sources and table numbers.

a Imputed capital services are equal to 4 percent times the current-cost net stock of government fixed assets and consumer durable goods.

$b$ The corporate share of gross private domestic investment is 56.5 percent. To determine the share of Schedule C corporations, we assume that the ratio of investments for these corporations and all other corporations is the same as the ratio of their depreciable assets. Based on balance sheet data from the IRS corporate tax returns, this would imply that 83.5 percent of corporate investment is made by Schedule C corporations. 
Table A2. Revised Fixed Asset Tables with Stocks End of Period, Averages Relative to Adjusted GNP, 2000-2010

\begin{tabular}{cc}
\hline \hline TANGiBle CAPITAL & \\
Fixed assets, private ${ }^{a}$ (FA 1.1) & 4.117 \\
Schedule C corporations & 2.193 \\
Other private business & .674 \\
Fixed assets, government (FA 1.1) & 1.519 \\
Consumer durables (FA 1.1) & .602 \\
Inventories ${ }^{a}$ (NIPA 5.7.5) & .304 \\
Schedule C corporations & .134 \\
Other private business & .103 \\
Land $^{a} \quad$ & .031 \\
Schedule C corporations & .885 \\
Other private business & .109 \\
Nonfinancial corporate (FOF B.102) & .776 \\
Nonfinancial noncorporate (FOF B.103) & .022 \\
Households and nonprofits (FOF B.100) & .298 \\
INTANGIBLE CAPITAL & .455 \\
TotaL & 1.7 \\
\hline \hline
\end{tabular}

Note: FA, fixed assets; FOF, flow of funds. Expressions in parentheses are the data sources and table numbers.

$a$ The corporate shares of private fixed assets, inventories, and land are 36.8 percent, 92.1 percent, and 15.0 percent, respectively. In the case of inventories, we assume that 13 percent of farm inventories are corporate based on the ratio of corporate farmland and buildings relative to total corporate stocks reported in Table 828 of the U.S. Statistical Abstract, 2012. To determine the share of Schedule C corporations, we assume that the ratio of stocks for these corporations and all other corporations is the same as the ratio of their depreciable assets. Based on balance sheet data from the IRS corporate tax returns, this would imply that 83.5 percent of corporate capital is owned by Schedule C corporations. 
Table A3. U.S. Household Net Worth and Government Debt Averages Relative to Adjusted GNP, 2000-2010

\begin{tabular}{lc}
\hline \hline Household Net Worth, End OF PERIOD & 4.100 \\
Assets (FOF B.100) & 4.947 \\
Tangible & 1.787 \\
Financial & 3.160 \\
Liabilities (FOF B.100) & .856 \\
Government DeBT, END OF PERIOD & .549 \\
State and local municipal securities (FOF L.104) & .166 \\
Federal Treasury securities (FOF L.105) & .381 \\
Federal budget agency securities (FOF L.105) & .002 \\
\hline \hline
\end{tabular}

Note: FOF, flow of funds. Expressions in parentheses are the data sources and table numbers. 
Table A4. U.S. Population, Employment, and Hours

Averages, 2000-2010

POPUlATION IN MiLlions

All ages (ERP B-34)

Ages 16 to 64 (ERP B-34)

POPULATION GROWTH (\%)

All ages (ERP B-34)

Ages 16 to 64 (ERP B-34)

FULL-Time EMPLOYEES IN MILLIONS (NIPA 6.5)

ANNUAL HOURS PER POPUlATION 16-64 (CPS, various)

Note: ERP, Economic Report of the President; NIPA, national income and product accounts; CPS, Current Population Survey. Expressions in parentheses are the data sources and table numbers. See Prescott, Ueberfeldt, and Cociuba (2005) for the full details on primary sources. 
Table A5. Aggregate Population Counts

CPS March Supplement, 2005

\begin{tabular}{|c|c|}
\hline Number of RECORDS: & 210,648 \\
\hline Tax Filers & 189,309 \\
\hline Filers & 83,451 \\
\hline Independent & 78,908 \\
\hline Dependent & 4,543 \\
\hline Joint-filing spouses & 38,320 \\
\hline Dependents & 67,538 \\
\hline Under 15 & 49,374 \\
\hline 15 and older & 18,164 \\
\hline Nonfilers & 21,339 \\
\hline Under 15 & 3,470 \\
\hline 15 and older & 17,869 \\
\hline Population (IN MILLIONS): & 291.2 \\
\hline Tax Filers & 256.9 \\
\hline Filers & 123.8 \\
\hline Independent & 117.8 \\
\hline Dependent & 6.0 \\
\hline Joint-filing spouses & 52.4 \\
\hline Dependents & 80.7 \\
\hline Under 15 & 56.3 \\
\hline 15 and older & 24.4 \\
\hline Nonfilers & 34.3 \\
\hline Under 15 & 29.8 \\
\hline 15 and older & 4.4 \\
\hline \multicolumn{2}{|l|}{ ADDENDUM: } \\
\hline Persons 15 and older & 230.4 \\
\hline Persons 65 and older & 35.2 \\
\hline Persons 15 and older, hours $>0$ & 135.0 \\
\hline Persons 15 and older, SS and Medicare recipients & 45.1 \\
\hline
\end{tabular}


Table A6. Adjusted Gross Incomes Reported by IRS and Estimated from CPS A. All Returns

\begin{tabular}{lrrr|rrr}
\hline \hline & \multicolumn{3}{c|}{ IRS Data } & \multicolumn{3}{c}{ CPS Estimates } \\
\cline { 2 - 7 } AGI & $\begin{array}{c}\text { Returns } \\
\text { Bracket }\end{array}$ & $\begin{array}{c}\text { Total AGI } \\
\text { (millions) }\end{array}$ & $\begin{array}{c}\text { AGI per } \\
\text { (billions) }\end{array}$ & $\begin{array}{c}\text { Return } \\
\text { (millions) }\end{array}$ & $\begin{array}{c}\text { Total AGI } \\
\text { (billions) }\end{array}$ & $\begin{array}{c}\text { AGI per } \\
\text { return }\end{array}$ \\
\hline No AGI & 1.9 & -86 & $-46,536$ & 7.4 & -2 & -315 \\
$1-5,000$ & 11.7 & 31 & 2,665 & 3.4 & 8 & 2,433 \\
$5-10,000$ & 12.1 & 91 & 7,488 & 6.8 & 51 & 7,466 \\
$10-15,000$ & 11.7 & 145 & 12,452 & 9.2 & 111 & 12,107 \\
$15-20,000$ & 11.3 & 197 & 17,470 & 9.6 & 163 & 17,064 \\
$20-25,000$ & 9.7 & 218 & 22,446 & 9.7 & 214 & 22,039 \\
$25-30,000$ & 8.5 & 234 & 27,436 & 8.5 & 228 & 26,905 \\
$30-40,000$ & 13.9 & 483 & 34,692 & 14.1 & 483 & 34,150 \\
$40-50,000$ & 10.6 & 473 & 44,779 & 10.7 & 474 & 44,216 \\
$50-75,000$ & 18.1 & 1110 & 61,484 & 19.0 & 1157 & 61,008 \\
$75-100,000$ & 10.1 & 872 & 86,209 & 11.0 & 942 & 85,957 \\
$100-200,000$ & 9.7 & 1288 & 132,331 & 10.7 & 1572 & 147,530 \\
$200-500,000$ & 2.4 & 677 & 288,223 & 3.2 & 881 & 273,720 \\
$500,000+$ & 0.7 & 1056 & $1,568,863$ & 0.6 & 572 & 945,105 \\
Total & 132.2 & 6,789 & 51,342 & 123.8 & 6,854 & 55,380 \\
\hline \hline
\end{tabular}


Table A6. Adjusted Gross Incomes Reported by IRS and Estimated from CPS (Cont.) B. Married Filing Jointly

\begin{tabular}{lccc|ccc}
\hline \hline & \multicolumn{3}{c|}{ IRS Data } & \multicolumn{3}{c}{ CPS Estimates } \\
\cline { 2 - 7 } AGI & $\begin{array}{c}\text { Returns } \\
\text { Bracket }\end{array}$ & $\begin{array}{c}\text { Total AGI } \\
\text { (millions) }\end{array}$ & $\begin{array}{c}\text { AGI per } \\
\text { return }\end{array}$ & $\begin{array}{c}\text { Returns } \\
\text { (millions) }\end{array}$ & $\begin{array}{c}\text { Total AGI } \\
\text { (billions) }\end{array}$ & $\begin{array}{c}\text { AGI per } \\
\text { return }\end{array}$ \\
\hline No AGI & 0.6 & -54 & $-98,180$ & 0.3 & -1 & $-4,006$ \\
$1-5,000$ & 0.8 & 2 & 2,665 & 0.5 & 1 & 2,421 \\
$5-10,000$ & 1.2 & 10 & 7,707 & 0.6 & 5 & 7,555 \\
$10-15,000$ & 2.1 & 26 & 12,656 & 1.0 & 11 & 12,082 \\
$15-20,000$ & 2.7 & 46 & 17,557 & 1.9 & 33 & 17,603 \\
$20-25,000$ & 2.3 & 53 & 22,493 & 2.4 & 53 & 22,268 \\
$25-30,000$ & 2.4 & 66 & 27,500 & 2.2 & 60 & 27,161 \\
$30-40,000$ & 4.7 & 163 & 34,887 & 4.8 & 167 & 34,607 \\
$40-50,000$ & 4.7 & 211 & 44,960 & 5.2 & 232 & 44,612 \\
$50-75,000$ & 11.5 & 718 & 62,318 & 12.2 & 754 & 61,764 \\
$75-100,000$ & 8.2 & 705 & 86,413 & 8.8 & 761 & 86,191 \\
$100-200,000$ & 8.3 & 1106 & 132,547 & 9.2 & 1366 & 148,645 \\
$200-500,000$ & 2.0 & 576 & 288,102 & 2.9 & 797 & 272,248 \\
$500,000+$ & 0.6 & 873 & $1,528,869$ & 0.5 & 472 & 935,140 \\
Total & 52.0 & 4502 & 86,612 & 52.4 & 4,711 & 89,847 \\
\hline \hline
\end{tabular}


Table A6. Adjusted Gross Incomes Reported by IRS and Estimated from CPS (Cont.) C. Head of Households

\begin{tabular}{lccc|ccc}
\hline \hline & \multicolumn{3}{c|}{ IRS Data } & \multicolumn{3}{c}{ CPS Estimates } \\
\cline { 2 - 7 } AGI & $\begin{array}{c}\text { Returns } \\
\text { Bracket }\end{array}$ & $\begin{array}{c}\text { Total AGI } \\
\text { (millions) }\end{array}$ & $\begin{array}{c}\text { AGI per } \\
\text { return }\end{array}$ & $\begin{array}{c}\text { Returns } \\
\text { (millions) }\end{array}$ & $\begin{array}{c}\text { Total AGI } \\
\text { (billions) }\end{array}$ & $\begin{array}{c}\text { AGI per } \\
\text { return }\end{array}$ \\
\hline No AGI & 0.2 & -3 & $-18,961$ & 0.9 & 0 & -329 \\
$1-5,000$ & 0.9 & 3 & 3,054 & 0.7 & 2 & 2,276 \\
$5-10,000$ & 2.2 & 17 & 7,681 & 0.8 & 6 & 7,281 \\
$10-15,000$ & 2.8 & 34 & 12,435 & 1.4 & 17 & 12,202 \\
$15-20,000$ & 2.7 & 48 & 17,508 & 1.4 & 23 & 17,158 \\
$20-25,000$ & 2.5 & 57 & 22,421 & 1.4 & 31 & 22,056 \\
$25-30,000$ & 2.0 & 54 & 27,353 & 1.2 & 31 & 26,873 \\
$30-40,000$ & 2.6 & 88 & 34,467 & 1.8 & 62 & 34,058 \\
$40-50,000$ & 1.6 & 69 & 44,689 & 1.1 & 48 & 43,827 \\
$50-75,000$ & 1.6 & 98 & 60,010 & 1.3 & 78 & 59,395 \\
$75-100,000$ & 0.4 & 35 & 85,866 & 0.4 & 34 & 84,442 \\
$100-200,000$ & 0.3 & 33 & 129,644 & 0.2 & 26 & 143,254 \\
$200-500,000$ & 0.1 & 15 & 285,291 & 0.1 & 18 & 275,164 \\
$500,000+$ & 0.0 & 20 & $1,526,938$ & 0.0 & 22 & $1,035,194$ \\
Total & 19.7 & 568 & 28,899 & 12.5 & 398 & 31,729 \\
\hline \hline
\end{tabular}


Table A6. Adjusted Gross Incomes Reported by IRS and Estimated from CPS (Cont.) D. Singles And Others

\begin{tabular}{lrcc|ccc}
\hline \hline & \multicolumn{3}{c|}{ IRS Data } & \multicolumn{3}{c}{ CPS Estimates } \\
\cline { 2 - 7 } AGI & $\begin{array}{c}\text { Returns } \\
\text { Bracket }\end{array}$ & $\begin{array}{c}\text { Total AGI } \\
\text { (millions) }\end{array}$ & $\begin{array}{c}\text { AGI per } \\
\text { (billions) }\end{array}$ & $\begin{array}{c}\text { Returns } \\
\text { return }\end{array}$ & $\begin{array}{c}\text { Total AGI } \\
\text { (millions) }\end{array}$ & $\begin{array}{c}\text { AGI per } \\
\text { (billions) }\end{array}$ \\
\hline No AGI & 1.2 & -30 & $-25,661$ & 6.3 & -1 & -157 \\
$1-5,000$ & 10.0 & 26 & 2,629 & 2.3 & 6 & 2,481 \\
$5-10,000$ & 8.7 & 65 & 7,410 & 5.4 & 40 & 7,483 \\
$10-15,000$ & 6.9 & 85 & 12,397 & 6.8 & 83 & 12,091 \\
$15-20,000$ & 5.9 & 103 & 17,414 & 6.3 & 107 & 16,885 \\
$20-25,000$ & 4.8 & 108 & 22,437 & 5.9 & 130 & 21,942 \\
$25-30,000$ & 4.2 & 114 & 27,439 & 5.1 & 137 & 26,802 \\
$30-40,000$ & 6.7 & 231 & 34,643 & 7.5 & 254 & 33,878 \\
$40-50,000$ & 4.3 & 193 & 44,616 & 4.4 & 195 & 43,848 \\
$50-75,000$ & 4.9 & 293 & 60,013 & 5.5 & 326 & 59,704 \\
$75-100,000$ & 1.6 & 132 & 85,227 & 1.7 & 146 & 85,109 \\
$100-200,000$ & 1.1 & 150 & 131,349 & 1.3 & 181 & 140,188 \\
$200-500,000$ & 0.3 & 86 & 289,573 & 0.2 & 65 & 292,652 \\
$500,000+$ & 0.1 & 163 & $1,832,644$ & 0.1 & 78 & 984,399 \\
Total & 60.6 & 1,719 & 28,370 & 58.8 & 1,745 & 29,686 \\
\hline \hline
\end{tabular}


Table A7. Distribution of Money Incomes Based on 2005 CPS March Supplement, with Families Sorted into AGi Groups

\begin{tabular}{|c|c|c|c|c|c|c|c|c|c|c|c|c|c|c|}
\hline \multirow{2}{*}{$\begin{array}{l}\text { Per Capita } \\
\text { Family AGI }{ }^{a}\end{array}$} & \multirow{2}{*}{$\begin{array}{l}\text { Tax } \\
\text { Filers }\end{array}$} & \multicolumn{2}{|c|}{ Dependents } & \multirow[b]{2}{*}{ Total $^{b}$} & \multirow{2}{*}{$\begin{array}{l}\text { Wage \& } \\
\text { Salary }\end{array}$} & \multirow{2}{*}{$\begin{array}{c}\text { Self- } \\
\text { Employed }\end{array}$} & \multirow{2}{*}{$\begin{array}{l}\text { Capital } \\
\text { Income }\end{array}$} & \multirow{2}{*}{$\begin{array}{c}\text { Social } \\
\text { Security }\end{array}$} & \multirow{2}{*}{$\begin{array}{l}\text { Worker's } \\
\text { Comp. }\end{array}$} & \multirow{2}{*}{$\begin{array}{c}\text { Other } \\
\text { Ret. }\end{array}$} & \multirow{2}{*}{$\begin{array}{l}\text { Public } \\
\text { Assist. }\end{array}$} & \multirow{2}{*}{$\begin{array}{c}\text { Unempl. } \\
\text { Ins. }\end{array}$} & \multirow{2}{*}{$\begin{array}{l}\text { Other } \\
\text { Income }\end{array}$} & \multirow{2}{*}{$\begin{array}{l}\text { Family \& } \\
\text { Friends }\end{array}$} \\
\hline & & $<15$ & $\geq 15$ & & & & & & & & & & & \\
\hline Nonfilers & 0.0 & 4.4 & 29.8 & 261 & 8 & 0 & 13 & 174 & 2 & 21 & 20 & 0 & 14 & 8 \\
\hline Filers, by AGI: & & & & & & & & & & & & & & \\
\hline No AGI & 4.6 & 0.7 & 0.7 & 60 & 9 & -1 & 5 & 30 & 0 & 9 & 2 & 1 & 3 & 3 \\
\hline $1-5,000$ & 5.9 & 2.7 & 3.0 & 56 & 23 & 3 & 1 & 15 & 1 & 2 & 4 & 1 & 4 & 3 \\
\hline $5-10,000$ & 13.5 & 5.6 & 5.0 & 194 & 118 & 12 & 6 & 28 & 1 & 12 & 4 & 2 & 7 & 4 \\
\hline $10-15,000$ & 20.6 & 6.9 & 4.5 & 380 & 257 & 20 & 11 & 40 & 2 & 30 & 3 & 3 & 10 & 5 \\
\hline $15-20,000$ & 20.1 & 6.5 & 3.3 & 455 & 349 & 23 & 12 & 28 & 1 & 27 & 2 & 3 & 7 & 4 \\
\hline $20-25,000$ & 20.0 & 6.0 & 2.4 & 536 & 433 & 28 & 15 & 21 & 1 & 25 & 1 & 3 & 7 & 4 \\
\hline $25-30,000$ & 16.9 & 5.3 & 1.4 & 526 & 433 & 25 & 16 & 16 & 1 & 24 & 1 & 3 & 5 & 3 \\
\hline $30-40,000$ & 25.8 & 7.7 & 1.6 & 965 & 799 & 44 & 33 & 26 & 1 & 45 & 1 & 4 & 8 & 5 \\
\hline $40-50,000$ & 17.2 & 5.4 & 1.0 & 812 & 689 & 36 & 34 & 13 & 0 & 30 & 0 & 2 & 5 & 3 \\
\hline $50-75,000$ & 16.2 & 4.6 & 0.9 & 994 & 821 & 50 & 57 & 17 & 0 & 39 & 0 & 2 & 4 & 3 \\
\hline $75-100,000$ & 7.9 & 2.6 & 0.2 & 618 & 507 & 33 & 41 & 10 & 0 & 24 & 0 & 1 & 1 & 2 \\
\hline $100-200,000$ & 5.6 & 1.7 & 0.2 & 690 & 560 & 46 & 54 & 8 & 0 & 19 & 0 & 0 & 1 & 1 \\
\hline $200-500,000$ & 1.3 & 0.5 & 0.1 & 299 & 258 & 24 & 13 & 1 & 0 & 2 & 0 & 0 & 0 & 0 \\
\hline $500,000+$ & 0.3 & 0.1 & 0.0 & 101 & 88 & 7 & 5 & 0 & 0 & 0 & 0 & 0 & 0 & 0 \\
\hline Total $^{c}$ & 176.2 & 60.7 & 54.2 & 6948 & 5351 & 350 & 313 & 426 & 12 & 312 & 36 & 25 & 76 & 47 \\
\hline
\end{tabular}

$a$ Families consist of related persons and unmarried partners in a household. Family AGI is the sum of member AGIs divided by all members age 15 and over.

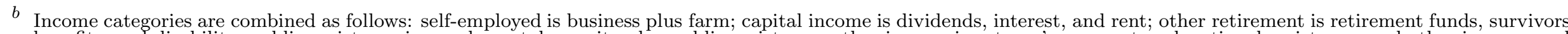

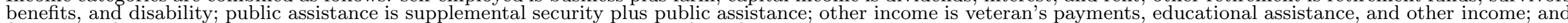
family and friends is child support, alimony, contributions, and assistance from friends.

$c$ Populations are in millions and CPS incomes are in billions. 
Table A8. Incomes Based on 2005 CPS March Supplement Per Working-Age Person, Families Sorted into AGi Groups

\begin{tabular}{|c|c|c|c|c|c|c|c|c|c|c|c|c|c|c|}
\hline \multirow{2}{*}{$\begin{array}{l}\text { Per Capita } \\
\text { Family AGI }\end{array}$} & \multirow{2}{*}{$\begin{array}{c}\text { Tax } \\
\text { Filers }\end{array}$} & \multicolumn{2}{|c|}{ Dependents } & \multirow[b]{2}{*}{ Total $^{b}$} & \multirow{2}{*}{$\begin{array}{l}\text { Wage \& } \\
\text { Salary }\end{array}$} & \multirow{2}{*}{$\begin{array}{c}\text { Self- } \\
\text { Employed }\end{array}$} & \multirow{2}{*}{$\begin{array}{l}\text { Capital } \\
\text { Income }\end{array}$} & \multirow{2}{*}{$\begin{array}{c}\text { Social } \\
\text { Security }\end{array}$} & \multirow{2}{*}{$\begin{array}{c}\text { Worker's } \\
\text { Comp. }\end{array}$} & \multirow{2}{*}{$\begin{array}{l}\text { Other } \\
\text { Ret. }\end{array}$} & \multicolumn{3}{|c|}{ Public Unempl. Other } & \multirow{2}{*}{$\begin{array}{l}\text { Family \& } \\
\text { e Friends }\end{array}$} \\
\hline & & $<15$ & $\geq 15$ & & & & & & & & Assist. & Ins. & Income & \\
\hline Nonfilers & 0.0 & 4.4 & 29.8 & 8,741 & 267 & 0 & 422 & 5,823 & 74 & 718 & 670 & 15 & 505 & 245 \\
\hline Filers, by AGI: & & & & & & & & & & & & & & \\
\hline No AGI & 4.6 & 0.7 & 0.7 & 11,461 & 1,757 & -278 & 939 & 5,715 & 51 & 1,775 & 301 & 97 & 613 & 492 \\
\hline $1-5,000$ & 5.9 & 2.7 & 3.0 & 6,308 & 2,549 & 386 & 121 & 1,673 & 117 & 258 & 407 & 67 & 399 & 331 \\
\hline $5-10,000$ & 13.5 & 5.6 & 5.0 & 10,513 & 6,373 & 632 & 304 & 1,535 & 77 & 646 & 212 & 127 & 377 & 230 \\
\hline $10-15,000$ & 20.6 & 6.9 & 4.5 & 15,098 & 10,208 & 790 & 428 & 1,587 & 73 & 1,181 & 114 & 130 & 382 & 203 \\
\hline $15-20,000$ & 20.1 & 6.5 & 3.3 & 19,364 & 14,845 & 959 & 504 & 1,192 & 49 & 1,149 & 68 & 131 & 286 & 184 \\
\hline $20-25,000$ & 20.0 & 6.0 & 2.4 & 23,934 & 19,299 & 1,235 & 650 & 917 & 56 & 1,132 & 45 & 132 & 301 & 166 \\
\hline $25-30,000$ & 16.9 & 5.3 & 1.4 & 28,630 & 23,576 & 1,366 & 861 & 857 & 40 & 1,330 & 33 & 155 & 251 & 160 \\
\hline $30-40,000$ & 25.8 & 7.7 & 1.6 & 35,316 & 29,229 & 1,613 & 1,212 & 934 & 45 & 1,664 & 20 & 138 & 282 & 178 \\
\hline $40-50,000$ & 17.2 & 5.4 & 1.0 & 44,412 & 37,704 & 1,954 & 1,848 & 728 & 22 & 1,647 & 13 & 94 & 255 & 148 \\
\hline $50-75,000$ & 16.2 & 4.6 & 0.9 & 58,016 & 47,947 & 2,916 & 3,374 & 966 & 21 & 2,255 & 14 & 108 & 236 & 180 \\
\hline $75-100,000$ & 7.9 & 2.6 & 0.2 & 75,742 & 62,044 & 4,082 & 4,927 & 1,227 & 25 & 2,932 & 13 & 113 & 162 & 215 \\
\hline $100-200,000$ & 5.6 & 1.7 & 0.2 & 118,020 & 95,744 & 7,925 & 9,268 & 1,348 & 3 & 3,319 & 7 & 72 & 182 & 152 \\
\hline $200-500,000$ & 1.3 & 0.5 & 0.1 & 209,156 & 180,372 & 17,014 & 8,907 & 754 & 3 & 1,573 & 12 & 191 & 200 & 132 \\
\hline $500,000+$ & 0.3 & 0.1 & 0.0 & 286,674 & 251,367 & 20,431 & 12,491 & 725 & 0 & 1,419 & 0 & 44 & 197 & 0 \\
\hline Total $^{c}$ & 176.2 & 60.7 & 54.2 & 30,150 & 23,220 & 1,518 & 1,360 & 1,848 & 53 & 1,353 & 158 & 109 & 328 & 203 \\
\hline
\end{tabular}

$a$ Families consist of related persons and unmarried partners in a household. Family AGI is the sum of member AGIs divided by all members age 15 and over.

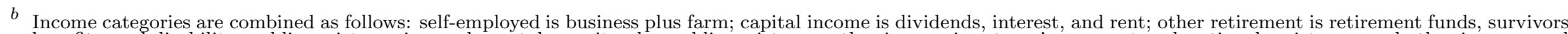

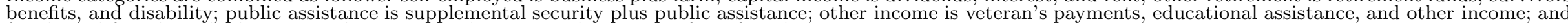
family and friends is child support, alimony, contributions, and assistance from friends.

$c$ Populations are in millions and CPS incomes are in dollars. 
Table A9. Distribution of Incomes Based on 2005 CPS March Supplement, Scaled to BeA Totals, With Families Sorted into AGi Groups

\begin{tabular}{|c|c|c|c|c|c|c|c|c|c|c|c|c|c|c|}
\hline \multirow{2}{*}{$\begin{array}{l}\text { Per Capita } \\
\text { Family AGI }\end{array}$} & \multirow{2}{*}{$\begin{array}{c}\text { Tax } \\
\text { Filers }\end{array}$} & \multicolumn{2}{|c|}{ Dependents } & \multirow[b]{2}{*}{ Total } & \multicolumn{3}{|c|}{ Incomes } & \multicolumn{3}{|c|}{ Transfers } & \multicolumn{3}{|c|}{ Wage Supplements } & \multirow{2}{*}{$\begin{array}{l}\text { Nondefense } \\
\text { Spending }\end{array}$} \\
\hline & & $<15$ & $\geq 15$ & & W\&S & Proprietors & Capital & SS & Medicare & Other & Insurance & Pension & FICA & \\
\hline Nonfilers & 0.0 & 4.4 & 29.8 & 773 & 8 & 0 & 19 & 198 & 136 & 194 & 1 & 0 & 1 & 217 \\
\hline \multicolumn{15}{|l|}{ Filers, by AGI: ${ }^{a}$} \\
\hline No AGI & 4.6 & 0.7 & 0.7 & 129 & 9 & -3 & 8 & 34 & 21 & 21 & 1 & 0 & 1 & 38 \\
\hline $1-5,000$ & 5.9 & 2.7 & 3.0 & 181 & 22 & 8 & 2 & 17 & 11 & 51 & 3 & 0 & 2 & 64 \\
\hline $5-10,000$ & 13.5 & 5.6 & 5.0 & 450 & 117 & 28 & 9 & 32 & 20 & 82 & 14 & 3 & 11 & 134 \\
\hline $10-15,000$ & 20.6 & 6.9 & 4.5 & 717 & 254 & 47 & 16 & 46 & 29 & 77 & 33 & 9 & 22 & 183 \\
\hline $15-20,000$ & 20.1 & 6.5 & 3.3 & 781 & 345 & 53 & 18 & 32 & 19 & 52 & 46 & 15 & 30 & 171 \\
\hline $20-25,000$ & 20.0 & 6.0 & 2.4 & 873 & 428 & 65 & 22 & 23 & 14 & 41 & 57 & 22 & 37 & 163 \\
\hline $25-30,000$ & 16.9 & 5.3 & 1.4 & 818 & 428 & 59 & 24 & 18 & 11 & 30 & 55 & 24 & 36 & 133 \\
\hline $30-40,000$ & 25.8 & 7.7 & 1.6 & 1440 & 790 & 104 & 51 & 29 & 17 & 39 & 97 & 50 & 65 & 199 \\
\hline $40-50,000$ & 17.2 & 5.4 & 1.0 & 1174 & 681 & 84 & 52 & 15 & 9 & 21 & 76 & 47 & 55 & 133 \\
\hline $50-75,000$ & 16.2 & 4.6 & 0.9 & 1387 & 812 & 118 & 88 & 19 & 10 & 18 & 77 & 56 & 64 & 125 \\
\hline $75-100,000$ & 7.9 & 2.6 & 0.2 & 837 & 501 & 79 & 61 & 11 & 5 & 6 & 41 & 36 & 37 & 59 \\
\hline $100-200,000$ & 5.6 & 1.7 & 0.2 & 905 & 553 & 110 & 83 & 9 & 4 & 2 & 30 & 39 & 32 & 42 \\
\hline $200-500,000$ & 1.3 & 0.5 & 0.1 & 382 & 255 & 57 & 19 & 1 & 1 & 1 & 7 & 19 & 11 & 10 \\
\hline $500,000+$ & 0.3 & 0.1 & 0.0 & 125 & 87 & 17 & 7 & 0 & 0 & 0 & 2 & 5 & 4 & 3 \\
\hline Unassigned $^{b}$ & 0.0 & 0.0 & 0.0 & 1263 & 103 & 84 & 1076 & 0 & 0 & 0 & 0 & 0 & 0 & 0 \\
\hline Total $^{c}$ & 176.2 & 60.7 & 54.2 & 12233 & 5392 & 911 & 1555 & 485 & 306 & 635 & 540 & 326 & 407 & 1675 \\
\hline
\end{tabular}

$a$ Families consist of related persons and unmarried partners in a household. Family AGI is the sum of member AGIs divided by all members age 15 and over.

$b$ Unassigned income is BEA personal income less BEA-derived AGI and CPS income of nonfilers. See main text and SCB (2007) for details.

$c$ Populations are in millions, BEA totals in billions. BEA data are from the 2006Q4 archive to be consistent with estimates in SCB (2007). 
Table A10. Incomes Based on 2005 CPS March Supplement Per Working Age Person, Scaled to BeA Totals, With Families Sorted into AGi Groups

\begin{tabular}{|c|c|c|c|c|c|c|c|c|c|c|c|c|c|}
\hline \multirow{2}{*}{$\begin{array}{l}\text { Per Capita } \\
\text { Family AGI }\end{array}$} & \multirow{2}{*}{$\begin{array}{c}\text { Tax } \\
\text { Filers }\end{array}$} & \multicolumn{2}{|c|}{ Dependents } & \multirow[b]{2}{*}{ Total $^{d}$} & \multicolumn{3}{|c|}{ Incomes } & \multicolumn{3}{|c|}{ Transfers } & \multicolumn{3}{|c|}{ Wage Supplements } \\
\hline & & $<15$ & $\geq 15$ & & $\mathrm{~W} \& \mathrm{~S}$ & Proprietors & Capital & SS & Medicare & Other & Insurance & Pension & FICA \\
\hline Nonfilers & 0.0 & 4.4 & 29.8 & 25,922 & 264 & 0 & 644 & 6,634 & 4,544 & 6,502 & 41 & 3 & 20 \\
\hline \multicolumn{14}{|l|}{ Filers, by AGI: $^{a}$} \\
\hline No AGI & 4.6 & 0.7 & 0.7 & 24,444 & 1,737 & -658 & 1,433 & 6,510 & 3,943 & 3,929 & 138 & 9 & 135 \\
\hline $1-5,000$ & 5.9 & 2.7 & 3.0 & 20,453 & 2,520 & 913 & 185 & 1,906 & 1,218 & 5,810 & 339 & 34 & 258 \\
\hline $5-10,000$ & 13.5 & 5.6 & 5.0 & 24,337 & 6,300 & 1,494 & 464 & 1,749 & 1,101 & 4,444 & 779 & 157 & 581 \\
\hline $10-15,000$ & 20.6 & 6.9 & 4.5 & 28,454 & 10,090 & 1,870 & 653 & 1,808 & 1,161 & 3,051 & 1,311 & 350 & 890 \\
\hline $15-20,000$ & 20.1 & 6.5 & 3.3 & 33,248 & 14,674 & 2,267 & 769 & 1,358 & 815 & 2,233 & 1,941 & 658 & 1,264 \\
\hline $20-25,000$ & 20.0 & 6.0 & 2.4 & 38,930 & 19,077 & 2,920 & 992 & 1,045 & 642 & 1,826 & 2,533 & 991 & 1,636 \\
\hline $25-30,000$ & 16.9 & 5.3 & 1.4 & 44,559 & 23,304 & 3,231 & 1,315 & 977 & 573 & 1,641 & 2,992 & 1,297 & 1,961 \\
\hline $30-40,000$ & 25.8 & 7.7 & 1.6 & 52,658 & 28,892 & 3,815 & 1,851 & 1,064 & 605 & 1,412 & 3,547 & 1,817 & 2,385 \\
\hline $40-50,000$ & 17.2 & 5.4 & 1.0 & 64,208 & 37,269 & 4,620 & 2,821 & 829 & 481 & 1,172 & 4,164 & 2,574 & 3,008 \\
\hline $50-75,000$ & 16.2 & 4.6 & 0.9 & 80,934 & 47,395 & 6,896 & 5,151 & 1,100 & 568 & 1,036 & 4,513 & 3,295 & 3,709 \\
\hline $75-100,000$ & 7.9 & 2.6 & 0.2 & 102,473 & 61,329 & 9,653 & 7,522 & 1,398 & 650 & 677 & 5,039 & 4,353 & 4,584 \\
\hline $100-200,000$ & 5.6 & 1.7 & 0.2 & 154,775 & 94,640 & 18,744 & 14,147 & 1,536 & 726 & 368 & 5,204 & 6,706 & 5,435 \\
\hline $200-500,000$ & 1.3 & 0.5 & 0.1 & 267,121 & 178,293 & 40,239 & 13,596 & 859 & 411 & 561 & 4,994 & 13,242 & 7,657 \\
\hline $500,000+$ & 0.3 & 0.1 & 0.0 & 356,157 & 248,470 & 48,322 & 19,068 & 826 & 334 & 659 & 4,809 & 14,705 & 11,696 \\
\hline Total $^{c}$ & 176.2 & 60.7 & 54.2 & 53,085 & 23,400 & 3,954 & 6,748 & 2,106 & 1,328 & 2,757 & 2,345 & 1,413 & 1,767 \\
\hline
\end{tabular}

a Families consist of related persons and unmarried partners in a household. Family AGI is the sum of member AGIs divided by all members age 15 and over.

$b$ Unassigned income is BEA personal income less BEA-derived AGI and CPS income of nonfilers. See SCB (2007).

c Populations are in millions. BEA data are from the 2006Q4 archive to be consistent with estimates in SCB (2007).

$d$ Totals include $\$ 7,269$ of nondefense spending per working-age person. 
Table A11. Tax Data from the CPS March Supplement, with Families Sorted into AGI Groups

\begin{tabular}{|c|c|c|c|c|c|c|c|c|c|c|c|c|c|}
\hline \multirow{2}{*}{$\begin{array}{l}\text { Per Capita } \\
\text { Family AGI }\end{array}$} & \multirow{2}{*}{$\begin{array}{c}\text { Tax } \\
\text { Filers }\end{array}$} & \multicolumn{2}{|c|}{ Dependents } & \multirow{2}{*}{$\begin{array}{l}\text { Total } \\
\text { AGI }\end{array}$} & \multirow{2}{*}{$\begin{array}{l}\text { Taxable } \\
\text { Income }\end{array}$} & \multirow{2}{*}{$\begin{array}{c}\text { FICA } \\
\text { Payment }\end{array}$} & \multicolumn{4}{|c|}{ Income Taxes } & \multicolumn{3}{|c|}{ Tax Credits } \\
\hline & & $<15$ & $\geq 15$ & & & & Fed BC & $\& \mathrm{AC}$ & State BC & $\& \mathrm{AC}$ & EITC & CTC & ACTC \\
\hline Nonfilers & 0.0 & 4.4 & 29.8 & 0 & 0 & 1 & 0 & 0 & 0 & 0 & 0 & 0 & 0 \\
\hline \multicolumn{14}{|l|}{ Filers, by AGI: ${ }^{a}$} \\
\hline No AGI & 4.6 & 0.7 & 0.7 & -2 & 0 & 1 & 0 & 0 & 0 & 0 & 0 & 0 & 0 \\
\hline $1-5,000$ & 5.9 & 2.7 & 3.0 & 25 & 1 & 2 & 0 & -5 & 0 & 0 & 4 & 0 & 0 \\
\hline $5-10,000$ & 13.5 & 5.6 & 5.0 & 142 & 23 & 10 & 2 & -11 & 1 & 1 & 10 & 1 & 3 \\
\hline $10-15,000$ & 20.6 & 6.9 & 4.5 & 313 & 109 & 22 & 10 & -1 & 5 & 4 & 7 & 3 & 4 \\
\hline $15-20,000$ & 20.1 & 6.5 & 3.3 & 408 & 204 & 29 & 20 & 15 & 9 & 8 & 3 & 4 & 3 \\
\hline $20-25,000$ & 20.0 & 6.0 & 2.4 & 500 & 294 & 36 & 32 & 29 & 12 & 11 & 2 & 5 & 2 \\
\hline $25-30,000$ & 16.9 & 5.3 & 1.4 & 500 & 322 & 35 & 38 & 37 & 14 & 13 & 1 & 5 & 1 \\
\hline $30-40,000$ & 25.8 & 7.7 & 1.6 & 941 & 656 & 64 & 86 & 85 & 28 & 26 & 0 & 8 & 0 \\
\hline $40-50,000$ & 17.2 & 5.4 & 1.0 & 814 & 603 & 54 & 92 & 92 & 26 & 25 & 0 & 5 & 0 \\
\hline $50-75,000$ & 16.2 & 4.6 & 0.9 & 1065 & 789 & 62 & 143 & 143 & 35 & 34 & 0 & 4 & 0 \\
\hline $75-100,000$ & 7.9 & 2.6 & 0.2 & 698 & 531 & 36 & 109 & 109 & 24 & 24 & 0 & 1 & 0 \\
\hline $100-200,000$ & 5.6 & 1.7 & 0.2 & 761 & 591 & 31 & 142 & 142 & 28 & 28 & 0 & 0 & 0 \\
\hline $200-500,000$ & 1.3 & 0.5 & 0.1 & 425 & 354 & 11 & 106 & 106 & 16 & 16 & 0 & 0 & 0 \\
\hline $500,000+$ & 0.3 & 0.1 & 0.0 & 265 & 203 & 4 & 66 & 66 & 10 & 10 & 0 & 0 & 0 \\
\hline Total $^{b}$ & 176.2 & 60.7 & 54.2 & 6854 & 4681 & 397 & 846 & 807 & 208 & 198 & 26 & 36 & 13 \\
\hline
\end{tabular}

$a$ Families consist of related persons and unmarried partners in a household. Family AGI is the sum of member AGIs divided by all members age 15 and over.

$b$ Populations are in millions. CPS tax data are in billions. 
Table A12. Tax Rates Based on Data from the CPS March Supplement, with Families Sorted into AGi Groups

\begin{tabular}{|c|c|c|c|c|c|c|c|c|c|c|c|c|c|}
\hline \multirow{2}{*}{$\begin{array}{l}\text { Per Capita } \\
\text { Family AGI }\end{array}$} & \multirow{2}{*}{$\begin{array}{l}\text { Tax } \\
\text { Filers }\end{array}$} & \multicolumn{2}{|c|}{ Dependents } & \multicolumn{6}{|c|}{ Marginal Tax Rates } & \multicolumn{4}{|c|}{ Average Tax Rates } \\
\hline & & $<15$ & $\geq 15$ & Total & Federal & EITC $^{c}$ & $\mathrm{CTC}^{c}$ & State & FICA & Total & Federal & State & FICA \\
\hline Nonfilers $^{b}$ & 0.0 & 4.4 & 29.8 & 14.2 & 0 & 0 & 0 & 0 & 14.2 & 14.2 & 0 & 0 & 14.2 \\
\hline \multicolumn{14}{|l|}{ Filers, by AGI: } \\
\hline No AGI & 4.6 & 0.7 & 0.7 & 14.6 & 0.0 & 0.1 & 0.0 & 0.0 & 14.4 & 14.4 & 0.0 & 0.0 & 14.4 \\
\hline $1-5,000$ & 5.9 & 2.7 & 3.0 & 4.7 & 0.9 & -10.3 & -0.9 & 0.2 & 14.8 & 13.2 & 0.1 & 0.1 & 14.3 \\
\hline $5-10,000$ & 13.5 & 5.6 & 5.0 & 20.7 & 5.1 & 1.8 & -2.2 & 1.2 & 14.7 & 13.8 & -0.8 & 0.5 & 14.1 \\
\hline $10-15,000$ & 20.6 & 6.9 & 4.5 & 28.2 & 9.6 & 2.6 & -1.1 & 2.4 & 14.7 & 15.3 & 0.5 & 1.1 & 13.7 \\
\hline $15-20,000$ & 20.1 & 6.5 & 3.3 & 32.6 & 13.1 & 1.9 & -0.4 & 3.2 & 14.7 & 18.7 & 2.8 & 1.7 & 14.2 \\
\hline $20-25,000$ & 20.0 & 6.0 & 2.4 & 34.2 & 14.9 & 1.0 & -0.1 & 3.8 & 14.7 & 21.4 & 4.8 & 2.1 & 14.4 \\
\hline $25-30,000$ & 16.9 & 5.3 & 1.4 & 35.3 & 15.8 & 1.0 & 0.0 & 4.0 & 14.5 & 23.5 & 6.5 & 2.4 & 14.6 \\
\hline $30-40,000$ & 25.8 & 7.7 & 1.6 & 35.9 & 17.1 & 0.3 & 0.0 & 4.3 & 14.2 & 25.6 & 8.3 & 2.7 & 14.6 \\
\hline $40-50,000$ & 17.2 & 5.4 & 1.0 & 41.2 & 23.2 & 0.0 & 0.0 & 4.7 & 13.3 & 28.2 & 10.6 & 3.1 & 14.5 \\
\hline $50-75,000$ & 16.2 & 4.6 & 0.9 & 41.9 & 24.8 & 0.0 & 0.0 & 5.0 & 12.1 & 30.3 & 13.0 & 3.3 & 14.0 \\
\hline $75-100,000$ & 7.9 & 2.6 & 0.2 & 41.8 & 27.3 & 0.0 & 0.0 & 5.1 & 9.4 & 32.3 & 15.5 & 3.5 & 13.3 \\
\hline $100-200,000$ & 5.6 & 1.7 & 0.2 & 41.2 & 30.0 & 0.0 & 0.0 & 5.4 & 5.9 & 32.7 & 18.1 & 3.8 & 10.9 \\
\hline $200-500,000$ & 1.3 & 0.5 & 0.1 & 43.6 & 34.4 & 0.0 & 0.0 & 5.3 & 3.9 & 35.2 & 24.1 & 3.9 & 7.2 \\
\hline $500,000+$ & 0.3 & 0.1 & 0.0 & 43.1 & 34.8 & 0.0 & 0.0 & 4.8 & 3.5 & 36.9 & 26.9 & 3.9 & 6.2 \\
\hline
\end{tabular}

$a$ Families consist of related persons and unmarried partners in a household. Family AGI is the sum of member AGIs divided by all members age 15 and over.

$b$ Populations of tax filers and dependents under and over age 15 are in millions, tax rates in percent.

$c$ Adjustments are made to federal tax rates to account for the impact of refundable tax credits and public assistance. See U.S. Congress, CBO (2012). 
Table A13. Transitions from Current U.S. Policy to New Policies

Continue U.S. Policy

\begin{tabular}{|c|c|c|c|c|c|c|}
\hline & $2011-20$ & $2021-30$ & $2031-40$ & $2041-70$ & 2071-99 & $\infty$ \\
\hline \multicolumn{7}{|l|}{ SHARES OF GNP: } \\
\hline Tax revenues (net) & 0.173 & 0.174 & 0.176 & 0.186 & 0.207 & 0.217 \\
\hline Profits, Schedule C & 0.026 & 0.026 & 0.026 & 0.027 & 0.027 & 0.028 \\
\hline Distributions, Schedule C & 0.004 & 0.004 & 0.004 & 0.005 & 0.005 & 0.006 \\
\hline Distributions, Other & 0.094 & 0.094 & 0.094 & 0.094 & 0.094 & 0.094 \\
\hline Consumption & 0.059 & 0.060 & 0.062 & 0.071 & 0.087 & 0.094 \\
\hline Labor inc. (net), by type & -0.009 & -0.010 & -0.011 & -0.010 & -0.006 & -0.004 \\
\hline Low & -0.052 & -0.052 & -0.052 & -0.051 & -0.050 & -0.049 \\
\hline Medium & -0.010 & -0.010 & -0.011 & -0.010 & -0.008 & -0.007 \\
\hline High & 0.040 & 0.040 & 0.040 & 0.040 & 0.040 & 0.040 \\
\hline Top 1 pct & 0.012 & 0.012 & 0.012 & 0.012 & 0.012 & 0.012 \\
\hline Retiree transfers, by type & 0.121 & 0.121 & 0.123 & 0.132 & 0.152 & 0.161 \\
\hline Low & 0.046 & 0.046 & 0.047 & 0.050 & 0.058 & 0.061 \\
\hline Medium & 0.048 & 0.049 & 0.049 & 0.053 & 0.061 & 0.064 \\
\hline High & 0.025 & 0.026 & 0.026 & 0.028 & 0.032 & 0.034 \\
\hline Top 1 pct & 0.001 & 0.001 & 0.001 & 0.001 & 0.002 & 0.002 \\
\hline Interest on debt & 0.025 & 0.025 & 0.024 & 0.024 & 0.024 & 0.023 \\
\hline Labor income & 0.585 & 0.584 & 0.583 & 0.581 & 0.579 & 0.577 \\
\hline Capital income & 0.415 & 0.416 & 0.417 & 0.419 & 0.421 & 0.423 \\
\hline Consumption & 0.745 & 0.747 & 0.752 & 0.760 & 0.772 & 0.778 \\
\hline Tangible investment & 0.212 & 0.210 & 0.205 & 0.197 & 0.185 & 0.177 \\
\hline Intangible investment & 0.134 & 0.133 & 0.131 & 0.127 & 0.122 & 0.119 \\
\hline Defense & 0.044 & 0.044 & 0.044 & 0.044 & 0.044 & 0.044 \\
\hline Tangible capital & 4.172 & 4.167 & 4.156 & 4.166 & 4.226 & 4.233 \\
\hline Intangible capital & 1.732 & 1.730 & 1.725 & 1.724 & 1.733 & 1.727 \\
\hline \multicolumn{7}{|l|}{ LEVELS: } \\
\hline Interest rate & 4.593 & 4.596 & 4.591 & 4.547 & 4.411 & 4.335 \\
\hline Wage rate & 1.007 & 1.007 & 1.007 & 1.014 & 1.033 & 1.045 \\
\hline Labor input & 0.982 & 0.979 & 0.972 & 0.952 & 0.916 & 0.900 \\
\hline GNP & 0.990 & 0.987 & 0.983 & 0.973 & 0.958 & 0.955 \\
\hline Net worth & 0.997 & 0.993 & 0.986 & 0.977 & 0.973 & 0.970 \\
\hline
\end{tabular}

Note: Tables A13-32 report averages over subperiods. Values for the wage rate, labor input, GNP, and net worth are detrended and defined relative to the current U.S. economy. 
Table A14. Transitions from Current U.S. Policy to New Policies

Social Security, Medicare, and FICA Taxes Phased Out,

Taxes and Transfers Phased Out at Same Rate

\begin{tabular}{|c|c|c|c|c|c|c|}
\hline & $2011-20$ & 2021-30 & $2031-40$ & $2041-70$ & 2071-99 & $\infty$ \\
\hline \multicolumn{7}{|l|}{ SHARES OF GNP: } \\
\hline Tax revenues (net) & 0.173 & 0.172 & 0.171 & 0.158 & 0.128 & 0.110 \\
\hline Profits, Schedule C & 0.025 & 0.026 & 0.026 & 0.025 & 0.025 & 0.025 \\
\hline Distributions, Schedule C & 0.004 & 0.004 & 0.004 & 0.004 & 0.004 & 0.005 \\
\hline Distributions, Other & 0.094 & 0.094 & 0.094 & 0.093 & 0.092 & 0.091 \\
\hline Consumption & 0.059 & 0.059 & 0.060 & 0.054 & 0.040 & 0.028 \\
\hline Labor inc. (net), by type & -0.009 & -0.010 & -0.012 & -0.018 & -0.034 & -0.040 \\
\hline Low & -0.051 & -0.051 & -0.051 & -0.049 & -0.046 & -0.046 \\
\hline Medium & -0.010 & -0.010 & -0.011 & -0.013 & -0.022 & -0.024 \\
\hline High & 0.040 & 0.039 & 0.038 & 0.034 & 0.024 & 0.020 \\
\hline Top 1 pct & 0.012 & 0.012 & 0.012 & 0.011 & 0.010 & 0.010 \\
\hline Retiree transfers, by type & 0.120 & 0.120 & 0.118 & 0.106 & 0.075 & 0.057 \\
\hline Low & 0.046 & 0.046 & 0.045 & 0.040 & 0.028 & 0.021 \\
\hline Medium & 0.048 & 0.048 & 0.047 & 0.042 & 0.030 & 0.023 \\
\hline High & 0.025 & 0.025 & 0.025 & 0.022 & 0.016 & 0.012 \\
\hline Top 1 pct & 0.001 & 0.001 & 0.001 & 0.001 & 0.001 & 0.001 \\
\hline Interest on debt & 0.025 & 0.024 & 0.024 & 0.024 & 0.022 & 0.020 \\
\hline Labor income & 0.585 & 0.585 & 0.585 & 0.586 & 0.584 & 0.581 \\
\hline Capital income & 0.415 & 0.415 & 0.415 & 0.414 & 0.416 & 0.419 \\
\hline Consumption & 0.742 & 0.743 & 0.743 & 0.738 & 0.748 & 0.756 \\
\hline Tangible investment & 0.215 & 0.213 & 0.214 & 0.219 & 0.209 & 0.195 \\
\hline Intangible investment & 0.135 & 0.135 & 0.135 & 0.136 & 0.132 & 0.127 \\
\hline Defense & 0.044 & 0.044 & 0.044 & 0.044 & 0.044 & 0.044 \\
\hline Tangible capital & 4.178 & 4.186 & 4.197 & 4.303 & 4.542 & 4.710 \\
\hline Intangible capital & 1.734 & 1.736 & 1.739 & 1.765 & 1.816 & 1.849 \\
\hline \multicolumn{7}{|l|}{ LEVELS: } \\
\hline Interest rate & 4.591 & 4.579 & 4.570 & 4.431 & 4.075 & 3.828 \\
\hline Wage rate & 1.007 & 1.008 & 1.009 & 1.031 & 1.088 & 1.128 \\
\hline Labor input & 0.985 & 0.982 & 0.984 & 0.996 & 0.991 & 0.981 \\
\hline GNP & 0.992 & 0.991 & 0.994 & 1.026 & 1.081 & 1.115 \\
\hline Net worth & 1.000 & 1.001 & 1.005 & 1.060 & 1.167 & 1.241 \\
\hline
\end{tabular}


Table A15. Transitions from Current U.S. Policy to New Policies

Social Security, Medicare, and FICA Taxes Phased Out,

Taxes Phased Out More Quickly Than Transfers

\begin{tabular}{|c|c|c|c|c|c|c|}
\hline & $2011-20$ & 2021-30 & $2031-40$ & $2041-70$ & 2071-99 & $\infty$ \\
\hline \multicolumn{7}{|l|}{ SHARES OF GNP: } \\
\hline Tax revenues (net) & 0.174 & 0.171 & 0.166 & 0.152 & 0.125 & 0.110 \\
\hline Profits, Schedule C & 0.026 & 0.025 & 0.025 & 0.024 & 0.025 & 0.026 \\
\hline Distributions, Schedule C & 0.004 & 0.003 & 0.003 & 0.003 & 0.004 & 0.005 \\
\hline Distributions, Other & 0.094 & 0.094 & 0.094 & 0.093 & 0.092 & 0.091 \\
\hline Consumption & 0.070 & 0.092 & 0.107 & 0.090 & 0.050 & 0.029 \\
\hline Labor inc. (net), by type & -0.021 & -0.044 & -0.062 & -0.058 & -0.045 & -0.040 \\
\hline Low & -0.052 & -0.054 & -0.054 & -0.051 & -0.047 & -0.046 \\
\hline Medium & -0.015 & -0.026 & -0.034 & -0.033 & -0.027 & -0.025 \\
\hline High & 0.035 & 0.025 & 0.016 & 0.016 & 0.018 & 0.020 \\
\hline Top 1 pct & 0.012 & 0.010 & 0.009 & 0.010 & 0.010 & 0.010 \\
\hline Retiree transfers, by type & 0.121 & 0.119 & 0.114 & 0.101 & 0.072 & 0.057 \\
\hline Low & 0.046 & 0.045 & 0.043 & 0.038 & 0.028 & 0.022 \\
\hline Medium & 0.048 & 0.048 & 0.046 & 0.040 & 0.029 & 0.023 \\
\hline High & 0.025 & 0.025 & 0.024 & 0.021 & 0.015 & 0.012 \\
\hline Top 1 pct & 0.001 & 0.001 & 0.001 & 0.001 & 0.001 & 0.001 \\
\hline Interest on debt & 0.025 & 0.025 & 0.025 & 0.023 & 0.021 & 0.020 \\
\hline Labor income & 0.584 & 0.587 & 0.588 & 0.587 & 0.584 & 0.581 \\
\hline Capital income & 0.416 & 0.413 & 0.412 & 0.413 & 0.416 & 0.419 \\
\hline Consumption & 0.749 & 0.737 & 0.725 & 0.730 & 0.748 & 0.761 \\
\hline Tangible investment & 0.207 & 0.219 & 0.231 & 0.227 & 0.209 & 0.195 \\
\hline Intangible investment & 0.133 & 0.138 & 0.141 & 0.138 & 0.132 & 0.127 \\
\hline Defense & 0.044 & 0.044 & 0.044 & 0.044 & 0.044 & 0.044 \\
\hline Tangible capital & 4.161 & 4.124 & 4.190 & 4.414 & 4.660 & 4.693 \\
\hline Intangible capital & 1.729 & 1.724 & 1.742 & 1.793 & 1.844 & 1.841 \\
\hline \multicolumn{7}{|l|}{ LEVELS: } \\
\hline Interest rate & 4.600 & 4.697 & 4.631 & 4.298 & 3.934 & 3.823 \\
\hline Wage rate & 1.006 & 0.993 & 1.002 & 1.050 & 1.109 & 1.128 \\
\hline Labor input & 0.979 & 1.008 & 1.034 & 1.030 & 0.997 & 0.979 \\
\hline GNP & 0.987 & 0.999 & 1.031 & 1.079 & 1.110 & 1.113 \\
\hline Net worth & 0.992 & 0.996 & 1.042 & 1.139 & 1.225 & 1.234 \\
\hline
\end{tabular}


Table A16. Transitions from Current U.S. Policy to New Policies

Social Security, Medicare, and FICA Taxes Phased Out,

Nonmarginal Employer Benefits Phased Out

\begin{tabular}{|c|c|c|c|c|c|c|}
\hline & $2011-20$ & 2021-30 & $2031-40$ & $2041-70$ & 2071-99 & $\infty$ \\
\hline \multicolumn{7}{|l|}{ SHARES OF GNP: } \\
\hline Tax revenues (net) & 0.172 & 0.169 & 0.165 & 0.152 & 0.126 & 0.111 \\
\hline Profits, Schedule C & 0.026 & 0.025 & 0.025 & 0.025 & 0.026 & 0.026 \\
\hline Distributions, Schedule C & 0.004 & 0.003 & 0.003 & 0.004 & 0.005 & 0.005 \\
\hline Distributions, Other & 0.094 & 0.094 & 0.094 & 0.093 & 0.092 & 0.092 \\
\hline Consumption & 0.063 & 0.072 & 0.077 & 0.060 & 0.020 & 0.001 \\
\hline Labor inc. (net), by type & -0.014 & -0.026 & -0.035 & -0.029 & -0.017 & -0.013 \\
\hline Low & -0.051 & -0.051 & -0.051 & -0.048 & -0.044 & -0.043 \\
\hline Medium & -0.013 & -0.019 & -0.024 & -0.021 & -0.014 & -0.012 \\
\hline High & 0.038 & 0.033 & 0.029 & 0.029 & 0.031 & 0.031 \\
\hline Top 1 pct & 0.012 & 0.011 & 0.010 & 0.010 & 0.010 & 0.010 \\
\hline Retiree transfers, by type & 0.120 & 0.117 & 0.113 & 0.100 & 0.072 & 0.057 \\
\hline Low & 0.046 & 0.045 & 0.043 & 0.038 & 0.027 & 0.021 \\
\hline Medium & 0.048 & 0.047 & 0.045 & 0.040 & 0.029 & 0.023 \\
\hline High & 0.025 & 0.025 & 0.024 & 0.021 & 0.015 & 0.012 \\
\hline Top 1 pct & 0.001 & 0.001 & 0.001 & 0.001 & 0.001 & 0.001 \\
\hline Interest on debt & 0.025 & 0.025 & 0.025 & 0.024 & 0.022 & 0.021 \\
\hline Labor income & 0.585 & 0.587 & 0.587 & 0.586 & 0.582 & 0.580 \\
\hline Capital income & 0.415 & 0.413 & 0.413 & 0.414 & 0.418 & 0.420 \\
\hline Consumption & 0.744 & 0.739 & 0.733 & 0.737 & 0.757 & 0.764 \\
\hline Tangible investment & 0.212 & 0.218 & 0.224 & 0.220 & 0.200 & 0.189 \\
\hline Intangible investment & 0.135 & 0.137 & 0.139 & 0.136 & 0.128 & 0.125 \\
\hline Defense & 0.044 & 0.044 & 0.044 & 0.044 & 0.044 & 0.044 \\
\hline Tangible capital & 4.159 & 4.121 & 4.139 & 4.319 & 4.518 & 4.559 \\
\hline Intangible capital & 1.730 & 1.723 & 1.728 & 1.768 & 1.808 & 1.814 \\
\hline \multicolumn{7}{|l|}{ LEVELS: } \\
\hline Interest rate & 4.619 & 4.700 & 4.688 & 4.409 & 4.078 & 3.999 \\
\hline Wage rate & 1.003 & 0.993 & 0.994 & 1.034 & 1.085 & 1.099 \\
\hline Labor input & 0.990 & 1.022 & 1.053 & 1.053 & 1.022 & 1.006 \\
\hline GNP & 0.994 & 1.013 & 1.044 & 1.089 & 1.116 & 1.116 \\
\hline Net worth & 0.998 & 1.010 & 1.045 & 1.128 & 1.200 & 1.207 \\
\hline
\end{tabular}


Table A17. Transitions from Current U.S. Policy to New Policies

Social Security, Medicare, and FICA Taxes Phased Out,

Worker Net Tax Functions Temporarily Changed

\begin{tabular}{|c|c|c|c|c|c|c|}
\hline & $2011-20$ & $2021-30$ & $2031-40$ & $2041-70$ & 2071-99 & $\infty$ \\
\hline \multicolumn{7}{|l|}{ SHARES OF GNP: } \\
\hline Tax revenues (net) & 0.169 & 0.164 & 0.160 & 0.149 & 0.126 & 0.110 \\
\hline Profits, Schedule C & 0.025 & 0.025 & 0.025 & 0.025 & 0.026 & 0.025 \\
\hline Distributions, Schedule C & 0.003 & 0.003 & 0.003 & 0.004 & 0.005 & 0.005 \\
\hline Distributions, Other & 0.094 & 0.094 & 0.094 & 0.093 & 0.092 & 0.091 \\
\hline Consumption & 0.055 & 0.050 & 0.047 & 0.030 & 0.015 & 0.029 \\
\hline Labor inc. (net), by type & -0.007 & -0.008 & -0.009 & -0.003 & -0.012 & -0.040 \\
\hline Low & -0.052 & -0.052 & -0.053 & -0.051 & -0.048 & -0.046 \\
\hline Medium & -0.008 & -0.009 & -0.009 & -0.005 & -0.010 & -0.024 \\
\hline High & 0.041 & 0.042 & 0.042 & 0.042 & 0.035 & 0.020 \\
\hline Top 1 pct & 0.012 & 0.011 & 0.011 & 0.011 & 0.010 & 0.010 \\
\hline Retiree transfers, by type & 0.118 & 0.114 & 0.108 & 0.096 & 0.071 & 0.057 \\
\hline Low & 0.045 & 0.043 & 0.041 & 0.037 & 0.027 & 0.022 \\
\hline Medium & 0.047 & 0.046 & 0.043 & 0.038 & 0.028 & 0.023 \\
\hline High & 0.025 & 0.024 & 0.023 & 0.020 & 0.015 & 0.012 \\
\hline Top 1 pct & 0.001 & 0.001 & 0.001 & 0.001 & 0.001 & 0.001 \\
\hline Interest on debt & 0.025 & 0.025 & 0.025 & 0.023 & 0.022 & 0.020 \\
\hline Labor income & 0.587 & 0.588 & 0.587 & 0.586 & 0.580 & 0.582 \\
\hline Capital income & 0.413 & 0.412 & 0.413 & 0.414 & 0.420 & 0.418 \\
\hline Consumption & 0.732 & 0.730 & 0.730 & 0.739 & 0.764 & 0.758 \\
\hline Tangible investment & 0.224 & 0.226 & 0.227 & 0.218 & 0.193 & 0.196 \\
\hline Intangible investment & 0.140 & 0.141 & 0.140 & 0.135 & 0.125 & 0.128 \\
\hline Defense & 0.044 & 0.044 & 0.044 & 0.044 & 0.044 & 0.044 \\
\hline Tangible capital & 4.166 & 4.155 & 4.177 & 4.335 & 4.475 & 4.729 \\
\hline Intangible capital & 1.736 & 1.734 & 1.737 & 1.773 & 1.795 & 1.856 \\
\hline \multicolumn{7}{|l|}{ LEVELS: } \\
\hline Interest rate & 4.648 & 4.678 & 4.636 & 4.386 & 4.112 & 3.828 \\
\hline Wage rate & 0.999 & 0.995 & 0.999 & 1.038 & 1.081 & 1.128 \\
\hline Labor input & 1.013 & 1.054 & 1.088 & 1.086 & 1.035 & 0.981 \\
\hline GNP & 1.008 & 1.044 & 1.085 & 1.128 & 1.128 & 1.114 \\
\hline Net worth & 1.015 & 1.049 & 1.094 & 1.172 & 1.202 & 1.244 \\
\hline
\end{tabular}


Table A18. Transitions from Current U.S. Policy to New Policies

Social Security, Medicare, and FICA Taxes Phased Out,

Worker Net Tax Functions Permanently Changed

\begin{tabular}{|c|c|c|c|c|c|c|}
\hline & $2011-20$ & 2021-30 & $2031-40$ & $2041-70$ & 2071-99 & $\infty$ \\
\hline \multicolumn{7}{|l|}{ SHARES OF GNP: } \\
\hline Tax revenues (net) & 0.169 & 0.164 & 0.160 & 0.148 & 0.123 & 0.109 \\
\hline Profits, Schedule C & 0.025 & 0.025 & 0.025 & 0.025 & 0.026 & 0.026 \\
\hline Distributions, Schedule C & 0.003 & 0.003 & 0.003 & 0.004 & 0.005 & 0.005 \\
\hline Distributions, Other & 0.094 & 0.094 & 0.094 & 0.093 & 0.092 & 0.092 \\
\hline Consumption & 0.055 & 0.050 & 0.047 & 0.029 & -0.008 & -0.025 \\
\hline Labor inc. (net), by type & -0.008 & -0.008 & -0.009 & -0.003 & 0.008 & 0.010 \\
\hline Low & -0.052 & -0.052 & -0.053 & -0.051 & -0.047 & -0.045 \\
\hline Medium & -0.008 & -0.009 & -0.009 & -0.005 & 0.001 & 0.002 \\
\hline High & 0.041 & 0.042 & 0.042 & 0.043 & 0.043 & 0.044 \\
\hline Top 1 pct & 0.012 & 0.011 & 0.011 & 0.011 & 0.011 & 0.011 \\
\hline Retiree transfers, by type & 0.118 & 0.114 & 0.108 & 0.096 & 0.069 & 0.054 \\
\hline Low & 0.045 & 0.043 & 0.041 & 0.036 & 0.026 & 0.021 \\
\hline Medium & 0.047 & 0.046 & 0.043 & 0.038 & 0.028 & 0.022 \\
\hline High & 0.025 & 0.024 & 0.023 & 0.020 & 0.015 & 0.011 \\
\hline Top 1 pct & 0.001 & 0.001 & 0.001 & 0.001 & 0.001 & 0.001 \\
\hline Interest on debt & 0.025 & 0.025 & 0.025 & 0.023 & 0.022 & 0.021 \\
\hline Labor income & 0.587 & 0.588 & 0.587 & 0.586 & 0.582 & 0.580 \\
\hline Capital income & 0.413 & 0.412 & 0.413 & 0.414 & 0.418 & 0.420 \\
\hline Consumption & 0.733 & 0.730 & 0.730 & 0.737 & 0.757 & 0.766 \\
\hline Tangible investment & 0.224 & 0.226 & 0.227 & 0.220 & 0.199 & 0.188 \\
\hline Intangible investment & 0.140 & 0.141 & 0.140 & 0.136 & 0.128 & 0.124 \\
\hline Defense & 0.044 & 0.044 & 0.044 & 0.044 & 0.044 & 0.044 \\
\hline Tangible capital & 4.166 & 4.151 & 4.172 & 4.338 & 4.494 & 4.527 \\
\hline Intangible capital & 1.736 & 1.733 & 1.736 & 1.773 & 1.802 & 1.805 \\
\hline \multicolumn{7}{|l|}{ LEVELS: } \\
\hline Interest rate & 4.648 & 4.681 & 4.643 & 4.379 & 4.108 & 4.025 \\
\hline Wage rate & 0.999 & 0.995 & 1.000 & 1.038 & 1.080 & 1.094 \\
\hline Labor input & 1.012 & 1.054 & 1.089 & 1.089 & 1.069 & 1.050 \\
\hline GNP & 1.008 & 1.044 & 1.085 & 1.131 & 1.162 & 1.161 \\
\hline Net worth & 1.014 & 1.048 & 1.093 & 1.176 & 1.243 & 1.249 \\
\hline
\end{tabular}


Table A19. Transitions from Current U.S. Policy to New Policies

Social Security, Medicare, and FICA Taxes Phased Out,

Worker Net Tax Functions Permanently Changed

(Medicare transfers not phased out)

\begin{tabular}{|c|c|c|c|c|c|c|}
\hline & $2011-20$ & $2021-30$ & $2031-40$ & $2041-70$ & 2071-99 & $\infty$ \\
\hline \multicolumn{7}{|l|}{ SHARES OF GNP: } \\
\hline Tax revenues (net) & 0.170 & 0.165 & 0.162 & 0.158 & 0.149 & 0.143 \\
\hline Profits, Schedule C & 0.025 & 0.025 & 0.025 & 0.026 & 0.027 & 0.027 \\
\hline Distributions, Schedule C & 0.003 & 0.003 & 0.003 & 0.004 & 0.005 & 0.005 \\
\hline Distributions, Other & 0.094 & 0.094 & 0.094 & 0.093 & 0.093 & 0.093 \\
\hline Consumption & 0.055 & 0.052 & 0.050 & 0.042 & 0.024 & 0.016 \\
\hline Labor inc. (net), by type & -0.008 & -0.008 & -0.010 & -0.007 & 0.001 & 0.003 \\
\hline Low & -0.052 & -0.053 & -0.054 & -0.053 & -0.050 & -0.049 \\
\hline Medium & -0.008 & -0.009 & -0.010 & -0.007 & -0.003 & -0.002 \\
\hline High & 0.041 & 0.042 & 0.042 & 0.042 & 0.043 & 0.043 \\
\hline Top 1 pct & 0.012 & 0.011 & 0.011 & 0.011 & 0.011 & 0.011 \\
\hline Retiree transfers, by type & 0.119 & 0.115 & 0.110 & 0.105 & 0.094 & 0.088 \\
\hline Low & 0.045 & 0.044 & 0.042 & 0.040 & 0.036 & 0.033 \\
\hline Medium & 0.047 & 0.046 & 0.044 & 0.042 & 0.038 & 0.035 \\
\hline High & 0.025 & 0.024 & 0.023 & 0.022 & 0.020 & 0.018 \\
\hline Top 1 pct & 0.001 & 0.001 & 0.001 & 0.001 & 0.001 & 0.001 \\
\hline Interest on debt & 0.025 & 0.025 & 0.025 & 0.024 & 0.023 & 0.022 \\
\hline Labor income & 0.587 & 0.588 & 0.587 & 0.584 & 0.580 & 0.579 \\
\hline Capital income & 0.413 & 0.412 & 0.413 & 0.416 & 0.420 & 0.421 \\
\hline Consumption & 0.733 & 0.733 & 0.734 & 0.748 & 0.765 & 0.774 \\
\hline Tangible investment & 0.223 & 0.223 & 0.223 & 0.210 & 0.192 & 0.183 \\
\hline Intangible investment & 0.139 & 0.140 & 0.138 & 0.132 & 0.125 & 0.122 \\
\hline Defense & 0.044 & 0.044 & 0.044 & 0.044 & 0.044 & 0.044 \\
\hline Tangible capital & 4.165 & 4.143 & 4.153 & 4.268 & 4.365 & 4.396 \\
\hline Intangible capital & 1.735 & 1.731 & 1.731 & 1.754 & 1.770 & 1.774 \\
\hline \multicolumn{7}{|l|}{ LEVELS: } \\
\hline Interest rate & 4.646 & 4.688 & 4.665 & 4.452 & 4.255 & 4.188 \\
\hline Wage rate & 0.999 & 0.994 & 0.997 & 1.027 & 1.058 & 1.068 \\
\hline Labor input & 1.011 & 1.051 & 1.083 & 1.072 & 1.044 & 1.024 \\
\hline GNP & 1.008 & 1.041 & 1.078 & 1.105 & 1.114 & 1.107 \\
\hline Net worth & 1.014 & 1.042 & 1.082 & 1.133 & 1.163 & 1.162 \\
\hline
\end{tabular}


Table A20. Transitions from Current U.S. Policy to New Policies

Social Security, Medicare, and FICA Taxes Phased Out,

Worker Net Tax Functions Permanently Changed

$($ Debt to $\mathrm{GNP}=1)$

\begin{tabular}{|c|c|c|c|c|c|c|}
\hline & $2011-20$ & $2021-30$ & $2031-40$ & $2041-70$ & 2071-99 & $\infty$ \\
\hline \multicolumn{7}{|l|}{ SHARES OF GNP: } \\
\hline Tax revenues (net) & 0.176 & 0.173 & 0.170 & 0.159 & 0.134 & 0.121 \\
\hline Profits, Schedule C & 0.026 & 0.025 & 0.025 & 0.025 & 0.026 & 0.027 \\
\hline Distributions, Schedule C & 0.004 & 0.003 & 0.003 & 0.004 & 0.005 & 0.005 \\
\hline Distributions, Other & 0.094 & 0.094 & 0.094 & 0.094 & 0.093 & 0.093 \\
\hline Consumption & 0.062 & 0.060 & 0.060 & 0.043 & 0.006 & -0.010 \\
\hline Labor inc. (net), by type & -0.009 & -0.010 & -0.013 & -0.007 & 0.004 & 0.006 \\
\hline Low & -0.051 & -0.053 & -0.054 & -0.052 & -0.048 & -0.047 \\
\hline Medium & -0.009 & -0.010 & -0.011 & -0.007 & -0.001 & -0.000 \\
\hline High & 0.041 & 0.041 & 0.041 & 0.042 & 0.043 & 0.043 \\
\hline Top 1 pct & 0.012 & 0.011 & 0.011 & 0.011 & 0.011 & 0.011 \\
\hline Retiree transfers, by type & 0.119 & 0.115 & 0.110 & 0.098 & 0.071 & 0.056 \\
\hline Low & 0.045 & 0.044 & 0.042 & 0.037 & 0.027 & 0.021 \\
\hline Medium & 0.048 & 0.046 & 0.044 & 0.039 & 0.028 & 0.022 \\
\hline High & 0.025 & 0.024 & 0.023 & 0.021 & 0.015 & 0.012 \\
\hline Top 1 pct & 0.001 & 0.001 & 0.001 & 0.001 & 0.001 & 0.001 \\
\hline Interest on debt & 0.047 & 0.047 & 0.047 & 0.045 & 0.042 & 0.042 \\
\hline Labor income & 0.586 & 0.587 & 0.586 & 0.585 & 0.581 & 0.579 \\
\hline Capital income & 0.414 & 0.413 & 0.414 & 0.415 & 0.419 & 0.421 \\
\hline Consumption & 0.741 & 0.737 & 0.737 & 0.742 & 0.762 & 0.773 \\
\hline Tangible investment & 0.215 & 0.219 & 0.219 & 0.215 & 0.194 & 0.184 \\
\hline Intangible investment & 0.136 & 0.138 & 0.137 & 0.134 & 0.126 & 0.122 \\
\hline Defense & 0.044 & 0.044 & 0.044 & 0.044 & 0.044 & 0.044 \\
\hline Tangible capital & 4.117 & 4.091 & 4.096 & 4.257 & 4.393 & 4.411 \\
\hline Intangible capital & 1.720 & 1.715 & 1.715 & 1.753 & 1.777 & 1.777 \\
\hline \multicolumn{7}{|l|}{ LEVELS: } \\
\hline Interest rate & 4.693 & 4.745 & 4.738 & 4.488 & 4.220 & 4.163 \\
\hline Wage rate & 1.006 & 0.998 & 1.000 & 1.035 & 1.076 & 1.087 \\
\hline Labor input & 1.014 & 1.052 & 1.084 & 1.085 & 1.065 & 1.048 \\
\hline GNP & 1.019 & 1.049 & 1.083 & 1.125 & 1.156 & 1.152 \\
\hline Net worth & 1.007 & 1.031 & 1.065 & 1.139 & 1.198 & 1.196 \\
\hline
\end{tabular}


Table A21. Transitions from Current U.S. Policy to New Policies

Social Security, Medicare, and FICA Taxes Phased Out,

Worker Net Tax Functions Permanently Changed

(Life expectancy depends on productivity)

\begin{tabular}{|c|c|c|c|c|c|c|}
\hline & $2011-20$ & $2021-30$ & $2031-40$ & $2041-70$ & 2071-99 & $\infty$ \\
\hline \multicolumn{7}{|l|}{ SHARES OF GNP: } \\
\hline Tax revenues (net) & 0.169 & 0.166 & 0.162 & 0.151 & 0.125 & 0.110 \\
\hline Profits, Schedule C & 0.025 & 0.025 & 0.025 & 0.025 & 0.026 & 0.026 \\
\hline Distributions, Schedule C & 0.003 & 0.003 & 0.003 & 0.004 & 0.005 & 0.005 \\
\hline Distributions, Other & 0.094 & 0.094 & 0.094 & 0.093 & 0.092 & 0.092 \\
\hline Consumption & 0.058 & 0.057 & 0.055 & 0.037 & -0.001 & -0.019 \\
\hline Labor inc. (net), by type & -0.012 & -0.013 & -0.014 & -0.008 & 0.003 & 0.006 \\
\hline Low & -0.055 & -0.056 & -0.057 & -0.055 & -0.050 & -0.049 \\
\hline Medium & -0.008 & -0.009 & -0.009 & -0.005 & 0.001 & 0.002 \\
\hline High & 0.040 & 0.041 & 0.041 & 0.042 & 0.042 & 0.043 \\
\hline Top 1 pct & 0.011 & 0.011 & 0.011 & 0.011 & 0.010 & 0.010 \\
\hline Retiree transfers, by type & 0.118 & 0.116 & 0.111 & 0.099 & 0.071 & 0.056 \\
\hline Low & 0.042 & 0.044 & 0.043 & 0.039 & 0.028 & 0.022 \\
\hline Medium & 0.048 & 0.046 & 0.044 & 0.039 & 0.028 & 0.022 \\
\hline High & 0.027 & 0.024 & 0.022 & 0.020 & 0.014 & 0.011 \\
\hline Top 1 pct & 0.001 & 0.001 & 0.001 & 0.001 & 0.001 & 0.001 \\
\hline Interest on debt & 0.025 & 0.025 & 0.025 & 0.023 & 0.022 & 0.021 \\
\hline Labor income & 0.586 & 0.588 & 0.588 & 0.586 & 0.582 & 0.580 \\
\hline Capital income & 0.414 & 0.412 & 0.412 & 0.414 & 0.418 & 0.420 \\
\hline Consumption & 0.737 & 0.730 & 0.729 & 0.737 & 0.757 & 0.767 \\
\hline Tangible investment & 0.219 & 0.226 & 0.228 & 0.220 & 0.199 & 0.189 \\
\hline Intangible investment & 0.138 & 0.141 & 0.140 & 0.136 & 0.128 & 0.125 \\
\hline Defense & 0.044 & 0.044 & 0.044 & 0.044 & 0.044 & 0.044 \\
\hline Tangible capital & 4.148 & 4.143 & 4.175 & 4.341 & 4.495 & 4.543 \\
\hline Intangible capital & 1.729 & 1.731 & 1.737 & 1.774 & 1.802 & 1.810 \\
\hline \multicolumn{7}{|l|}{ LEVELS: } \\
\hline Interest rate & 4.658 & 4.692 & 4.642 & 4.375 & 4.107 & 4.015 \\
\hline Wage rate & 0.996 & 0.992 & 0.998 & 1.037 & 1.080 & 1.095 \\
\hline Labor input & 1.016 & 1.051 & 1.081 & 1.080 & 1.060 & 1.042 \\
\hline GNP & 1.007 & 1.034 & 1.073 & 1.116 & 1.148 & 1.149 \\
\hline Net worth & 1.005 & 1.032 & 1.076 & 1.156 & 1.223 & 1.234 \\
\hline
\end{tabular}


Table A22. Transitions from Current U.S. Policy to New Policies

Social Security, Medicare, and FICA Taxes Phased Out,

Worker Net Tax Functions Permanently Changed

(Age-dependent productivities-CPS profiles)

\begin{tabular}{|c|c|c|c|c|c|c|}
\hline & $2011-20$ & $2021-30$ & $2031-40$ & $2041-70$ & 2071-99 & $\infty$ \\
\hline \multicolumn{7}{|l|}{ SHARES OF GNP: } \\
\hline Tax revenues (net) & 0.162 & 0.157 & 0.153 & 0.143 & 0.119 & 0.105 \\
\hline Profits, Schedule C & 0.025 & 0.025 & 0.025 & 0.025 & 0.026 & 0.026 \\
\hline Distributions, Schedule C & 0.003 & 0.003 & 0.003 & 0.004 & 0.004 & 0.005 \\
\hline Distributions, Other & 0.094 & 0.094 & 0.094 & 0.093 & 0.092 & 0.092 \\
\hline Consumption & 0.037 & 0.032 & 0.028 & 0.013 & -0.019 & -0.038 \\
\hline Labor inc. (net), by type & 0.003 & 0.004 & 0.003 & 0.007 & 0.016 & 0.019 \\
\hline Low & -0.047 & -0.048 & -0.049 & -0.047 & -0.043 & -0.042 \\
\hline Medium & -0.004 & -0.003 & -0.003 & 0.000 & 0.004 & 0.005 \\
\hline High & 0.043 & 0.044 & 0.044 & 0.045 & 0.045 & 0.046 \\
\hline Top 1 pct & 0.011 & 0.011 & 0.010 & 0.010 & 0.010 & 0.010 \\
\hline Retiree transfers, by type & 0.111 & 0.107 & 0.102 & 0.090 & 0.065 & 0.051 \\
\hline Low & 0.042 & 0.041 & 0.039 & 0.034 & 0.025 & 0.019 \\
\hline Medium & 0.045 & 0.043 & 0.041 & 0.036 & 0.026 & 0.020 \\
\hline High & 0.023 & 0.022 & 0.021 & 0.019 & 0.014 & 0.011 \\
\hline Top 1 pct & 0.001 & 0.001 & 0.001 & 0.001 & 0.001 & 0.001 \\
\hline Interest on debt & 0.025 & 0.025 & 0.025 & 0.023 & 0.022 & 0.021 \\
\hline Labor income & 0.587 & 0.588 & 0.588 & 0.585 & 0.582 & 0.580 \\
\hline Capital income & 0.413 & 0.412 & 0.412 & 0.415 & 0.418 & 0.420 \\
\hline Consumption & 0.735 & 0.729 & 0.729 & 0.740 & 0.756 & 0.766 \\
\hline Tangible investment & 0.221 & 0.228 & 0.228 & 0.217 & 0.201 & 0.190 \\
\hline Intangible investment & 0.139 & 0.142 & 0.140 & 0.135 & 0.129 & 0.125 \\
\hline Defense & 0.044 & 0.044 & 0.044 & 0.044 & 0.044 & 0.044 \\
\hline Tangible capital & 4.166 & 4.145 & 4.171 & 4.326 & 4.493 & 4.558 \\
\hline Intangible capital & 1.735 & 1.732 & 1.736 & 1.769 & 1.803 & 1.812 \\
\hline \multicolumn{7}{|l|}{ LEVELS: } \\
\hline Interest rate & 4.641 & 4.696 & 4.649 & 4.387 & 4.115 & 3.987 \\
\hline Wage rate & 0.997 & 0.990 & 0.996 & 1.034 & 1.076 & 1.097 \\
\hline Labor input & 1.015 & 1.063 & 1.100 & 1.095 & 1.073 & 1.056 \\
\hline GNP & 1.009 & 1.047 & 1.091 & 1.132 & 1.161 & 1.169 \\
\hline Net worth & 1.011 & 1.046 & 1.095 & 1.170 & 1.238 & 1.260 \\
\hline
\end{tabular}


Table A23. Transitions from Current U.S. Policy to New Policies

Social Security, Medicare, and FICA Taxes Phased Out,

Worker Net Tax Functions Permanently Changed

(Age-dependent productivities-Hansen)

\begin{tabular}{|c|c|c|c|c|c|c|}
\hline & $2011-20$ & $2021-30$ & $2031-40$ & $2041-70$ & 2071-99 & $\infty$ \\
\hline \multicolumn{7}{|l|}{ SHARES OF GNP: } \\
\hline Tax revenues (net) & 0.173 & 0.167 & 0.163 & 0.150 & 0.124 & 0.110 \\
\hline Profits, Schedule C & 0.026 & 0.026 & 0.026 & 0.026 & 0.027 & 0.028 \\
\hline Distributions, Schedule C & 0.004 & 0.004 & 0.004 & 0.004 & 0.005 & 0.006 \\
\hline Distributions, Other & 0.095 & 0.095 & 0.095 & 0.094 & 0.094 & 0.094 \\
\hline Consumption & 0.058 & 0.052 & 0.049 & 0.029 & -0.009 & -0.028 \\
\hline Labor inc. (net), by type & -0.010 & -0.010 & -0.011 & -0.004 & 0.008 & 0.011 \\
\hline Low & -0.052 & -0.053 & -0.054 & -0.051 & -0.047 & -0.045 \\
\hline Medium & -0.009 & -0.009 & -0.010 & -0.005 & 0.000 & 0.002 \\
\hline High & 0.039 & 0.041 & 0.041 & 0.042 & 0.043 & 0.044 \\
\hline Top 1 pct & 0.012 & 0.011 & 0.011 & 0.011 & 0.011 & 0.010 \\
\hline Retiree transfers, by type & 0.120 & 0.115 & 0.109 & 0.096 & 0.069 & 0.054 \\
\hline Low & 0.045 & 0.044 & 0.042 & 0.037 & 0.026 & 0.020 \\
\hline Medium & 0.048 & 0.046 & 0.044 & 0.039 & 0.028 & 0.022 \\
\hline High & 0.025 & 0.024 & 0.023 & 0.020 & 0.014 & 0.011 \\
\hline Top 1 pct & 0.001 & 0.001 & 0.001 & 0.001 & 0.001 & 0.001 \\
\hline Interest on debt & 0.027 & 0.027 & 0.027 & 0.025 & 0.024 & 0.023 \\
\hline Labor income & 0.585 & 0.586 & 0.585 & 0.583 & 0.580 & 0.577 \\
\hline Capital income & 0.415 & 0.414 & 0.415 & 0.417 & 0.420 & 0.423 \\
\hline Consumption & 0.744 & 0.743 & 0.744 & 0.749 & 0.766 & 0.776 \\
\hline Tangible investment & 0.212 & 0.213 & 0.213 & 0.207 & 0.191 & 0.178 \\
\hline Intangible investment & 0.135 & 0.135 & 0.134 & 0.131 & 0.124 & 0.120 \\
\hline Defense & 0.044 & 0.044 & 0.044 & 0.044 & 0.044 & 0.044 \\
\hline Tangible capital & 3.933 & 3.914 & 3.929 & 4.068 & 4.233 & 4.261 \\
\hline Intangible capital & 1.672 & 1.667 & 1.669 & 1.701 & 1.736 & 1.737 \\
\hline \multicolumn{7}{|l|}{ LEVELS: } \\
\hline Interest rate & 4.980 & 5.007 & 4.977 & 4.729 & 4.424 & 4.330 \\
\hline Wage rate & 0.992 & 0.989 & 0.992 & 1.025 & 1.070 & 1.082 \\
\hline Labor input & 1.012 & 1.055 & 1.090 & 1.100 & 1.089 & 1.074 \\
\hline GNP & 0.997 & 1.036 & 1.076 & 1.126 & 1.170 & 1.172 \\
\hline Net worth & 1.014 & 1.049 & 1.092 & 1.175 & 1.261 & 1.270 \\
\hline
\end{tabular}


Table A24. Transitions from Current U.S. Policy to New Policies

Social Security, Medicare, and FICA Taxes Phased Out,

Worker Net Tax Functions Permanently Changed

(No annuity markets)

\begin{tabular}{|c|c|c|c|c|c|c|}
\hline & $2011-20$ & $2021-30$ & $2031-40$ & $2041-70$ & 2071-99 & $\infty$ \\
\hline \multicolumn{7}{|l|}{ SHARES OF GNP: } \\
\hline Tax revenues (net) & 0.145 & 0.142 & 0.138 & 0.121 & 0.083 & 0.064 \\
\hline Profits, Schedule C & 0.027 & 0.027 & 0.027 & 0.027 & 0.028 & 0.028 \\
\hline Distributions, Schedule C & 0.004 & 0.004 & 0.004 & 0.004 & 0.005 & 0.006 \\
\hline Distributions, Other & 0.095 & 0.095 & 0.096 & 0.095 & 0.094 & 0.094 \\
\hline Consumption & 0.041 & 0.041 & 0.038 & 0.016 & -0.037 & -0.058 \\
\hline Labor inc. (net), by type & -0.023 & -0.025 & -0.027 & -0.021 & -0.008 & -0.006 \\
\hline Low & -0.057 & -0.058 & -0.060 & -0.057 & -0.052 & -0.051 \\
\hline Medium & -0.015 & -0.016 & -0.017 & -0.013 & -0.007 & -0.006 \\
\hline High & 0.037 & 0.039 & 0.039 & 0.039 & 0.041 & 0.041 \\
\hline Top 1 pct & 0.011 & 0.011 & 0.011 & 0.011 & 0.011 & 0.011 \\
\hline Retiree transfers, by type & 0.128 & 0.124 & 0.119 & 0.106 & 0.076 & 0.060 \\
\hline Low & 0.049 & 0.047 & 0.045 & 0.040 & 0.029 & 0.023 \\
\hline Medium & 0.051 & 0.050 & 0.048 & 0.042 & 0.030 & 0.024 \\
\hline High & 0.027 & 0.026 & 0.025 & 0.022 & 0.016 & 0.013 \\
\hline Top 1 pct & 0.001 & 0.001 & 0.001 & 0.001 & 0.001 & 0.001 \\
\hline Interest on debt & 0.027 & 0.027 & 0.027 & 0.026 & 0.024 & 0.024 \\
\hline Labor income & 0.583 & 0.584 & 0.583 & 0.581 & 0.579 & 0.577 \\
\hline Capital income & 0.417 & 0.416 & 0.417 & 0.419 & 0.421 & 0.423 \\
\hline Consumption & 0.753 & 0.751 & 0.751 & 0.755 & 0.771 & 0.790 \\
\hline Tangible investment & 0.204 & 0.206 & 0.205 & 0.201 & 0.185 & 0.173 \\
\hline Intangible investment & 0.131 & 0.132 & 0.131 & 0.128 & 0.122 & 0.118 \\
\hline Defense & 0.044 & 0.044 & 0.044 & 0.044 & 0.044 & 0.044 \\
\hline Tangible capital & 3.894 & 3.858 & 3.849 & 3.974 & 4.120 & 4.154 \\
\hline Intangible capital & 1.659 & 1.650 & 1.645 & 1.675 & 1.706 & 1.714 \\
\hline \multicolumn{7}{|l|}{ LEVELS: } \\
\hline Interest rate & 5.011 & 5.076 & 5.083 & 4.849 & 4.560 & 4.504 \\
\hline Wage rate & 1.007 & 0.999 & 0.997 & 1.028 & 1.071 & 1.080 \\
\hline Labor input & 1.013 & 1.050 & 1.084 & 1.087 & 1.075 & 1.056 \\
\hline GNP & 1.019 & 1.047 & 1.081 & 1.120 & 1.160 & 1.152 \\
\hline Net worth & 1.007 & 1.026 & 1.057 & 1.124 & 1.198 & 1.198 \\
\hline
\end{tabular}


Table A25. Transitions from Current U.S. Policy to New Policies

Social Security, Medicare, and FICA Taxes Phased Out,

Worker Net Tax Functions Permanently Changed

(Intergenerational transfers included)

\begin{tabular}{|c|c|c|c|c|c|c|}
\hline & $2011-20$ & $2021-30$ & $2031-40$ & $2041-70$ & 2071-99 & $\infty$ \\
\hline \multicolumn{7}{|l|}{ SHARES OF GNP: } \\
\hline Tax revenues (net) & 0.103 & 0.099 & 0.096 & 0.080 & 0.043 & 0.025 \\
\hline Profits, Schedule C & 0.024 & 0.024 & 0.024 & 0.025 & 0.025 & 0.026 \\
\hline Distributions, Schedule C & 0.003 & 0.003 & 0.003 & 0.003 & 0.004 & 0.005 \\
\hline Distributions, Other & 0.093 & 0.094 & 0.094 & 0.093 & 0.092 & 0.092 \\
\hline Consumption & 0.023 & 0.018 & 0.014 & -0.006 & -0.051 & -0.075 \\
\hline Labor inc. (net), by type & -0.040 & -0.039 & -0.040 & -0.034 & -0.027 & -0.024 \\
\hline Low & -0.053 & -0.054 & -0.055 & -0.052 & -0.049 & -0.047 \\
\hline Medium & -0.022 & -0.021 & -0.020 & -0.016 & -0.012 & -0.011 \\
\hline High & 0.025 & 0.027 & 0.027 & 0.026 & 0.026 & 0.027 \\
\hline Top 1 pct & 0.009 & 0.009 & 0.008 & 0.008 & 0.008 & 0.007 \\
\hline Retiree transfers, by type & 0.089 & 0.085 & 0.081 & 0.068 & 0.039 & 0.023 \\
\hline Low & 0.045 & 0.043 & 0.041 & 0.037 & 0.027 & 0.021 \\
\hline Medium & 0.037 & 0.036 & 0.034 & 0.029 & 0.017 & 0.011 \\
\hline High & 0.008 & 0.008 & 0.007 & 0.004 & -0.002 & -0.006 \\
\hline Top 1 pct & -0.002 & -0.002 & -0.002 & -0.002 & -0.002 & -0.002 \\
\hline Interest on debt & 0.024 & 0.024 & 0.024 & 0.023 & 0.021 & 0.021 \\
\hline Labor income & 0.588 & 0.589 & 0.588 & 0.586 & 0.583 & 0.580 \\
\hline Capital income & 0.412 & 0.411 & 0.412 & 0.414 & 0.417 & 0.420 \\
\hline Consumption & 0.729 & 0.728 & 0.727 & 0.734 & 0.754 & 0.763 \\
\hline Tangible investment & 0.227 & 0.229 & 0.229 & 0.223 & 0.203 & 0.189 \\
\hline Intangible investment & 0.141 & 0.142 & 0.141 & 0.137 & 0.130 & 0.124 \\
\hline Defense & 0.044 & 0.044 & 0.044 & 0.044 & 0.044 & 0.044 \\
\hline Tangible capital & 4.284 & 4.250 & 4.254 & 4.426 & 4.569 & 4.552 \\
\hline Intangible capital & 1.766 & 1.759 & 1.758 & 1.795 & 1.822 & 1.806 \\
\hline \multicolumn{7}{|l|}{ LEVELS: } \\
\hline Interest rate & 4.487 & 4.545 & 4.536 & 4.270 & 4.028 & 3.963 \\
\hline Wage rate & 0.999 & 0.992 & 0.993 & 1.033 & 1.070 & 1.081 \\
\hline Labor input & 1.008 & 1.052 & 1.089 & 1.086 & 1.063 & 1.054 \\
\hline GNP & 1.006 & 1.040 & 1.079 & 1.123 & 1.146 & 1.153 \\
\hline Net worth & 1.011 & 1.039 & 1.078 & 1.159 & 1.214 & 1.216 \\
\hline
\end{tabular}


Table A26. Transitions from Current U.S. Policy to New Policies

Social Security, Medicare, and FICA Taxes Phased Out,

Worker Net Tax Functions Permanently Changed

(Labor elasticity cut by 5)

\begin{tabular}{|c|c|c|c|c|c|c|}
\hline & $2011-20$ & $2021-30$ & $2031-40$ & $2041-70$ & 2071-99 & $\infty$ \\
\hline \multicolumn{7}{|l|}{ SHARES OF GNP: } \\
\hline Tax revenues (net) & 0.176 & 0.174 & 0.172 & 0.161 & 0.134 & 0.117 \\
\hline Profits, Schedule C & 0.026 & 0.026 & 0.026 & 0.026 & 0.026 & 0.027 \\
\hline Distributions, Schedule C & 0.004 & 0.004 & 0.004 & 0.004 & 0.005 & 0.005 \\
\hline Distributions, Other & 0.094 & 0.094 & 0.094 & 0.094 & 0.093 & 0.093 \\
\hline Consumption & 0.066 & 0.071 & 0.075 & 0.061 & 0.024 & 0.004 \\
\hline Labor inc. (net), by type & -0.015 & -0.021 & -0.027 & -0.024 & -0.015 & -0.012 \\
\hline Low & -0.050 & -0.054 & -0.057 & -0.055 & -0.052 & -0.051 \\
\hline Medium & -0.011 & -0.012 & -0.013 & -0.012 & -0.008 & -0.006 \\
\hline High & 0.036 & 0.035 & 0.033 & 0.033 & 0.035 & 0.036 \\
\hline Top 1 pct & 0.010 & 0.010 & 0.010 & 0.010 & 0.010 & 0.010 \\
\hline Retiree transfers, by type & 0.123 & 0.121 & 0.119 & 0.107 & 0.079 & 0.062 \\
\hline Low & 0.047 & 0.046 & 0.045 & 0.041 & 0.030 & 0.024 \\
\hline Medium & 0.049 & 0.049 & 0.048 & 0.043 & 0.032 & 0.025 \\
\hline High & 0.026 & 0.026 & 0.025 & 0.023 & 0.017 & 0.013 \\
\hline Top 1 pct & 0.001 & 0.001 & 0.001 & 0.001 & 0.001 & 0.001 \\
\hline Interest on debt & 0.025 & 0.025 & 0.025 & 0.024 & 0.023 & 0.022 \\
\hline Labor income & 0.584 & 0.584 & 0.585 & 0.583 & 0.581 & 0.579 \\
\hline Capital income & 0.416 & 0.416 & 0.415 & 0.417 & 0.419 & 0.421 \\
\hline Consumption & 0.749 & 0.747 & 0.744 & 0.750 & 0.763 & 0.774 \\
\hline Tangible investment & 0.208 & 0.209 & 0.212 & 0.207 & 0.194 & 0.183 \\
\hline Intangible investment & 0.133 & 0.134 & 0.134 & 0.131 & 0.126 & 0.122 \\
\hline Defense & 0.044 & 0.044 & 0.044 & 0.044 & 0.044 & 0.044 \\
\hline Tangible capital & 4.115 & 4.082 & 4.087 & 4.193 & 4.351 & 4.403 \\
\hline Intangible capital & 1.717 & 1.709 & 1.711 & 1.733 & 1.766 & 1.774 \\
\hline \multicolumn{7}{|l|}{ LEVELS: } \\
\hline Interest rate & 4.669 & 4.723 & 4.725 & 4.541 & 4.273 & 4.163 \\
\hline Wage rate & 1.008 & 1.001 & 1.001 & 1.027 & 1.068 & 1.085 \\
\hline Labor input & 0.979 & 0.992 & 1.004 & 0.995 & 0.962 & 0.942 \\
\hline GNP & 0.986 & 0.991 & 1.003 & 1.023 & 1.032 & 1.030 \\
\hline Net worth & 0.961 & 0.960 & 0.972 & 1.011 & 1.052 & 1.060 \\
\hline
\end{tabular}


Table A27. Transitions from Current U.S. Policy to New Policies

Social Security, Medicare, and FICA Taxes Phased Out,

Worker Net Tax Functions Permanently Changed

(Labor elasticity cut by 2)

\begin{tabular}{|c|c|c|c|c|c|c|}
\hline & $2011-20$ & $2021-30$ & $2031-40$ & $2041-70$ & 2071-99 & $\infty$ \\
\hline \multicolumn{7}{|l|}{ SHARES OF GNP: } \\
\hline Tax revenues (net) & 0.174 & 0.171 & 0.166 & 0.154 & 0.127 & 0.113 \\
\hline Profits, Schedule C & 0.026 & 0.026 & 0.026 & 0.025 & 0.026 & 0.027 \\
\hline Distributions, Schedule C & 0.004 & 0.004 & 0.004 & 0.004 & 0.005 & 0.005 \\
\hline Distributions, Other & 0.094 & 0.094 & 0.094 & 0.094 & 0.093 & 0.092 \\
\hline Consumption & 0.065 & 0.064 & 0.062 & 0.045 & 0.007 & -0.011 \\
\hline Labor inc. (net), by type & -0.015 & -0.017 & -0.019 & -0.013 & -0.003 & -0.000 \\
\hline Low & -0.052 & -0.054 & -0.056 & -0.053 & -0.050 & -0.048 \\
\hline Medium & -0.010 & -0.011 & -0.011 & -0.008 & -0.004 & -0.003 \\
\hline High & 0.036 & 0.037 & 0.037 & 0.038 & 0.041 & 0.041 \\
\hline Top 1 pct & 0.011 & 0.011 & 0.010 & 0.010 & 0.010 & 0.010 \\
\hline Retiree transfers, by type & 0.122 & 0.119 & 0.114 & 0.102 & 0.074 & 0.058 \\
\hline Low & 0.046 & 0.045 & 0.043 & 0.039 & 0.028 & 0.022 \\
\hline Medium & 0.049 & 0.048 & 0.046 & 0.041 & 0.029 & 0.023 \\
\hline High & 0.026 & 0.025 & 0.024 & 0.021 & 0.015 & 0.012 \\
\hline Top 1 pct & 0.001 & 0.001 & 0.001 & 0.001 & 0.001 & 0.001 \\
\hline Interest on debt & 0.025 & 0.025 & 0.025 & 0.024 & 0.022 & 0.022 \\
\hline Labor income & 0.585 & 0.586 & 0.586 & 0.585 & 0.581 & 0.579 \\
\hline Capital income & 0.415 & 0.414 & 0.414 & 0.415 & 0.419 & 0.421 \\
\hline Consumption & 0.743 & 0.740 & 0.737 & 0.740 & 0.758 & 0.770 \\
\hline Tangible investment & 0.213 & 0.216 & 0.219 & 0.216 & 0.198 & 0.186 \\
\hline Intangible investment & 0.136 & 0.137 & 0.137 & 0.135 & 0.128 & 0.123 \\
\hline Defense & 0.044 & 0.044 & 0.044 & 0.044 & 0.044 & 0.044 \\
\hline Tangible capital & 4.125 & 4.086 & 4.098 & 4.262 & 4.462 & 4.471 \\
\hline Intangible capital & 1.722 & 1.713 & 1.715 & 1.753 & 1.794 & 1.791 \\
\hline \multicolumn{7}{|l|}{ LEVELS: } \\
\hline Interest rate & 4.673 & 4.744 & 4.728 & 4.473 & 4.139 & 4.089 \\
\hline Wage rate & 1.006 & 0.997 & 0.999 & 1.035 & 1.086 & 1.096 \\
\hline Labor input & 0.996 & 1.029 & 1.057 & 1.056 & 1.024 & 1.007 \\
\hline GNP & 1.000 & 1.022 & 1.053 & 1.092 & 1.118 & 1.112 \\
\hline Net worth & 0.967 & 0.980 & 1.012 & 1.084 & 1.152 & 1.147 \\
\hline
\end{tabular}


Table A28. Transitions from Current U.S. Policy to New Policies

Social Security, Medicare, and FICA Taxes Phased Out,

Worker Net Tax Functions Permanently Changed

(More spending categories included in $G$ )

\begin{tabular}{|c|c|c|c|c|c|c|}
\hline & $2011-20$ & $2021-30$ & $2031-40$ & $2041-70$ & 2071-99 & $\infty$ \\
\hline \multicolumn{7}{|l|}{ SHARES OF GNP: } \\
\hline Tax revenues (net) & 0.196 & 0.190 & 0.186 & 0.175 & 0.148 & 0.133 \\
\hline Profits, Schedule C & 0.025 & 0.025 & 0.025 & 0.025 & 0.026 & 0.026 \\
\hline Distributions, Schedule C & 0.003 & 0.003 & 0.003 & 0.004 & 0.005 & 0.005 \\
\hline Distributions, Other & 0.094 & 0.094 & 0.094 & 0.093 & 0.092 & 0.092 \\
\hline Consumption & 0.056 & 0.050 & 0.046 & 0.030 & -0.006 & -0.025 \\
\hline Labor inc. (net), by type & 0.018 & 0.018 & 0.018 & 0.022 & 0.031 & 0.034 \\
\hline Low & -0.042 & -0.042 & -0.043 & -0.041 & -0.037 & -0.036 \\
\hline Medium & 0.002 & 0.002 & 0.002 & 0.005 & 0.010 & 0.011 \\
\hline High & 0.046 & 0.047 & 0.047 & 0.047 & 0.047 & 0.048 \\
\hline Top 1 pct & 0.012 & 0.011 & 0.011 & 0.011 & 0.011 & 0.011 \\
\hline Retiree transfers, by type & 0.111 & 0.106 & 0.101 & 0.089 & 0.060 & 0.045 \\
\hline Low & 0.042 & 0.040 & 0.038 & 0.034 & 0.023 & 0.017 \\
\hline Medium & 0.044 & 0.042 & 0.040 & 0.035 & 0.024 & 0.018 \\
\hline High & 0.023 & 0.022 & 0.021 & 0.019 & 0.013 & 0.009 \\
\hline Top 1 pct & 0.001 & 0.001 & 0.001 & 0.001 & 0.001 & 0.000 \\
\hline Interest on debt & 0.025 & 0.025 & 0.025 & 0.024 & 0.022 & 0.022 \\
\hline Labor income & 0.587 & 0.588 & 0.587 & 0.586 & 0.582 & 0.580 \\
\hline Capital income & 0.413 & 0.412 & 0.413 & 0.414 & 0.418 & 0.420 \\
\hline Consumption & 0.701 & 0.700 & 0.699 & 0.709 & 0.725 & 0.739 \\
\hline Tangible investment & 0.222 & 0.224 & 0.224 & 0.215 & 0.199 & 0.188 \\
\hline Intangible investment & 0.139 & 0.140 & 0.138 & 0.134 & 0.128 & 0.124 \\
\hline Defense & 0.077 & 0.077 & 0.077 & 0.077 & 0.077 & 0.077 \\
\hline Tangible capital & 4.109 & 4.099 & 4.123 & 4.262 & 4.438 & 4.520 \\
\hline Intangible capital & 1.721 & 1.719 & 1.723 & 1.752 & 1.787 & 1.806 \\
\hline \multicolumn{7}{|l|}{ LEVELS: } \\
\hline Interest rate & 4.730 & 4.752 & 4.710 & 4.464 & 4.168 & 4.056 \\
\hline Wage rate & 0.996 & 0.993 & 0.998 & 1.036 & 1.081 & 1.099 \\
\hline Labor input & 1.015 & 1.057 & 1.090 & 1.087 & 1.070 & 1.051 \\
\hline GNP & 1.004 & 1.042 & 1.082 & 1.122 & 1.159 & 1.162 \\
\hline Net worth & 1.016 & 1.052 & 1.098 & 1.170 & 1.249 & 1.270 \\
\hline
\end{tabular}


Table A29. Transitions from Current U.S. Policy to New Policies

Social Security, Medicare, and FICA Taxes Phased Out,

Worker Net Tax Functions Permanently Changed

(Fewer spending categories included in $G$ )

\begin{tabular}{|c|c|c|c|c|c|c|}
\hline & $2011-20$ & $2021-30$ & $2031-40$ & $2041-70$ & 2071-99 & $\infty$ \\
\hline \multicolumn{7}{|l|}{ SHARES OF GNP: } \\
\hline Tax revenues (net) & 0.140 & 0.135 & 0.130 & 0.120 & 0.095 & 0.082 \\
\hline Profits, Schedule C & 0.024 & 0.025 & 0.025 & 0.025 & 0.025 & 0.026 \\
\hline Distributions, Schedule C & 0.003 & 0.003 & 0.003 & 0.004 & 0.004 & 0.005 \\
\hline Distributions, Other & 0.094 & 0.094 & 0.094 & 0.093 & 0.092 & 0.092 \\
\hline Consumption & 0.056 & 0.053 & 0.050 & 0.032 & -0.006 & -0.023 \\
\hline Labor inc. (net), by type & -0.037 & -0.039 & -0.041 & -0.034 & -0.020 & -0.017 \\
\hline Low & -0.063 & -0.065 & -0.066 & -0.063 & -0.058 & -0.057 \\
\hline Medium & -0.021 & -0.022 & -0.023 & -0.019 & -0.011 & -0.010 \\
\hline High & 0.035 & 0.037 & 0.037 & 0.037 & 0.038 & 0.039 \\
\hline Top 1 pct & 0.012 & 0.012 & 0.011 & 0.011 & 0.011 & 0.011 \\
\hline Retiree transfers, by type & 0.127 & 0.123 & 0.117 & 0.105 & 0.080 & 0.066 \\
\hline Low & 0.048 & 0.047 & 0.044 & 0.040 & 0.030 & 0.025 \\
\hline Medium & 0.051 & 0.049 & 0.047 & 0.042 & 0.032 & 0.026 \\
\hline High & 0.027 & 0.026 & 0.025 & 0.022 & 0.017 & 0.014 \\
\hline Top 1 pct & 0.001 & 0.001 & 0.001 & 0.001 & 0.001 & 0.001 \\
\hline Interest on debt & 0.024 & 0.025 & 0.024 & 0.023 & 0.022 & 0.021 \\
\hline Labor income & 0.588 & 0.588 & 0.588 & 0.585 & 0.582 & 0.580 \\
\hline Capital income & 0.412 & 0.412 & 0.412 & 0.415 & 0.418 & 0.420 \\
\hline Consumption & 0.764 & 0.768 & 0.766 & 0.774 & 0.790 & 0.804 \\
\hline Tangible investment & 0.230 & 0.227 & 0.228 & 0.220 & 0.203 & 0.192 \\
\hline Intangible investment & 0.142 & 0.141 & 0.140 & 0.136 & 0.130 & 0.126 \\
\hline Defense & 0.006 & 0.006 & 0.006 & 0.006 & 0.006 & 0.006 \\
\hline Tangible capital & 4.220 & 4.206 & 4.216 & 4.361 & 4.544 & 4.614 \\
\hline Intangible capital & 1.751 & 1.748 & 1.748 & 1.778 & 1.814 & 1.830 \\
\hline \multicolumn{7}{|l|}{ LEVELS: } \\
\hline Interest rate & 4.586 & 4.607 & 4.584 & 4.345 & 4.051 & 3.960 \\
\hline Wage rate & 0.994 & 0.992 & 0.995 & 1.029 & 1.075 & 1.089 \\
\hline Labor input & 1.018 & 1.053 & 1.089 & 1.091 & 1.074 & 1.054 \\
\hline GNP & 1.008 & 1.041 & 1.080 & 1.124 & 1.162 & 1.160 \\
\hline Net worth & 1.020 & 1.051 & 1.093 & 1.168 & 1.249 & 1.262 \\
\hline
\end{tabular}


Table A30. Transitions from Current U.S. Policy to New Policies

Social Security, Medicare, and FICA Taxes Phased Out,

Worker Net Tax Functions Permanently Changed

(One-sector, one-capital model)

\begin{tabular}{|c|c|c|c|c|c|c|}
\hline & $2011-20$ & $2021-30$ & $2031-40$ & $2041-70$ & 2071-99 & $\infty$ \\
\hline \multicolumn{7}{|l|}{ SHARES OF GNP: } \\
\hline Tax revenues (net) & 0.156 & 0.154 & 0.151 & 0.143 & 0.119 & 0.105 \\
\hline Profits, Schedule C & 0.051 & 0.051 & 0.052 & 0.051 & 0.049 & 0.048 \\
\hline Distributions, Schedule C & 0.000 & 0.000 & 0.000 & 0.000 & 0.000 & 0.000 \\
\hline Distributions, Other & 0.000 & 0.000 & 0.000 & 0.000 & 0.000 & 0.000 \\
\hline Consumption & 0.087 & 0.083 & 0.077 & 0.068 & 0.039 & 0.024 \\
\hline Labor inc. (net), by type & 0.018 & 0.020 & 0.022 & 0.024 & 0.031 & 0.034 \\
\hline Low & -0.047 & -0.048 & -0.049 & -0.048 & -0.046 & -0.045 \\
\hline Medium & 0.003 & 0.004 & 0.005 & 0.006 & 0.009 & 0.010 \\
\hline High & 0.048 & 0.050 & 0.053 & 0.054 & 0.056 & 0.056 \\
\hline Top 1 pct & 0.014 & 0.014 & 0.013 & 0.013 & 0.012 & 0.012 \\
\hline Retiree transfers, by type & 0.111 & 0.108 & 0.104 & 0.095 & 0.070 & 0.055 \\
\hline Low & 0.042 & 0.041 & 0.040 & 0.036 & 0.027 & 0.021 \\
\hline Medium & 0.044 & 0.043 & 0.042 & 0.038 & 0.028 & 0.022 \\
\hline High & 0.023 & 0.023 & 0.022 & 0.020 & 0.015 & 0.012 \\
\hline Top 1 pct & 0.001 & 0.001 & 0.001 & 0.001 & 0.001 & 0.001 \\
\hline Interest on debt & 0.019 & 0.019 & 0.019 & 0.018 & 0.017 & 0.017 \\
\hline Labor income & 0.670 & 0.670 & 0.670 & 0.670 & 0.670 & 0.670 \\
\hline Capital income & 0.330 & 0.330 & 0.330 & 0.330 & 0.330 & 0.330 \\
\hline Consumption & 0.681 & 0.693 & 0.694 & 0.699 & 0.705 & 0.710 \\
\hline Tangible investment & 0.276 & 0.264 & 0.263 & 0.256 & 0.251 & 0.246 \\
\hline Intangible investment & 0.001 & 0.001 & 0.001 & 0.001 & 0.001 & 0.001 \\
\hline Defense & 0.044 & 0.044 & 0.044 & 0.044 & 0.044 & 0.044 \\
\hline Tangible capital & 3.028 & 3.020 & 2.977 & 3.019 & 3.108 & 3.138 \\
\hline Intangible capital & 0.011 & 0.011 & 0.011 & 0.011 & 0.011 & 0.011 \\
\hline \multicolumn{7}{|l|}{ LEVELS: } \\
\hline Interest rate & 3.558 & 3.564 & 3.637 & 3.462 & 3.238 & 3.180 \\
\hline Wage rate & 1.004 & 1.003 & 0.999 & 1.010 & 1.026 & 1.031 \\
\hline Labor input & 1.005 & 1.028 & 1.065 & 1.067 & 1.053 & 1.042 \\
\hline GNP & 1.010 & 1.033 & 1.065 & 1.079 & 1.081 & 1.074 \\
\hline Net worth & 1.023 & 1.044 & 1.063 & 1.089 & 1.118 & 1.120 \\
\hline
\end{tabular}


Table A31. Transitions from Current U.S. Policy to New Policies

Social Security, Medicare, and FICA Taxes Phased Out,

Worker Net Tax Functions Permanently Changed

(More AGI bins for net tax function)

\begin{tabular}{|c|c|c|c|c|c|c|}
\hline & $2011-20$ & $2021-30$ & $2031-40$ & $2041-70$ & 2071-99 & $\infty$ \\
\hline \multicolumn{7}{|l|}{ SHARES OF GNP: } \\
\hline Tax revenues (net) & 0.165 & 0.161 & 0.158 & 0.149 & 0.123 & 0.109 \\
\hline Profits, Schedule C & 0.024 & 0.024 & 0.025 & 0.025 & 0.026 & 0.026 \\
\hline Distributions, Schedule C & 0.003 & 0.003 & 0.003 & 0.004 & 0.005 & 0.005 \\
\hline Distributions, Other & 0.093 & 0.093 & 0.094 & 0.093 & 0.092 & 0.092 \\
\hline Consumption & 0.052 & 0.047 & 0.044 & 0.029 & -0.007 & -0.025 \\
\hline Labor inc. (net), by type & -0.007 & -0.006 & -0.008 & -0.003 & 0.008 & 0.010 \\
\hline Low & -0.050 & -0.051 & -0.052 & -0.051 & -0.047 & -0.046 \\
\hline Medium & -0.007 & -0.006 & -0.007 & -0.005 & 0.000 & 0.001 \\
\hline High & 0.037 & 0.039 & 0.040 & 0.042 & 0.044 & 0.045 \\
\hline Top 1 pct & 0.012 & 0.012 & 0.011 & 0.011 & 0.011 & 0.011 \\
\hline Retiree transfers, by type & 0.115 & 0.111 & 0.107 & 0.096 & 0.070 & 0.055 \\
\hline Low & 0.044 & 0.042 & 0.041 & 0.037 & 0.026 & 0.021 \\
\hline Medium & 0.046 & 0.045 & 0.043 & 0.038 & 0.028 & 0.022 \\
\hline High & 0.024 & 0.023 & 0.023 & 0.020 & 0.015 & 0.011 \\
\hline Top 1 pct & 0.001 & 0.001 & 0.001 & 0.001 & 0.001 & 0.001 \\
\hline Interest on debt & 0.024 & 0.024 & 0.024 & 0.023 & 0.022 & 0.022 \\
\hline Labor income & 0.588 & 0.588 & 0.586 & 0.585 & 0.581 & 0.580 \\
\hline Capital income & 0.412 & 0.412 & 0.414 & 0.415 & 0.419 & 0.420 \\
\hline Consumption & 0.728 & 0.731 & 0.735 & 0.741 & 0.759 & 0.769 \\
\hline Tangible investment & 0.228 & 0.225 & 0.221 & 0.216 & 0.198 & 0.188 \\
\hline Intangible investment & 0.142 & 0.141 & 0.138 & 0.135 & 0.128 & 0.124 \\
\hline Defense & 0.044 & 0.044 & 0.044 & 0.044 & 0.044 & 0.044 \\
\hline Tangible capital & 4.318 & 4.280 & 4.252 & 4.347 & 4.467 & 4.523 \\
\hline Intangible capital & 1.775 & 1.764 & 1.754 & 1.775 & 1.796 & 1.808 \\
\hline \multicolumn{7}{|l|}{ LEVELS: } \\
\hline Interest rate & 4.444 & 4.482 & 4.506 & 4.360 & 4.141 & 4.057 \\
\hline Wage rate & 0.999 & 0.993 & 0.990 & 1.011 & 1.045 & 1.059 \\
\hline Labor input & 1.010 & 1.043 & 1.072 & 1.077 & 1.062 & 1.044 \\
\hline GNP & 1.005 & 1.033 & 1.061 & 1.091 & 1.118 & 1.118 \\
\hline Net worth & 1.010 & 1.031 & 1.052 & 1.101 & 1.153 & 1.164 \\
\hline
\end{tabular}


Table A32. Transitions from Current U.S. Policy to New Policies

Social Security, Medicare, and FICA Taxes Phased Out,

Worker Net Tax Functions Permanently Changed

(Seven productivity levels)

\begin{tabular}{|c|c|c|c|c|c|c|}
\hline & $2011-20$ & 2021-30 & $2031-40$ & $2041-70$ & 2071-99 & $\infty$ \\
\hline \multicolumn{7}{|l|}{ SHARES OF GNP: } \\
\hline Tax revenues (net) & 0.170 & 0.166 & 0.164 & 0.153 & 0.127 & 0.112 \\
\hline Profits, Schedule C & 0.024 & 0.024 & 0.025 & 0.025 & 0.026 & 0.027 \\
\hline Distributions, Schedule C & 0.003 & 0.003 & 0.003 & 0.004 & 0.005 & 0.005 \\
\hline Distributions, Other & 0.093 & 0.093 & 0.094 & 0.093 & 0.092 & 0.092 \\
\hline Consumption & 0.059 & 0.055 & 0.055 & 0.039 & 0.002 & -0.015 \\
\hline Labor inc. (net), by type & -0.010 & -0.010 & -0.013 & -0.008 & 0.001 & 0.003 \\
\hline Very low & -0.028 & -0.029 & -0.029 & -0.029 & -0.027 & -0.026 \\
\hline$:$ & -0.022 & -0.023 & -0.024 & -0.023 & -0.022 & -0.021 \\
\hline$:$ & -0.011 & -0.012 & -0.013 & -0.011 & -0.008 & -0.008 \\
\hline$:$ & 0.002 & 0.003 & 0.003 & 0.004 & 0.005 & 0.006 \\
\hline$:$ & 0.019 & 0.019 & 0.019 & 0.020 & 0.022 & 0.022 \\
\hline$:$ & 0.019 & 0.020 & 0.020 & 0.020 & 0.021 & 0.021 \\
\hline Top 1 pct & 0.012 & 0.012 & 0.012 & 0.011 & 0.011 & 0.011 \\
\hline Retiree transfers, by type & 0.120 & 0.116 & 0.112 & 0.101 & 0.073 & 0.058 \\
\hline Very low & 0.023 & 0.022 & 0.021 & 0.019 & 0.014 & 0.011 \\
\hline : & 0.023 & 0.022 & 0.021 & 0.019 & 0.014 & 0.011 \\
\hline$:$ & 0.024 & 0.023 & 0.022 & 0.020 & 0.015 & 0.012 \\
\hline$:$ & 0.024 & 0.023 & 0.022 & 0.020 & 0.015 & 0.012 \\
\hline$:$ & 0.018 & 0.017 & 0.017 & 0.015 & 0.011 & 0.009 \\
\hline$:$ & 0.007 & 0.007 & 0.007 & 0.006 & 0.004 & 0.003 \\
\hline Top 1 pct & 0.001 & 0.001 & 0.001 & 0.001 & 0.001 & 0.001 \\
\hline Interest on debt & 0.024 & 0.024 & 0.024 & 0.023 & 0.022 & 0.022 \\
\hline Labor income & 0.588 & 0.588 & 0.586 & 0.585 & 0.581 & 0.579 \\
\hline Capital income & 0.412 & 0.412 & 0.414 & 0.415 & 0.419 & 0.421 \\
\hline Consumption & 0.727 & 0.731 & 0.737 & 0.739 & 0.759 & 0.770 \\
\hline Tangible investment & 0.229 & 0.225 & 0.219 & 0.217 & 0.197 & 0.186 \\
\hline Intangible investment & 0.142 & 0.140 & 0.137 & 0.135 & 0.128 & 0.124 \\
\hline Defense & 0.044 & 0.044 & 0.044 & 0.044 & 0.044 & 0.044 \\
\hline Tangible capital & 4.295 & 4.281 & 4.253 & 4.347 & 4.482 & 4.482 \\
\hline Intangible capital & 1.769 & 1.764 & 1.754 & 1.774 & 1.798 & 1.795 \\
\hline \multicolumn{7}{|l|}{ LEVELS: } \\
\hline Interest rate & 4.478 & 4.481 & 4.497 & 4.355 & 4.114 & 4.084 \\
\hline Wage rate & 0.999 & 0.999 & 0.997 & 1.018 & 1.054 & 1.059 \\
\hline Labor input & 1.012 & 1.037 & 1.061 & 1.069 & 1.045 & 1.031 \\
\hline GNP & 1.006 & 1.031 & 1.055 & 1.087 & 1.108 & 1.102 \\
\hline Net worth & 1.012 & 1.035 & 1.052 & 1.104 & 1.153 & 1.146 \\
\hline
\end{tabular}


Figure A1. Percentage Welfare Gains by Age Cohort and Productivity Type Social Security, Medicare, and FICA Taxes Phased Out,

Taxes and Transfers Phased Out at Same Rate

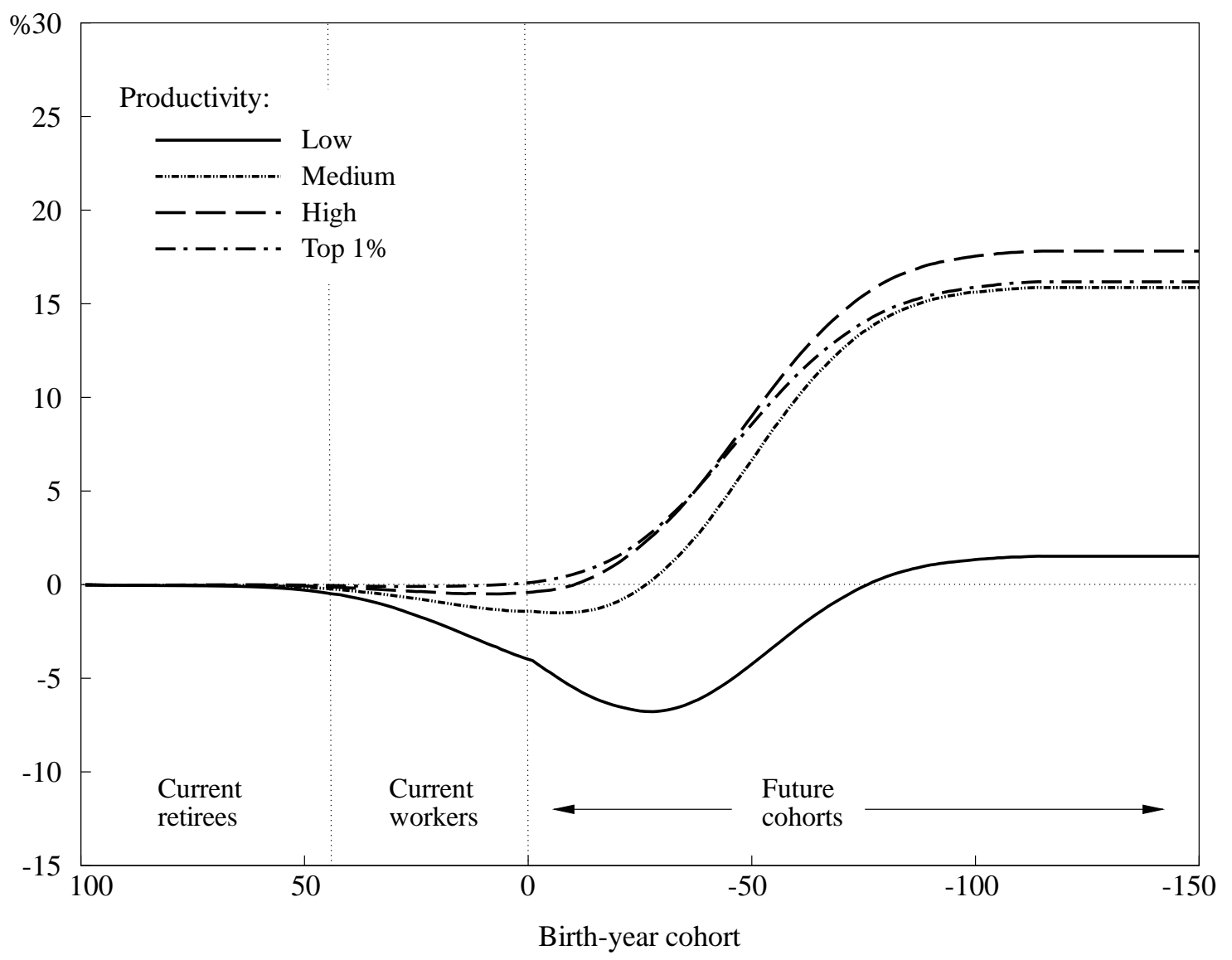


Figure A2. Percentage Welfare Gains by Age Cohort and Baseline Agi Social Security, Medicare, and FICA Taxes Phased Out,

Taxes Phased Out More Quickly Than Transfers

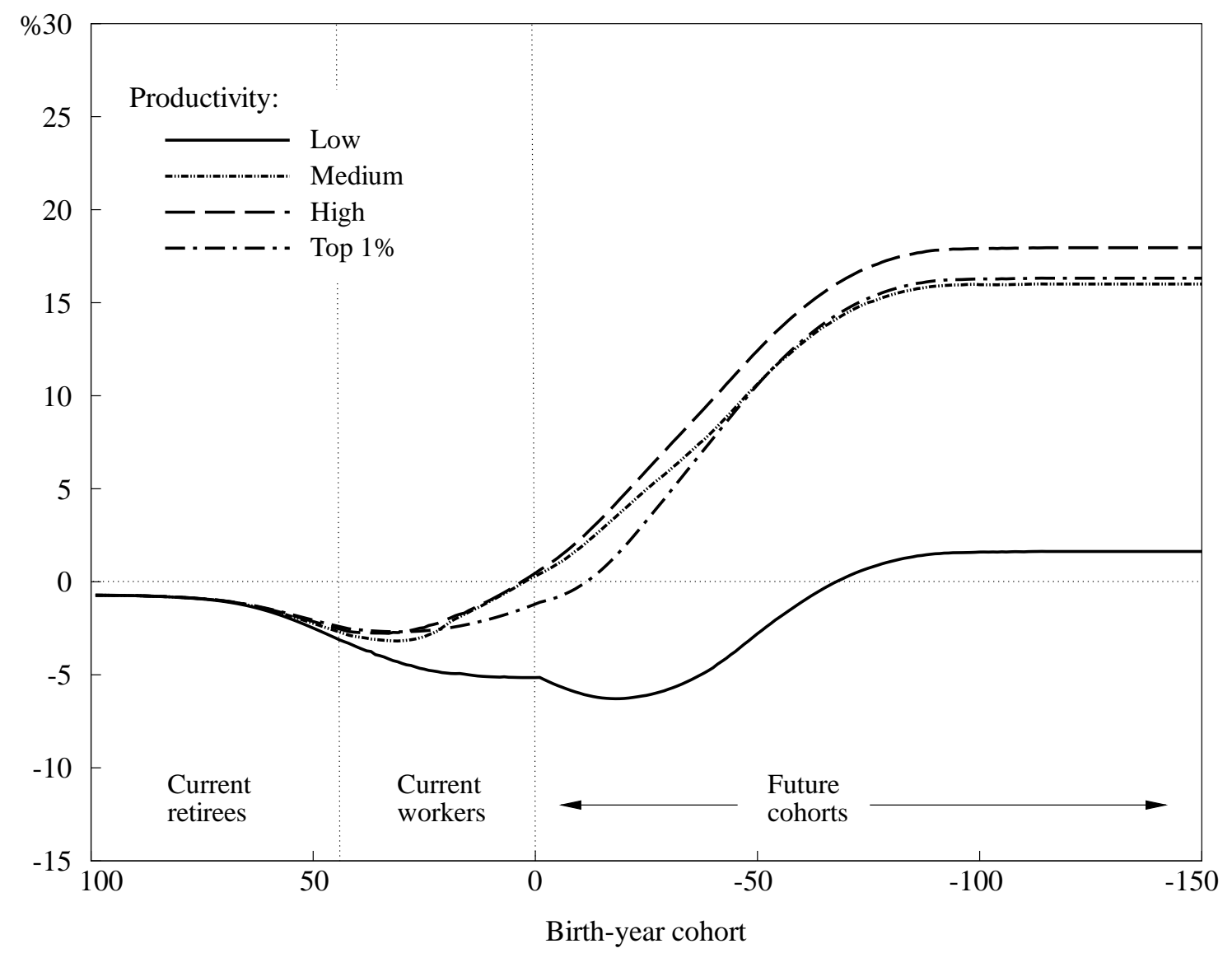


Figure A3. Percentage Welfare Gains by Age Cohort and Baseline Agi Social Security, Medicare, and FICA Taxes Phased Out,

Nonmarginal Employer Benefits Phased Out

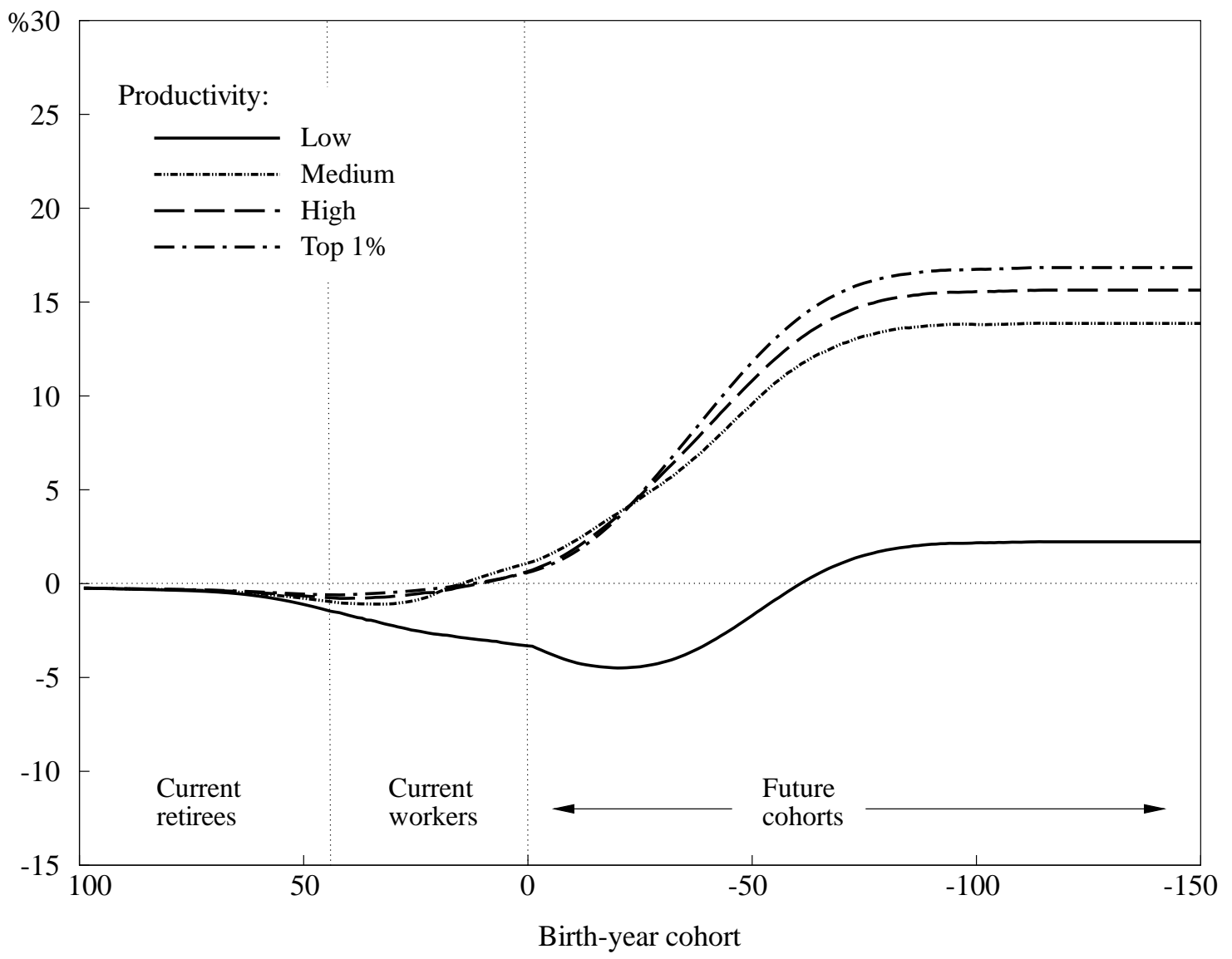


Figure A4. Percentage Welfare Gains by Age Cohort and Baseline Agi Social Security, Medicare, and FICA Taxes Phased Out,

Worker Net Tax Functions Temporarily Changed

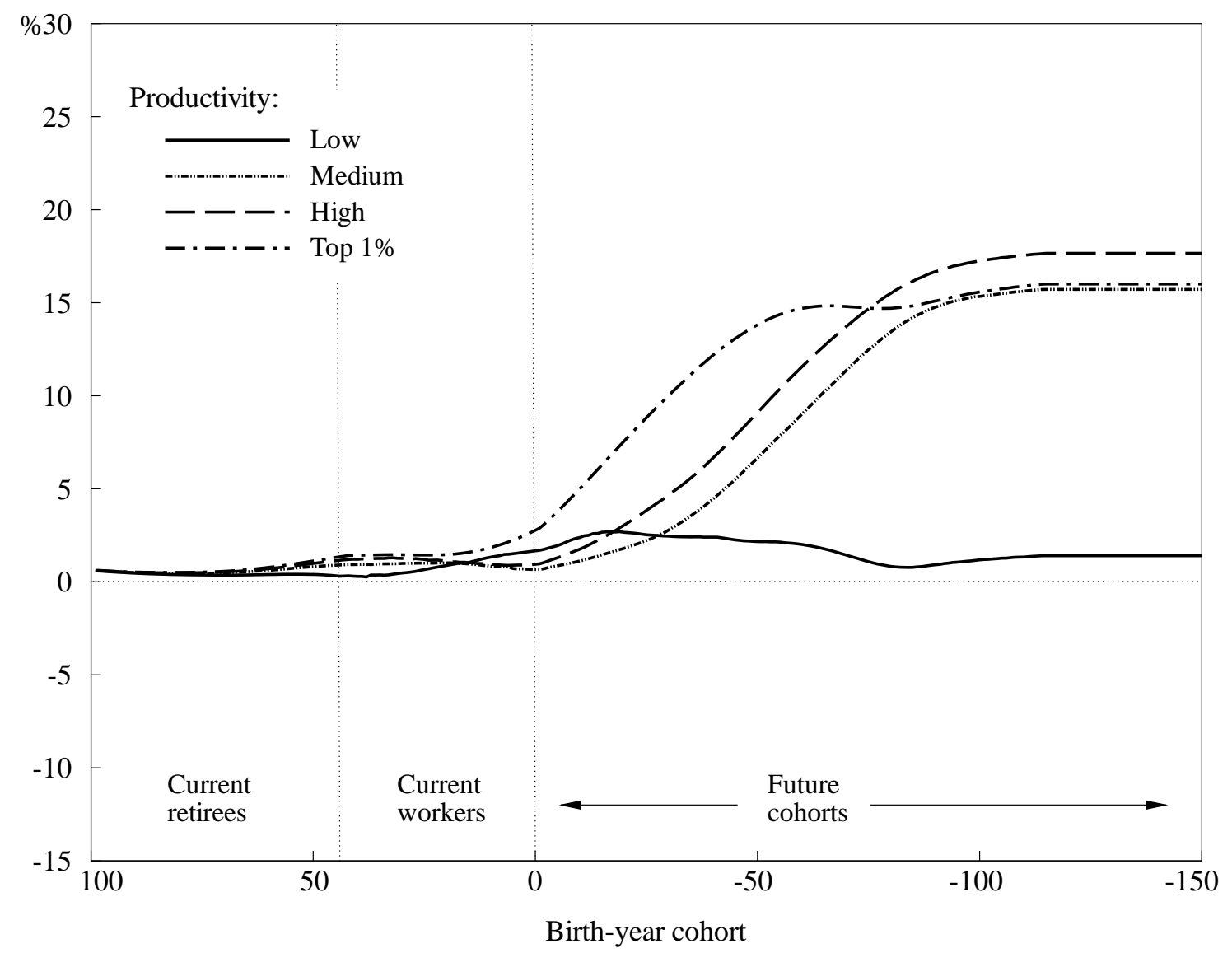


Figure A5. Percentage Welfare Gains by Age Cohort and Baseline Agi Social Security, Medicare, and FICA Taxes Phased Out,

Worker Net Tax Functions Permanently Changed

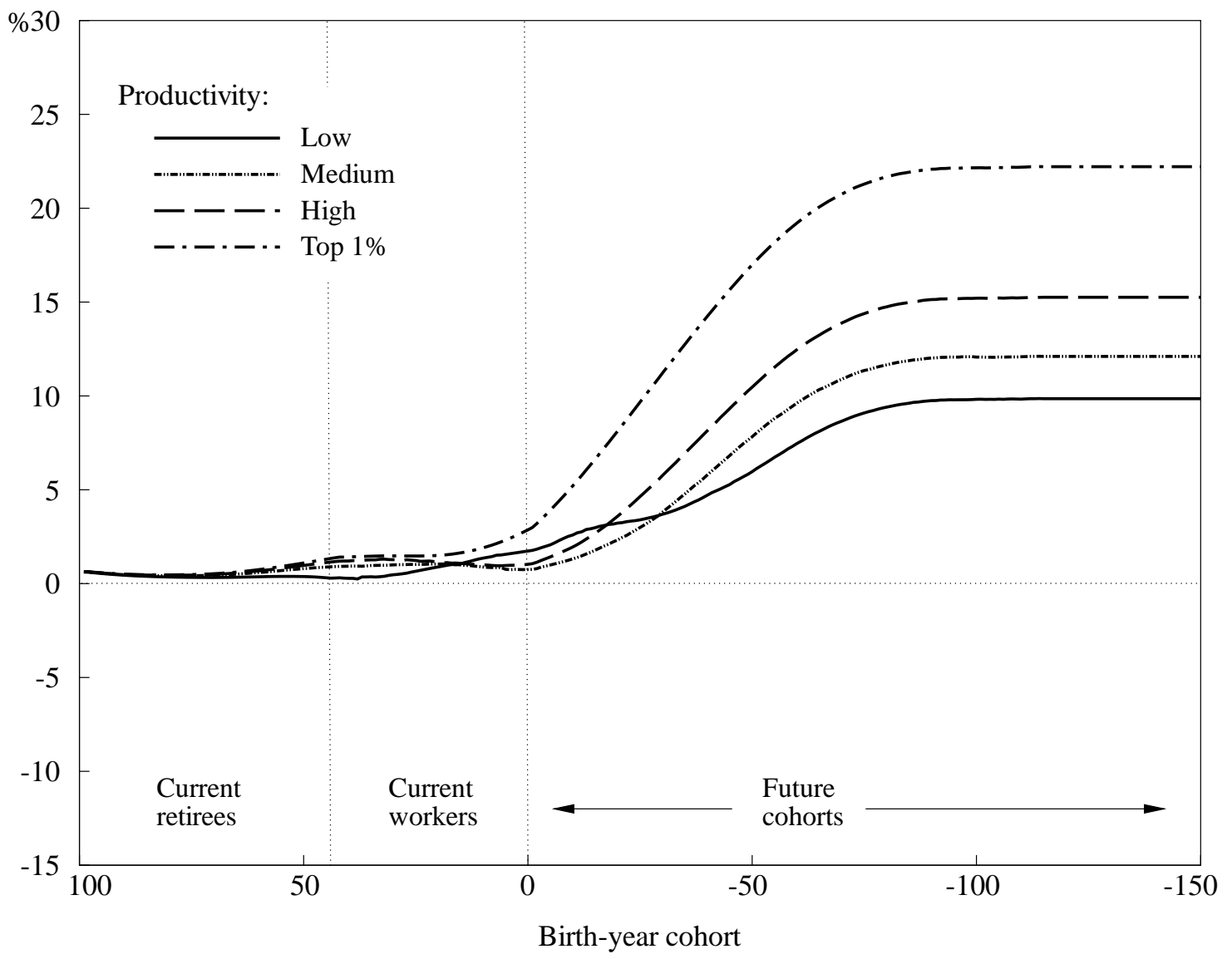


Figure A6. Percentage Welfare Gains by Age Cohort and Baseline Agi Social Security, Medicare, and FICA Taxes Phased Out,

Worker Net Tax Functions Permanently Changed

(Medicare transfers not phased out)

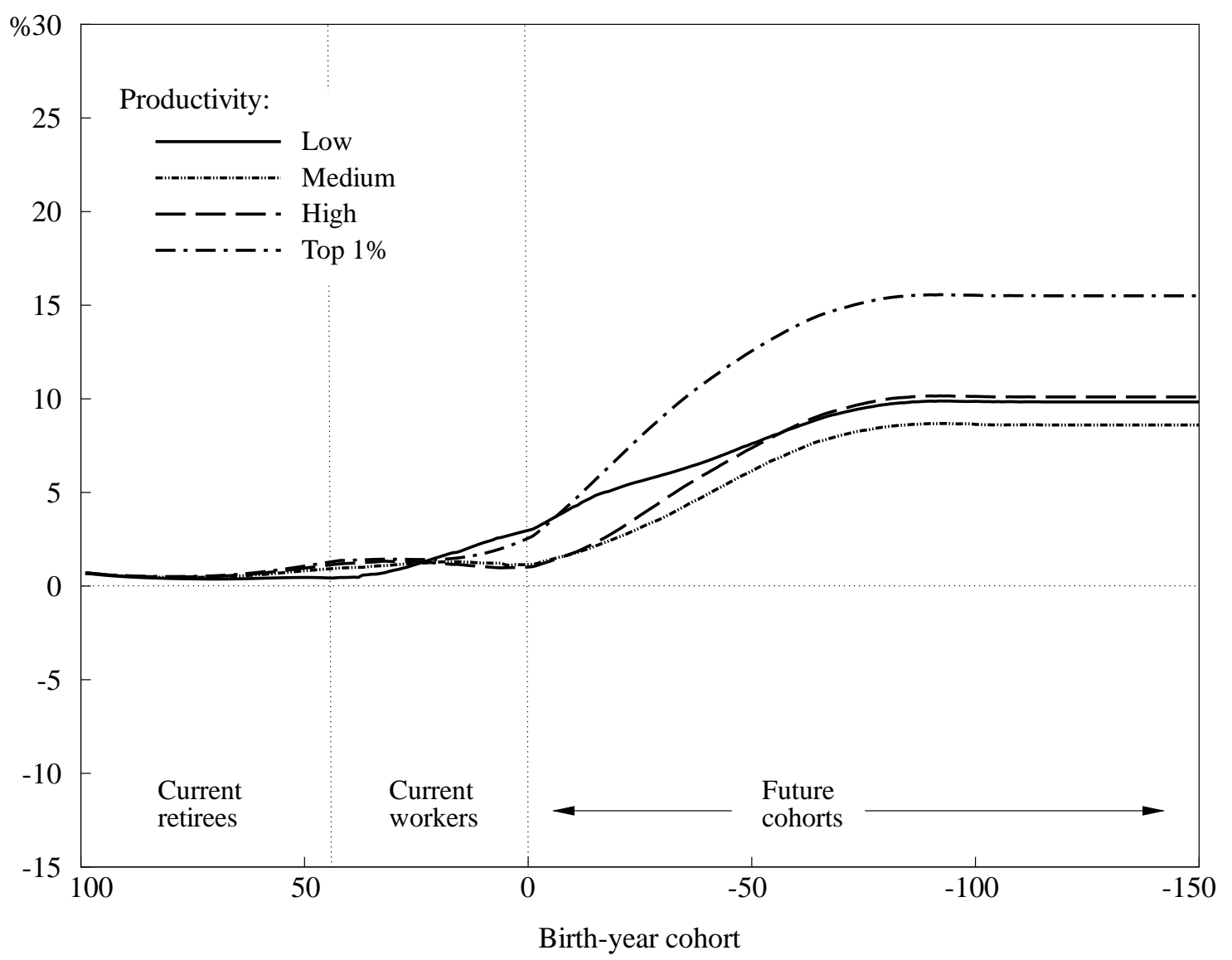


Figure A7. Percentage Welfare Gains by Age Cohort and Baseline Agi Social Security, Medicare, and FICA Taxes Phased Out,

Worker Net Tax Functions Permanently Changed

$($ Debt to GNP $=1)$

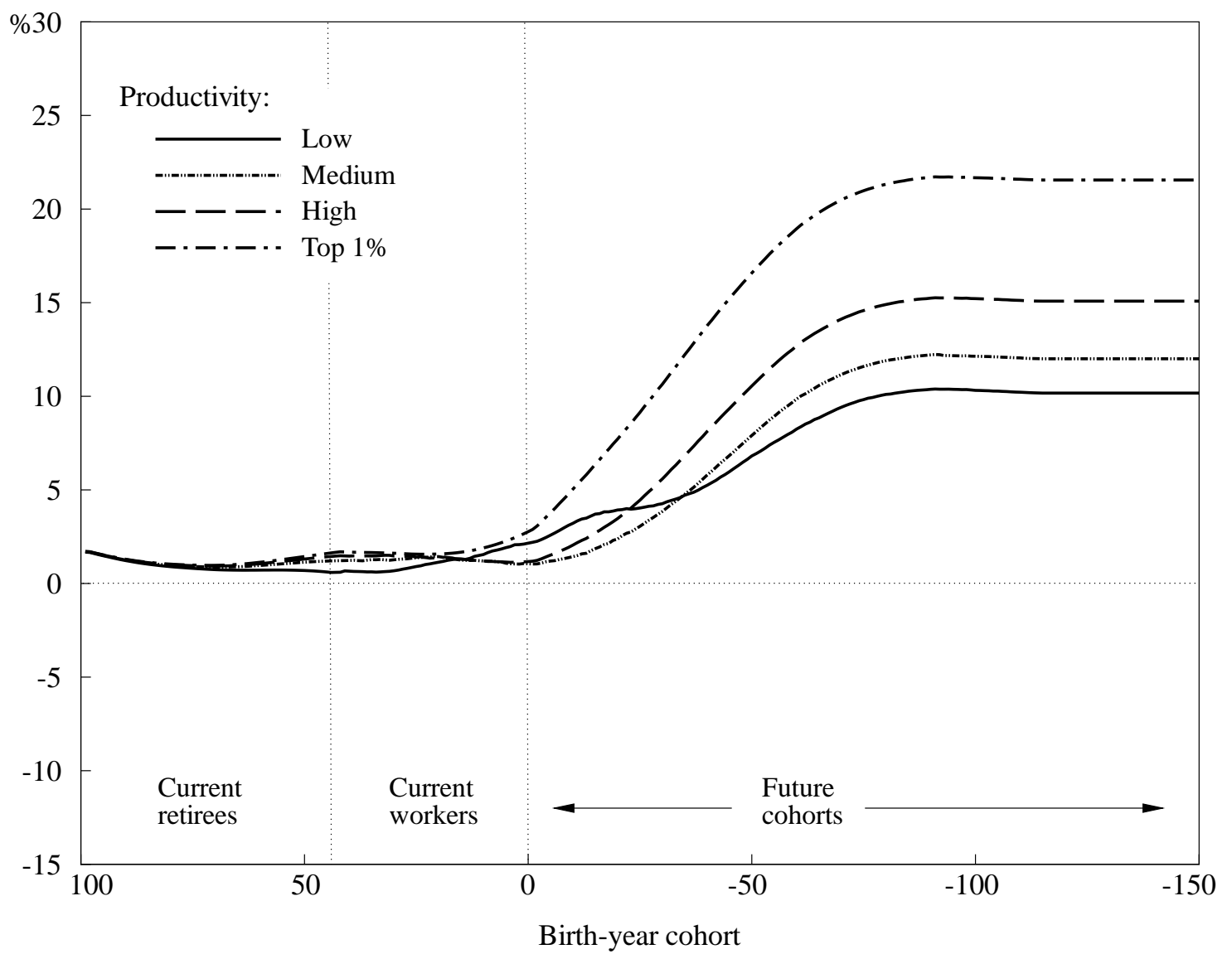


Figure A8. Percentage Welfare Gains by Age Cohort and Baseline Agi Social Security, Medicare, and FICA Taxes Phased Out,

Worker Net Tax Functions Permanently Changed

(Life expectancy depends on productivity)

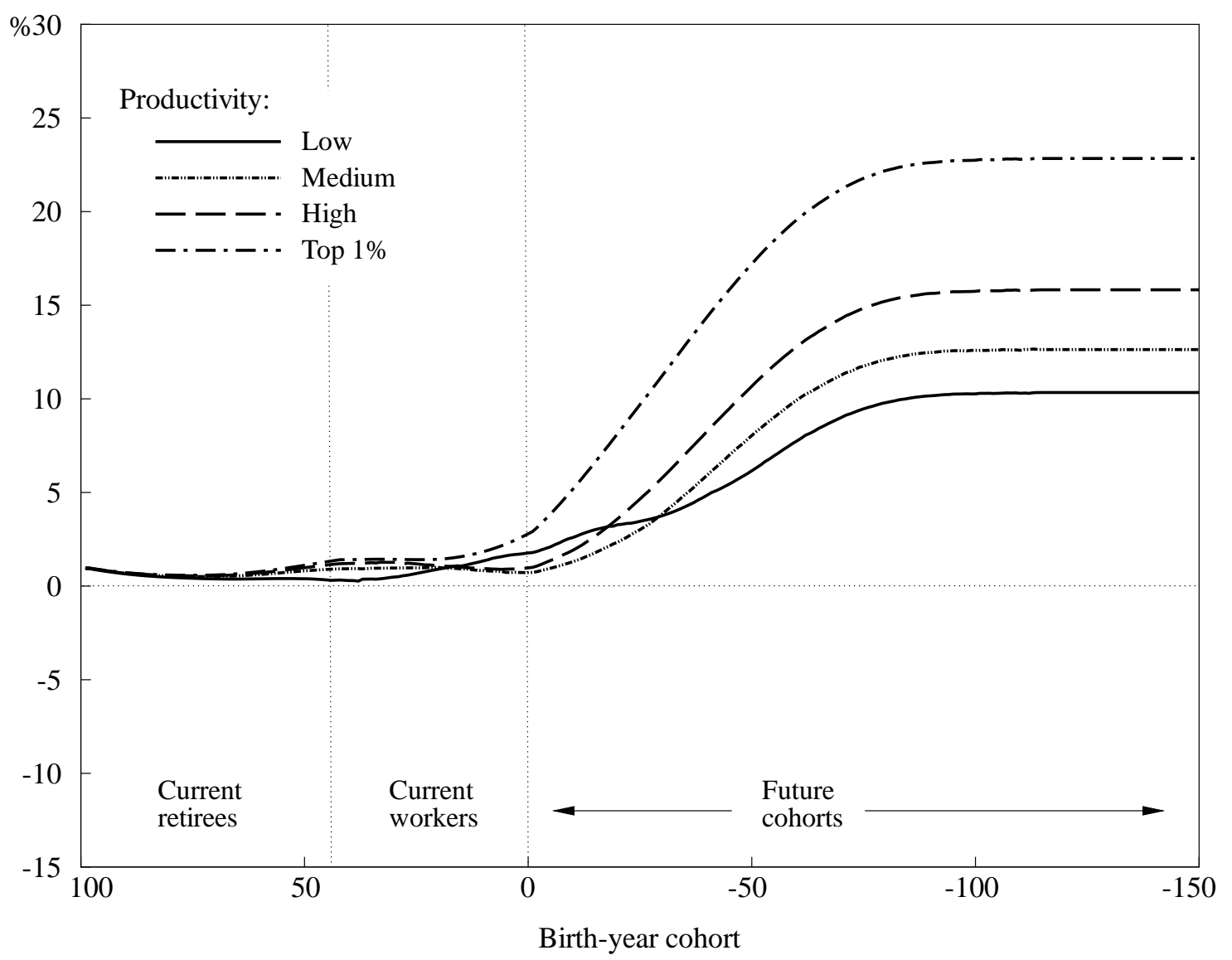


Figure A9. Percentage Welfare Gains by Age Cohort and Baseline Agi Social Security, Medicare, and FICA Taxes Phased Out,

Worker Net Tax Functions Permanently Changed

(Age-dependent productivities-CPS profiles)

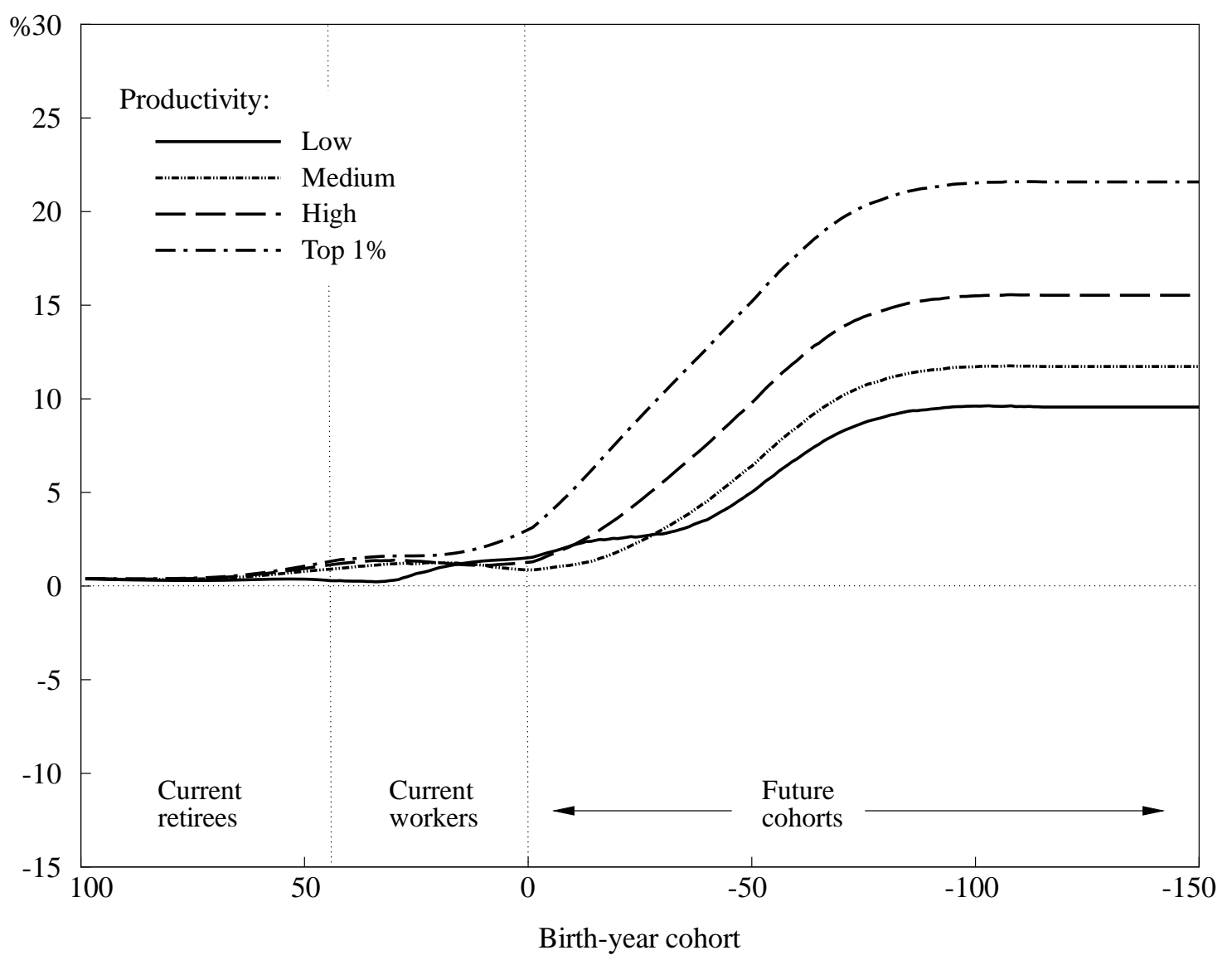


Figure A10. Percentage Welfare Gains by Age Cohort and Baseline Agi Social Security, Medicare, and FICA Taxes Phased Out,

Worker Net Tax Functions Permanently Changed

(Age-dependent productivities-Hansen (1993))

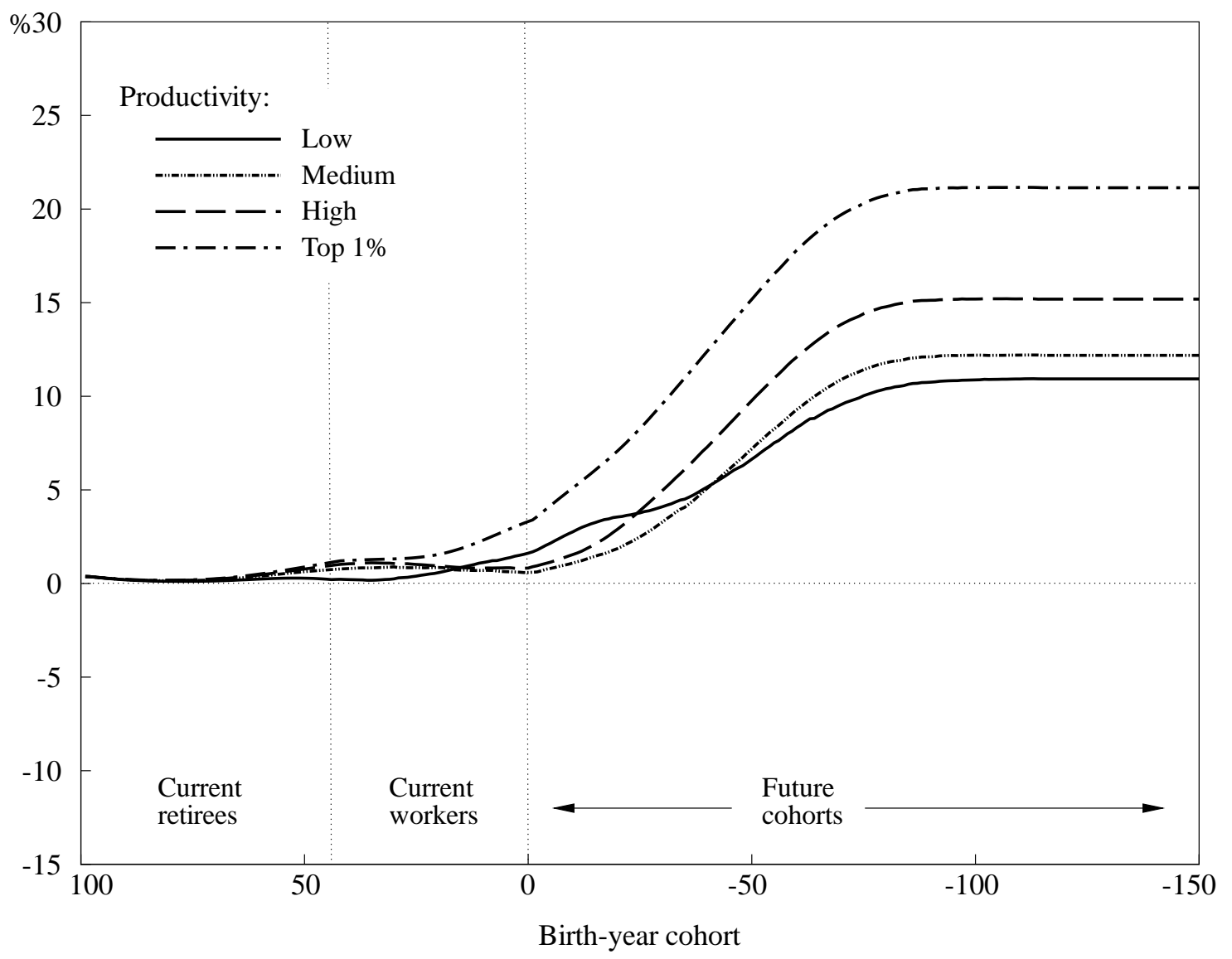


Figure A11. Percentage Welfare Gains by Age Cohort and Baseline Agi Social Security, Medicare, and FICA Taxes Phased Out,

Worker Net Tax Functions Permanently Changed

(No annuity markets)

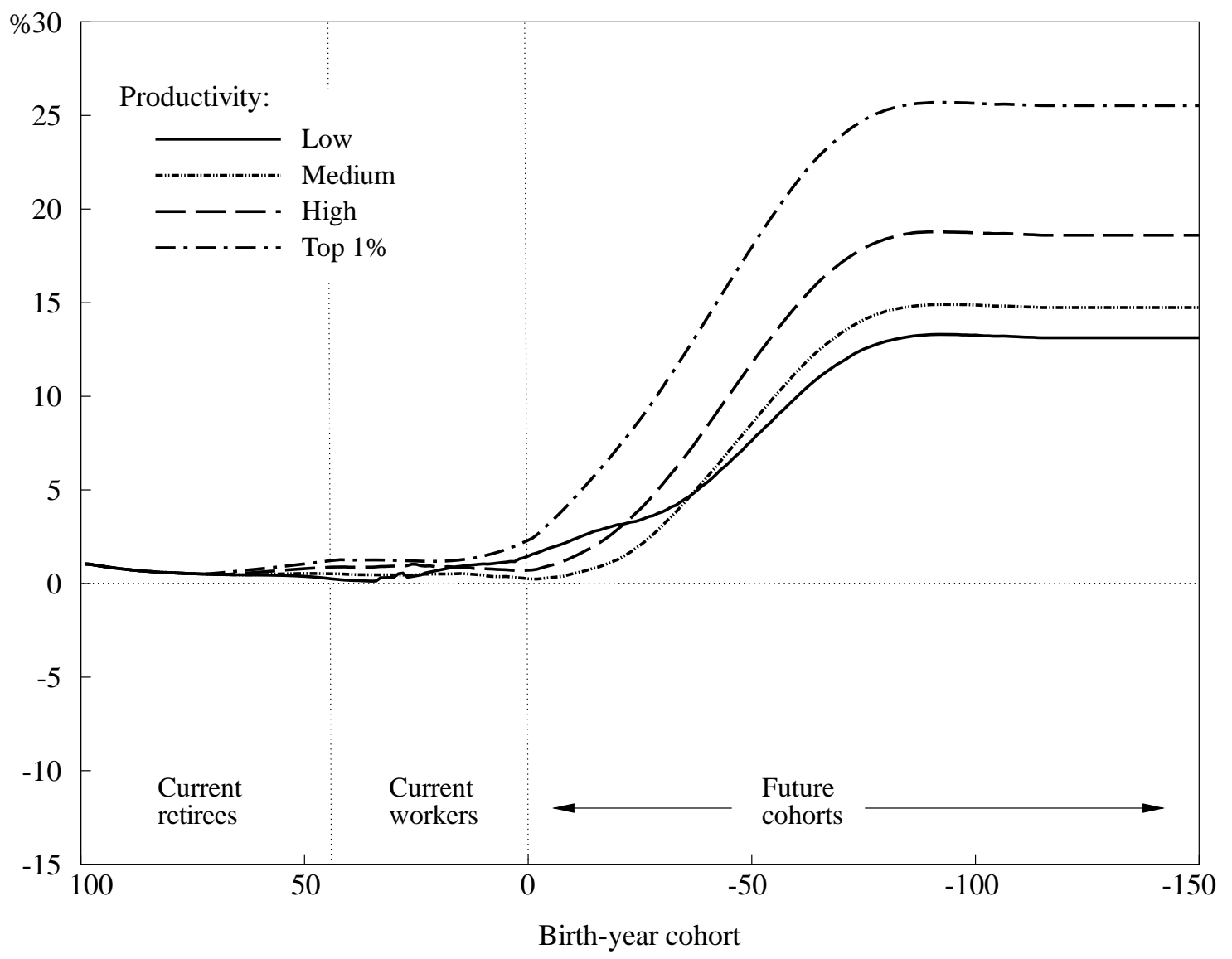


Figure A12. Percentage Welfare Gains by Age Cohort and Baseline Agi Social Security, Medicare, and FICA Taxes Phased Out,

Worker Net Tax Functions Permanently Changed

(Intergenerational transfers included)

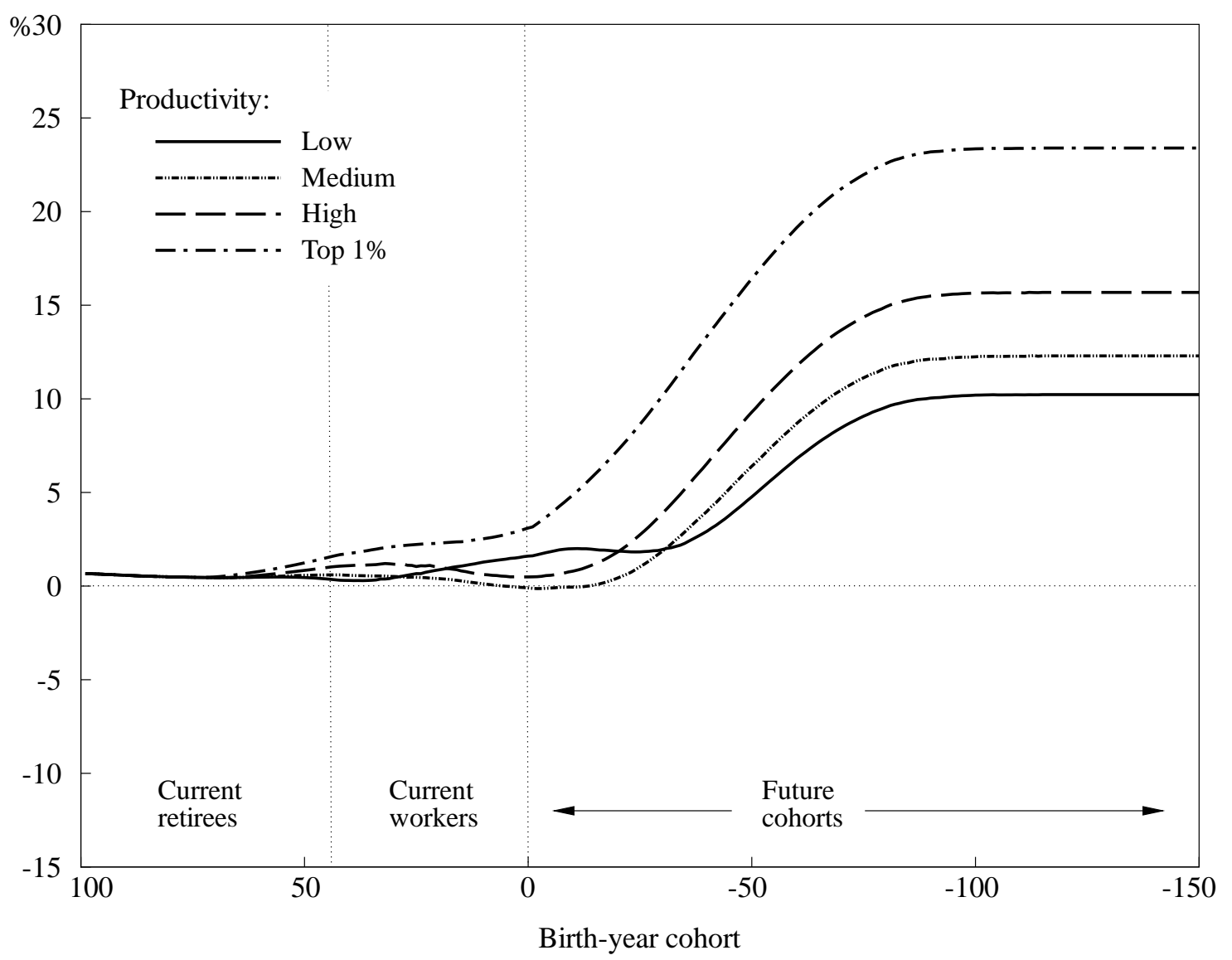


Figure A13. Percentage Welfare Gains by Age Cohort and Baseline Agi Social Security, Medicare, and FICA Taxes Phased Out,

Worker Net Tax Functions Permanently Changed

(Labor elasticity cut by five)

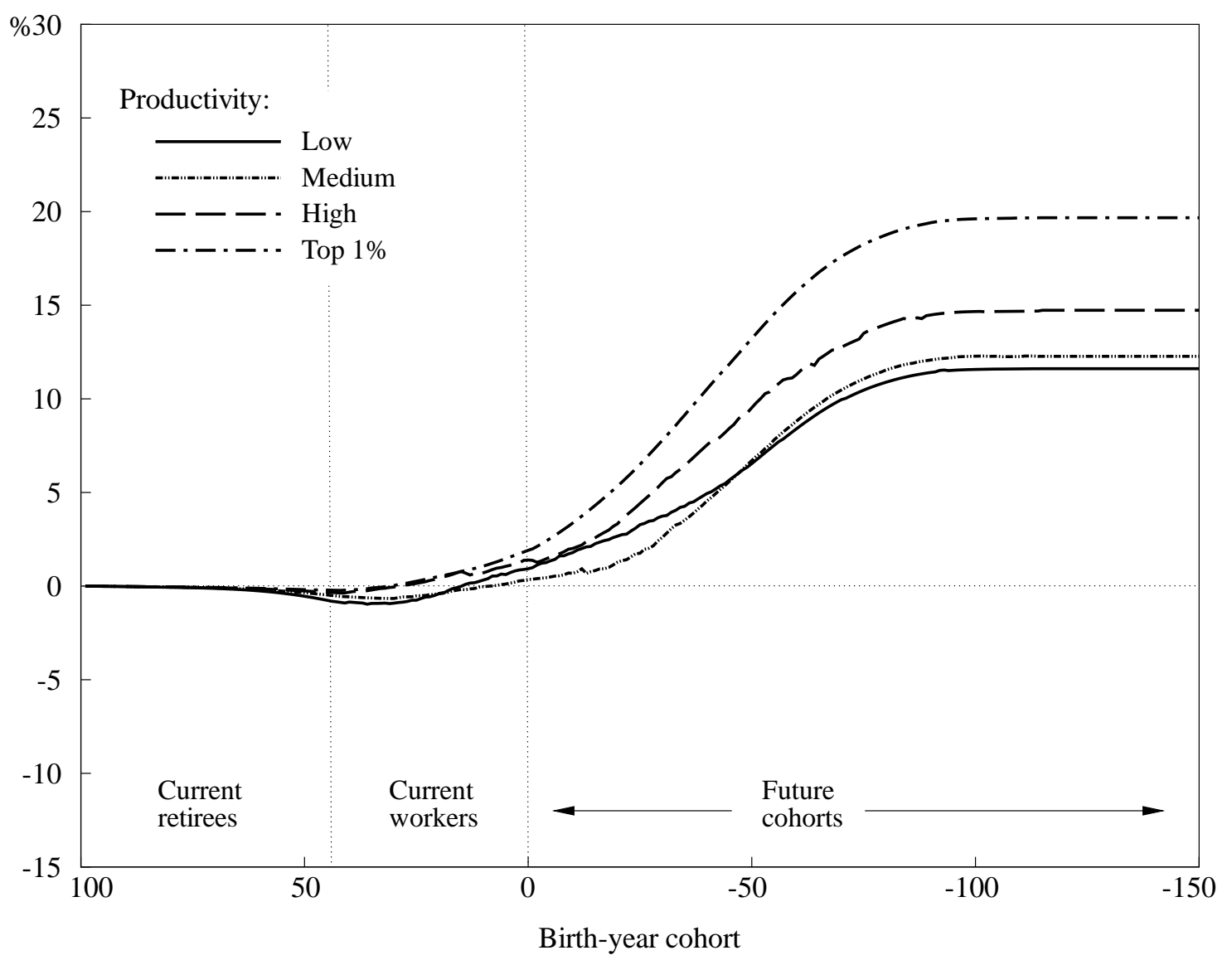


Figure A14. Percentage Welfare Gains by Age Cohort and Baseline Agi Social Security, Medicare, and FICA Taxes Phased Out,

Worker Net Tax Functions Permanently Changed

(Labor elasticity cut by two)

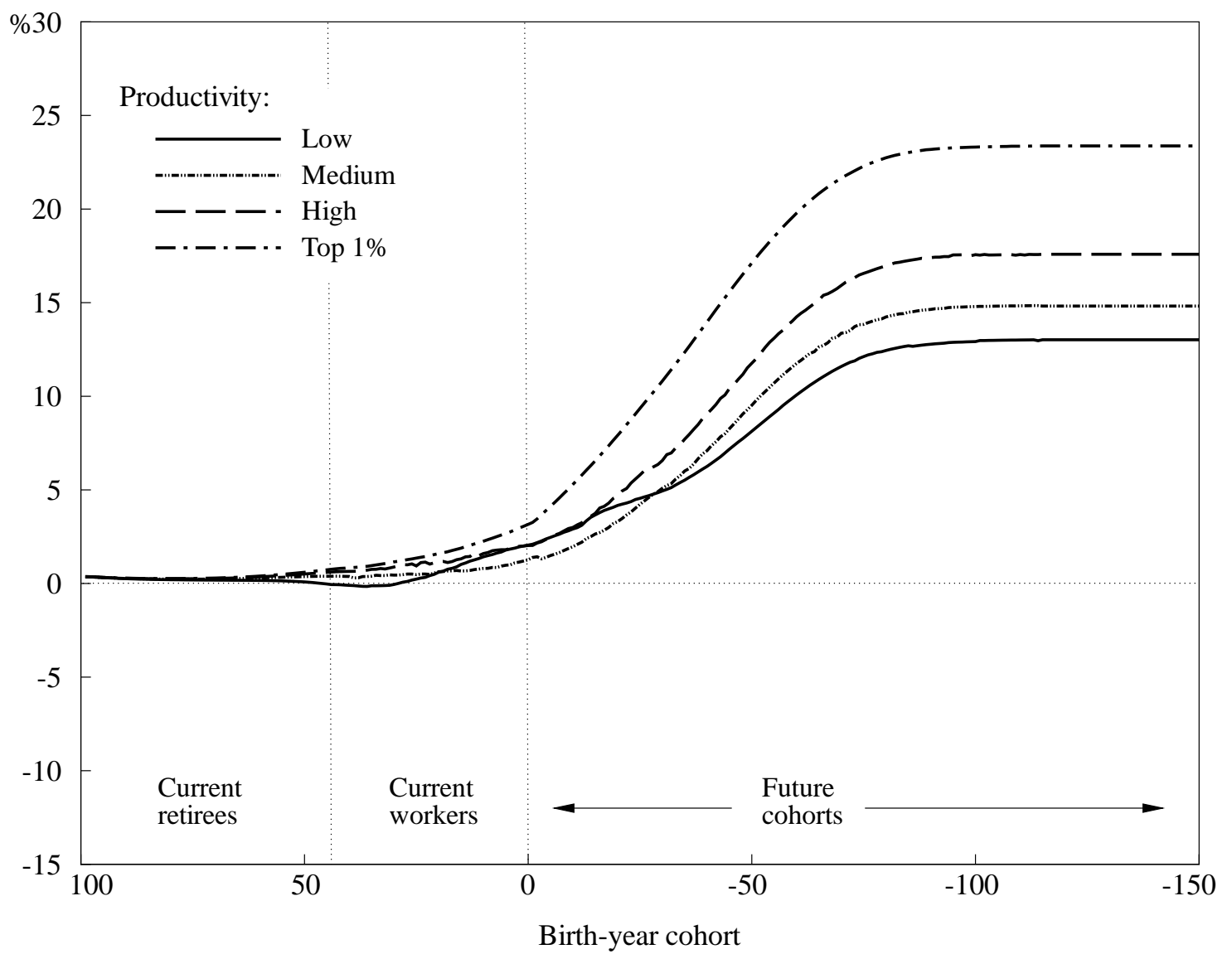


Figure A15. Percentage Welfare Gains by Age Cohort and Baseline Agi Social Security, Medicare, and FICA Taxes Phased Out,

Worker Net Tax Functions Permanently Changed (More spending categories included in $G$ )

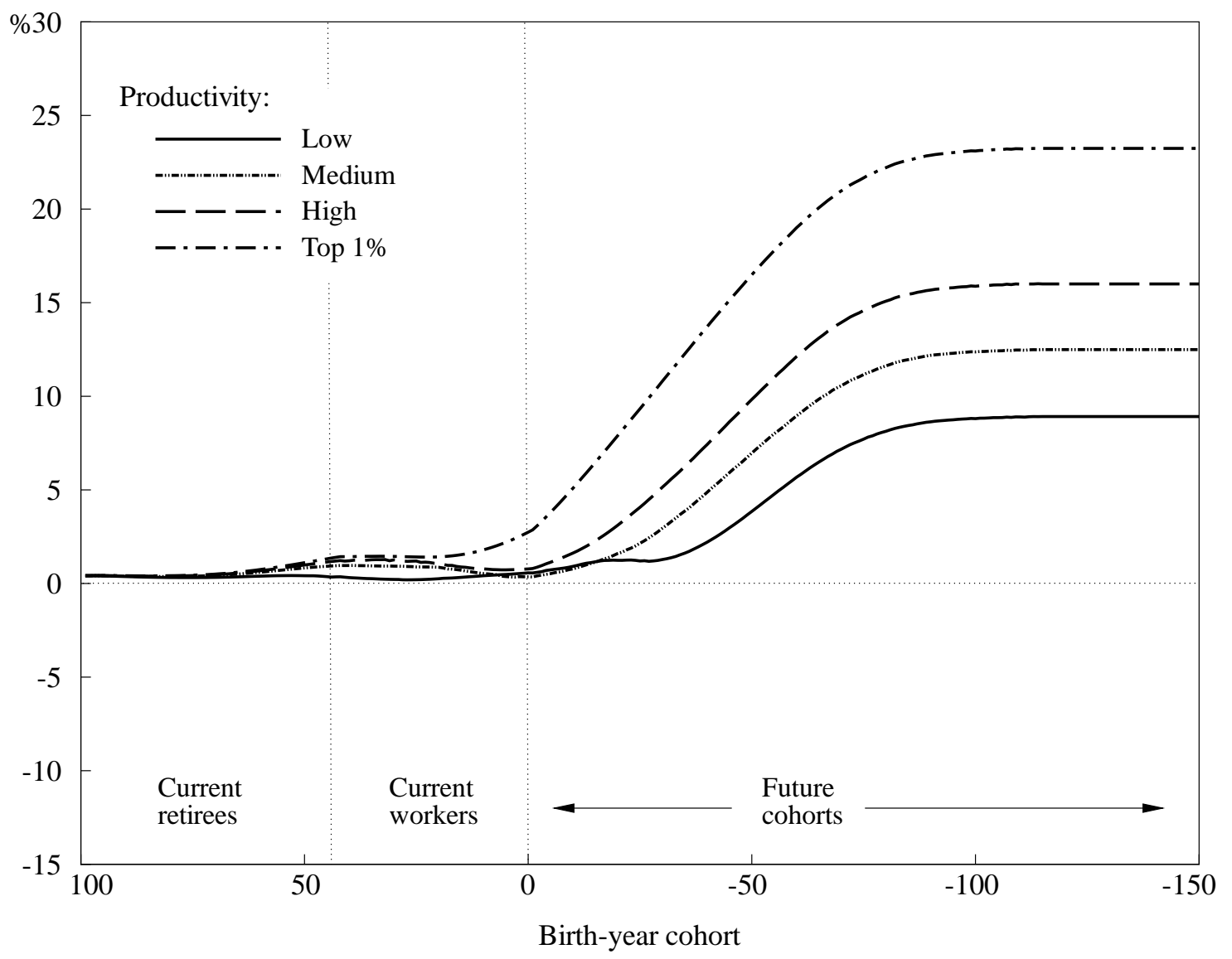


Figure A16. Percentage Welfare Gains by Age Cohort and Baseline Agi Social Security, Medicare, and FICA Taxes Phased Out,

Worker Net Tax Functions Permanently Changed

(Fewer spending categories included in $G$ )

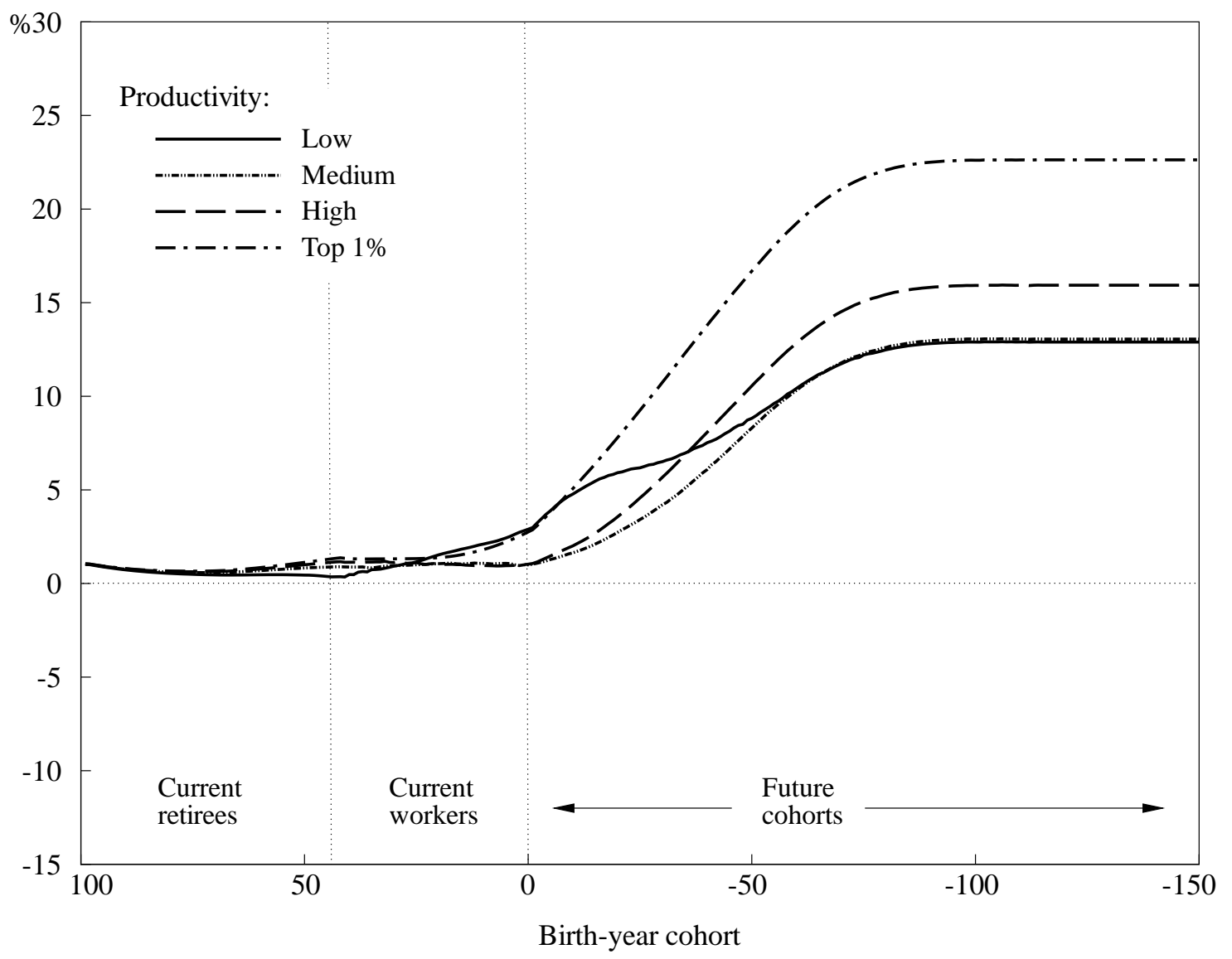


Figure A17. Percentage Welfare Gains by Age Cohort and Baseline Agi Social Security, Medicare, and FICA Taxes Phased Out,

Worker Net Tax Functions Permanently Changed

(More AGI bins for net tax function)

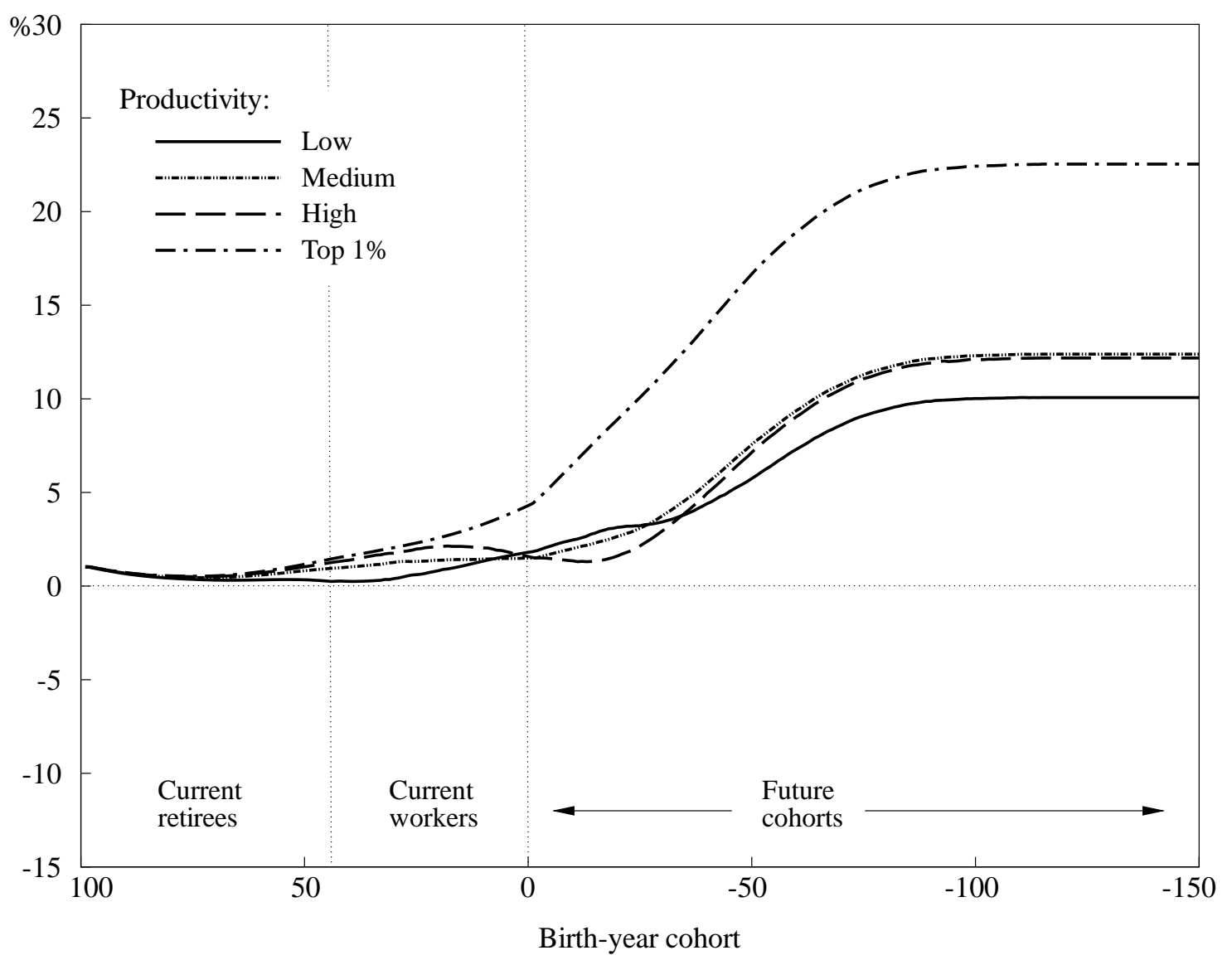


Figure A18. Percentage Welfare Gains by Age Cohort and Baseline Agi Social Security, Medicare, and FICA Taxes Phased Out,

Worker Net Tax Functions Permanently Changed

(One-sector, one-capital model)

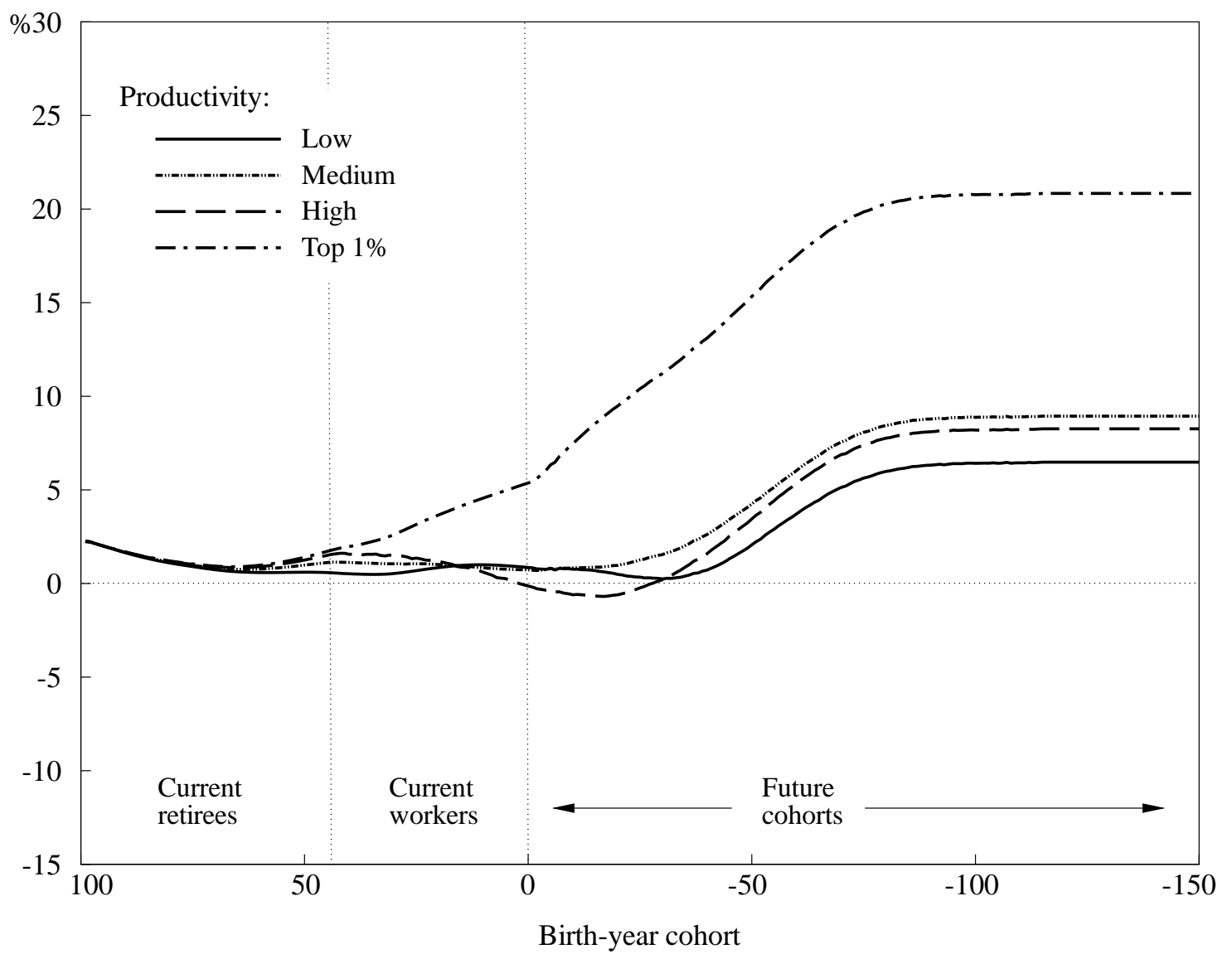


Figure A19. Percentage Welfare Gains by Age Cohort and Baseline Agi Social Security, Medicare, and FICA Taxes Phased Out,

Worker Net Tax Functions Permanently Changed

(Seven productivity levels)

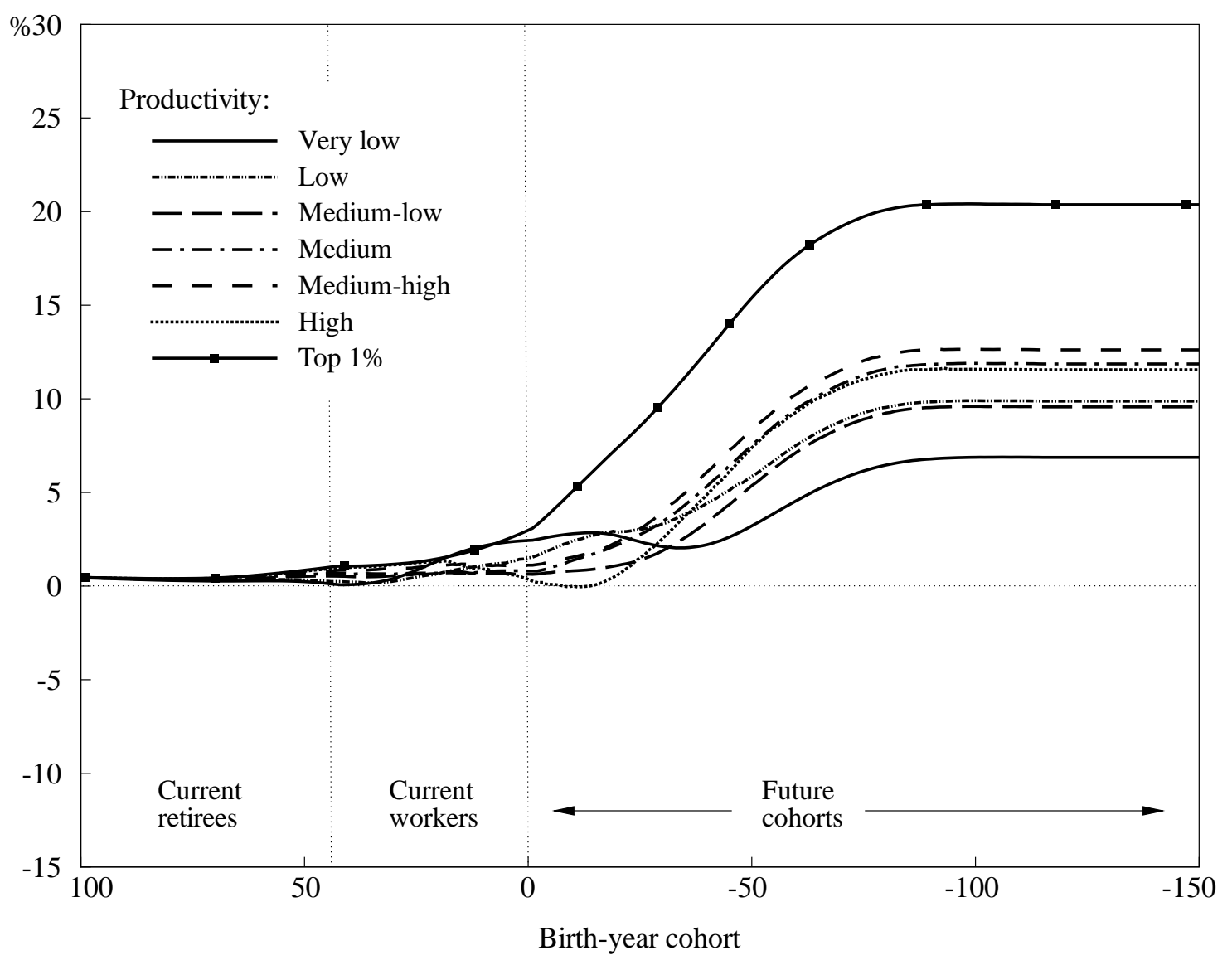

